Protocolos de interação baseados

em conhecimento: implementação

da plataforma JamSession

\author{
Diego Mira David
}

\author{
DISSERTAÇÃO APRESENTADA \\ $\mathrm{AO}$ \\ Instituto DE MATEMÁticA E EstatísticA \\ DA \\ Universidade DE SÃo Paulo \\ PARA \\ OBTENÇÃO DO TÍTULO \\ $\mathrm{DE}$ \\ Mestre em CiÊnCIAS
}

Programa: Mestrado em Ciência da Computação

Orientador: Prof. Dr. Flávio Soares Corrêa da Silva 


\section{Protocolos de interação baseados em conhecimento: implementação da plataforma JamSession}

Esta dissertação contém as correções e alterações sugeridas pela Comissão Julgadora durante a defesa

realizada por Diego Mira David em 14/12/2012.

O original encontra-se disponível no Instituto de

Matemática e Estatística da Universidade de São Paulo.

Comissão Julgadora:

- Prof. Dr. Flávio Soares Corrêa da Silva (orientador) - IME-USP

- Prof. Dr. Pedro Luiz Pizzigatti Correa - EP-USP

- Prof. Dr. Ricardo Nakamura - EP-USP 


\section{Agradecimentos}

Primeiramente, agradeço ao meu orientador, Dr. Flávio Soares Corrêa da Silva, pela confiança, incentivo, paciência e orientação durante todo o percurso deste mestrado. Seu inestimável apoio foi fundamental para a realização deste trabalho.

Agradeço aos professores e a todos os amigos que fiz no Instituto de Matemática e Estatística (IME-USP) durante todos esses anos desde a graduação. Agradeço aos membros do LIDET (Laboratory of Interactivity and Digital Entertainment Technology), em especial Cláudia Josimar Abrão de Araújo e Mirtha Lina Fernández Venero, pela contribuição nesta dissertação.

Agradeço também aos professores que participaram das bancas de qualificação e defesa, Dra. Ana Cristina Vieira de Melo, Dr. Francisco Carlos da Rocha Reverbel, Dr. Pedro Luiz Pizzigatti Correa e Dr. Ricardo Nakamura, pelos comentários e sugestões.

Sou muito grato a Opus Software, empresa em que trabalhei durante o desenvolvimento deste trabalho, pela flexibilidade fornecida para que eu pudesse cursar o mestrado. Agradeço especialmente ao Alexandre Barbosa, Francisco Barguil, Marcos Giacometti e Patrick Theys por todo apoio fornecido durante estes anos.

Finalmente, agradeço à minha família e especialmente aos meus queridos pais, Felisberto e Zilda, por todo o apoio nos momentos mais difíceis. 


\section{Resumo}

\section{Protocolos de interação baseados em conhecimento: implementação da plataforma JamSession}

JamSession foi proposto como uma plataforma para mediar e coordenar, por meio de protocolos de interação baseados em conhecimento, recursos computacionais existentes com o objetivo de compor novos serviços e desenvolver aplicações inovadoras. Entre as principais características da plataforma estão sua base formal e declarativa para permitir análise e verificação formal dos protocolos, alta performance e foco na usabilidade.

A plataforma pode ser utilizada, por exemplo, na construção de ambientes inteligentes e no aprimoramento dos serviços de governo eletrônico, onde o JamSession pode atuar mediando a interação entre sistemas oferecidos por órgãos públicos visando a ampliação dos serviços oferecidos.

O objetivo deste trabalho é o desenvolvimento da plataforma JamSession e sua aplicação em problemas concretos de integração e coordenação.

Entre as aplicações consideradas para validar a plataforma desenvolvida estão a integração de workflows interorganizacionais e a demonstração do uso da plataforma na construção de ambientes virtuais interativos. Como prova de conceito, também foi elaborado o sistema OpenMuseum, cujo objetivo é proporcionar aos museus físicos uma presença virtual provendo funcionalidades num ambiente de interoperabilidade entre instituições.

Palavras-chave: JamSession, protocolos de interação, orquestração, coordenação, sistemas distribuídos. 


\section{Abstract}

\section{Knowledge-based interaction protocols: implementation of JamSession platform}

JamSession was proposed as a platform to mediate and coordinate, by means of knowledgebased interaction protocols, existing computational resources in order to compose new services and develop innovative applications. Among the main features of the platform are its formal and declarative foundations to provide the means for formal analysis and verification of protocols, high performance and focus on usability.

The platform can be used, for instance, to build intelligent environments and to improve egovernment services, where JamSession may mediate the interaction between systems offered by public agencies aiming to expand the services provided.

The aim of this work is the development of JamSession platform and its application in practical demanding integration and coordination.

Among the applications considered to validate the developed platform are the integration of inter-organizational workflows and its use to build interactive virtual environments. As proof of concept, a system called OpenMuseum was also developed. The goal is to provide physical museums with a virtual presence and interoperability between institutions.

Keywords: JamSession, interaction protocols, orchestration, coordination, distributed systems. 


\section{Sumário}

Lista de Abreviaturas $\quad$ xiii

Lista de Figuras $\quad$ xv

Lista de Tabelas $\quad$ xvii

1 Introdução $\quad 1$

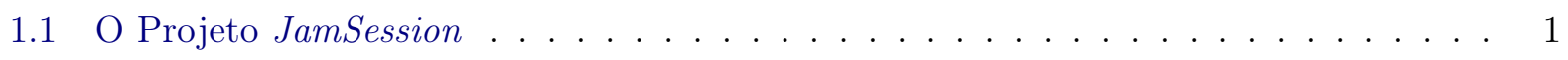

1.2 Motivação . . . . . . . . . . . . . . . . . . . . . . . 2

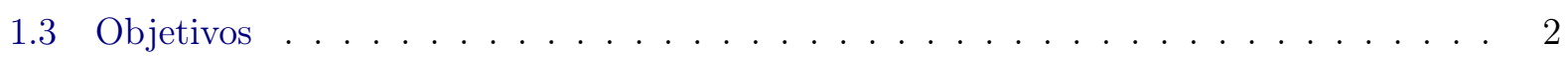

1.4 Organização do Documento . . . . . . . . . . . . . . . . . . . . 2

2 Coordenação de serviços $\quad 5$

2.1 Introdução . . . . . . . . . . . . . . . . . . . . . . . . . 5

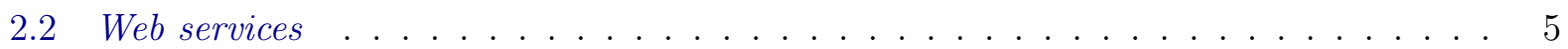

2.3 Arquitetura Orientada a Serviços $(\mathrm{SOA}) \ldots \ldots \ldots \ldots \ldots$

2.3.1 Elementos de uma arquitetura SOA . . . . . . . . . . . . . . . . . 7

2.3 .2 Modelo de referência para SOA . . . . . . . . . . . . . . . . . 9

2.4 Composição de serviços . . . . . . . . . . . . . . . . . . . . . . . . . 10

2.5 Orquestração . . . . . . . . . . . . . . . . . . . . . . . . . . . 11

2.5.1 BPEL - Business Process Execution Language . . . . . . . . . . . . . . . . . . 12

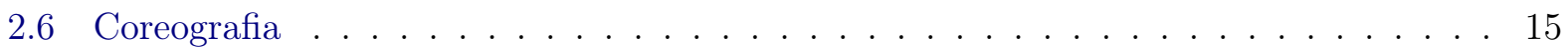

2.6.1 WS-CDL (Choreography Description Language) . . . . . . . . . . . . . . . . 16

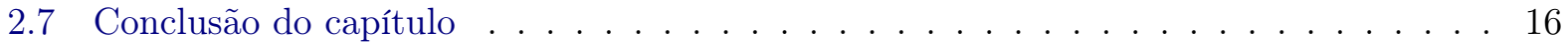

2.7 .1 Posicionamento da plataforma JamSession . . . . . . . . . . . . . . . . . . . 16

3 Projetos Relacionados $r$

3.1 Instituições Eletrônicas . . . . . . . . . . . . . . . . . . . . . . . . 20

3.2 OpenKnowledge . . . . . . . . . . . . . . . . . . . . . . . . . 21

3.3 Multilayered Multiagent Situated Systems (MMASS) _ . . . . . . . . . . . . 25

3.3 .1 Agentes situados . . . . . . . . . . . . . . . . . . . 25

3.3.2 Ambiente multicamadas . . . . . . . . . . . . . . . . . . 25

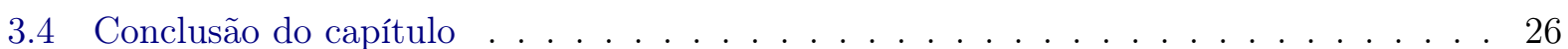


4 Plataforma Teórica $\quad 27$

4.1 O conceito de localização . . . . . . . . . . . . . . . . . . . . . 27

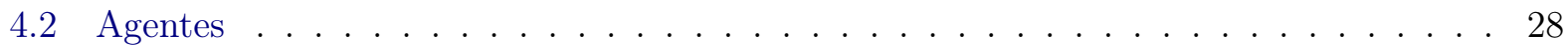

4.3 Predicados . . . . . . . . . . . . . . . . . . . . . . . . . . 29

4.4 Protocolos . . . . . . . . . . . . . . . . . . . . . . . . 29

4.5 Representação gráfica . . . . . . . . . . . . . . . . . . . . 31

4.6 Análise formal . . . . . . . . . . . . . . . . . . . . . . . . 33

4.6 .1 Análise de configurações . . . . . . . . . . . . . . . . . . . . . . 33

4.6 .2 Redes de Petri . . . . . . . . . . . . . . . . . . . . . . 33

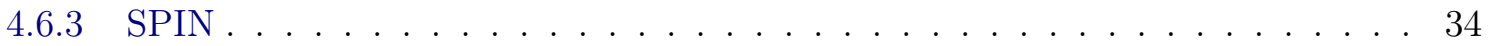

4.7 Conclusão do capítulo . . . . . . . . . . . . . . . . . . . . . . 34

5 Implementação $\quad 35$

5.1 Espaço de tuplas . . . . . . . . . . . . . . . . . . . . . . . 36

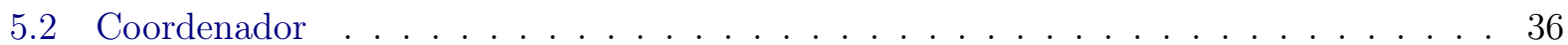

5.3 Comunicação . . . . . . . . . . . . . . . . . . . . . . . 37

5.3 .1 Operações . . . . . . . . . . . . . . . . . . . . . . . . . 38

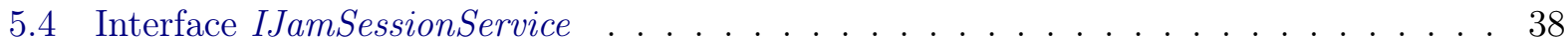

5.5 Definição dos mundos e agentes . . . . . . . . . . . . . . . . . . . . . . . 39

5.6 Implementação de protocolos . . . . . . . . . . . . . . . . . . . . . . . . 41

5.7 Editor de Protocolos . . . . . . . . . . . . . . . . . . . . . . . . . 41

5.8 Geração de código . . . . . . . . . . . . . . . . . . . . . . . . . . . 42

5.9 Avaliação dos protocolos . . . . . . . . . . . . . . . . . . . . . . . 44

5.10 Variáveis . . . . . . . . . . . . . . . . . . . . . . . . . . . 44

5.10 .1 Parâmetros de entrada e saída . . . . . . . . . . . . . . . . . . . . 44

5.11 Localizações e agentes . . . . . . . . . . . . . . . . . . . . . . 45

5.12 Variável Any . . . . . . . . . . . . . . . . . . . . . . . . 45

5.12 .1 Uso de variáveis para movimentar agentes . . . . . . . . . . . . . . . . 45

5.12 .2 Uso de variáveis para avaliar predicados $/$ protocolos . . . . . . . . . . . . . 46

5.13 Implementação de predicados . . . . . . . . . . . . . . . . . . . . . . . . 46

5.14 Interface IPredicate . . . . . . . . . . . . . . . . . . . . . . 47

5.15 Utilização de parâmetros . . . . . . . . . . . . . . . . . . . . . . . . . . 47

5.15 .1 Acesso ao agente e à localização . . . . . . . . . . . . . . . . . . . . . . . . 47

5.16 Exemplos de predicados . . . . . . . . . . . . . . . . . . . . 48

5.17 Utilitário de testes . . . . . . . . . . . . . . . . . . . . . 50 50

5.18 Conclusão do capítulo . . . . . . . . . . . . . . . . . . . . . . 51

6 Aplicações $\quad 53$

6.1 Integração de workflows . . . . . . . . . . . . . . . . . . . 53

6.1 .1 Protocolos de interação . . . . . . . . . . . . . . . . . . 55

6.1.2 Avaliação de um protocolo a partir de uma etapa do workflow . . . . . . . . . 57

6.1.3 Execução de um workflow do Bonita a partir de um predicado . . . . . . . . 58

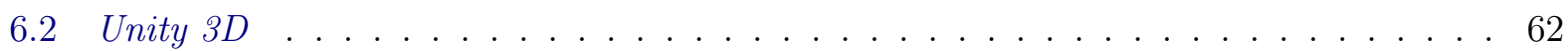

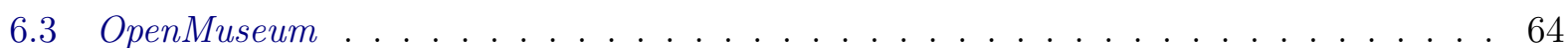


6.3 .1 Prova de conceito . . . . . . . . . . . . . . . . . 65

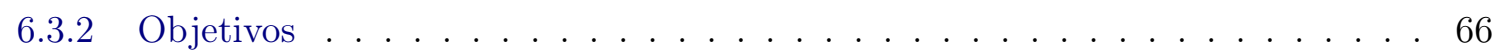

6.3 .3 Modelagem com JamSession . . . . . . . . . . . . . . . . . . . 68

6.3 .4 Integração com redes sociais . . . . . . . . . . . . . . . . . . . . 72

6.3 .5 Aplicações . . . . . . . . . . . . . . . . . . . . . . 74

6.3 .6 Tecnologia utilizada . . . . . . . . . . . . . . . . . 75

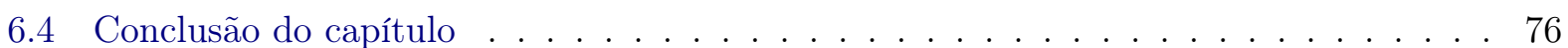

$\begin{array}{lll}7 & \text { Conclusões } & 77\end{array}$

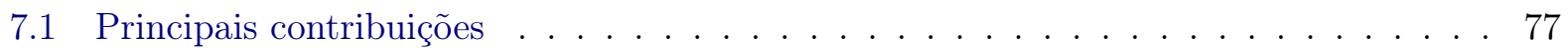

7.2 Trabalhos futuros . . . . . . . . . . . . . . . . . . . 78

$\begin{array}{ll}\text { Referências Bibliográficas } & 79\end{array}$

$\begin{array}{ll}\text { Índice Remissivo } & 83\end{array}$ 


\section{Lista de Abreviaturas}

$\begin{array}{ll}\text { API } & \text { Application Programming Interface } \\ \text { BPEL } & \text { Business Process Execution Language } \\ \text { CORBA } & \text { Common Object Request Broker Architecture } \\ \text { DLL } & \text { Dynamic-Link Library } \\ \text { HTTP } & \text { Hypertext Transfer Protocol } \\ \text { KBIP } & \text { Knowledge-Based Interaction Protocol } \\ \text { LCC } & \text { Lightweight Coordination Calculus } \\ \text { MMASS } & \text { Multilayered Multiagent Situated Systems } \\ \text { OASIS } & \text { Organization for the Advancement of Structured Information Standards } \\ \text { REST } & \text { Representational State Transfer } \\ \text { RMI } & \text { Remote Method Invocation } \\ \text { RPC } & \text { Remote Procedure Calls } \\ \text { SOA } & \text { Service-Oriented Architecture } \\ \text { SOAP } & \text { Simple Object Access Protocol } \\ \text { SOC } & \text { Service-Oriented Computing } \\ \text { TCP } & \text { Transmission Control Protocol } \\ \text { UDDI } & \text { Universal Description, Discovery and Integration } \\ \text { URL } & \text { Uniform Resource Locator } \\ \text { W3C } & \text { World Wide Web Consortium } \\ \text { WCF } & \text { Windows Communication Foundation } \\ \text { WS-BPEL } & \text { Web Services Business Process Execution Language (WS-BPEL) } \\ \text { WS-CDL } & \text { Web Services Choreography Description Language } \\ \text { WSDL } & \text { Web Services Description Language } \\ \text { WSFL } & \text { Web Services Flow Language } \\ \text { XML } & \text { eXtensible Markup Language }\end{array}$




\section{Lista de Figuras}

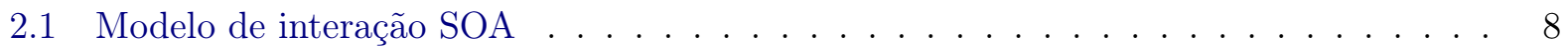

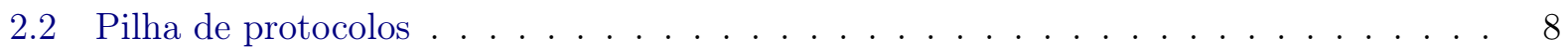

2.3 Principais conceitos do modelo de referência para SOA (OASIS) . . . . . . . . . . 9

2.4 Orquestração de serviços . . . . . . . . . . . . . . . . . . . . . . 11

2.5 Definição de um processo WS-BPEL . . . . . . . . . . . . . . . . . . 14

2.6 Coreografia de serviços . . . . . . . . . . . . . . . . . . . . . 15

3.1 Trecho de modelo de interação especificado em LCC . . . . . . . . . . . . . . . 22

3.2 Exemplo de modelo de interação informante/solicitante . . . . . . . . . . . . . . . . . 23

4.1 Grafo de localizações . . . . . . . . . . . . . . . . . . . . . . . . 28

4.2 Representações gráficas das entidades . . . . . . . . . . . . . . . . . . . . . . 31

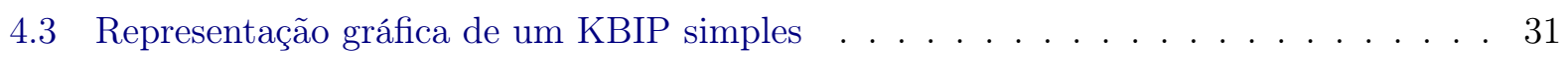

4.4 Configuração inicial . . . . . . . . . . . . . . . . . . . . . . . . . . . 32

5.1 JamSession - Arquitetura . . . . . . . . . . . . . . . . . 37

5.2 Editor de protocolos. . . . . . . . . . . . . . . . . . . . . . . . . . . . . . . . . .

5.3 Editor de protocolos: Compilação. . . . . . . . . . . . . . . . . . . . . . 42

5.4 Ilustração do uso de variáveis. . . . . . . . . . . . . . . . . . . . . . . 44

5.5 Ilustração do uso de variáveis. . . . . . . . . . . . . . . . . . . . . . . . . 45

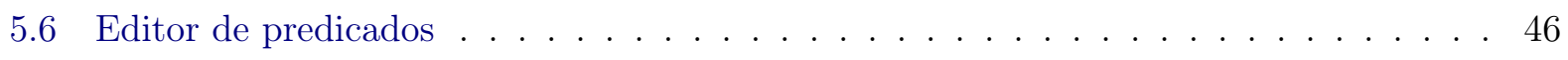

5.7 Utilitário de testes: Tela principal. . . . . . . . . . . . . . . . . . . 50

5.8 Utilitário de testes: Protocolos e predicados habilitados. . . . . . . . . . . . . 50

6.1 Workflow hierárquico . . . . . . . . . . . . . . . . . 53

6.2 Configuração inicial para o padrão de integração hierárquico . . . . . . . . . . . . . 54

6.3 Integração de workflows: Protocolo $P_{1}^{A} \ldots \ldots \ldots \ldots \ldots \ldots$. . . . . . . . . 55

6.4 Integração de workflows: Protocolo $P^{B} \ldots \ldots \ldots \ldots \ldots$. . . . . . . . . 56

6.5 Integração de workflows: Protocolo $P_{2}^{A} \ldots \ldots \ldots \ldots \ldots \ldots$

6.6 Integração de workflows: Connector implementado. . . . . . . . . . . . . . . . . 57

6.7 Integração de workflows: Predicado implementado . . . . . . . . . . . . . . . . . . . . . . 58

6.8 Integração de workflows: Instâncias do workflow B em execução . . . . . . . . . . . . 60

6.9 Integração de workflows: Workflow A . . . . . . . . . . . . . . . . . 61

6.10 Aplicativo de exemplo ilustrando o uso do JamSession num contexto de ambientes

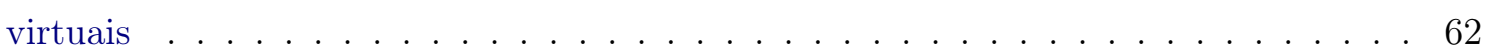

6.11 OpenMuseum - Visão Geral ． . . . . . . . . . . . . . . . . . . 67 
6.12 OpenMuseum - Arquitetura . . . . . . . . . . . . . . . . 68

6.13 OpenMuseum - Estrutura de localizações . . . . . . . . . . . . . . . . . . . . 69

6.14 OpenMuseum - Busca de obras . . . . . . . . . . . . . . . . . . . . 74

6.15 OpenMuseum - Exibição da exposição ． . . . . . . . . . . . . . . . . . . 74

6.16 OpenMuseum - Interface 3D . . . . . . . . . . . . . . . . . . 75 


\section{Lista de Tabelas}

2.1 BPEL - Atividades básicas . . . . . . . . . . . . . . . . . . . . . 13

2.2 BPEL - Atividades estruturadas . . . . . . . . . . . . . . . . . . 13

5.1 JamSession - Operações implementadas pelo coordenador . . . . . . . . . . . 38

5.2 JamSession - Operações implementadas pelos clientes . . . . . . . . . . . . . . 38 


\section{Capítulo 1}

\section{Introdução}

\subsection{O Projeto JamSession}

JamSession [13] foi proposto como uma plataforma para projetar e implementar sistemas cujas principais características são a interatividade, inteligência e mobilidade. A plataforma permite a coordenação dos serviços e recursos distribuídos por meio de protocolos de interação baseados em conhecimento.

Trata-se de um projeto de pesquisa desenvolvido pelo grupo LIDET (Laboratory of Interactivity and Digital Entertainment Technology) ${ }^{1}$, financiado pela FAPESP e Microsoft Research. O projeto surgiu com o objetivo de desenvolver ferramentas e recursos para o desenvolvimento de ambientes ricos de multimídia através dos quais os usuários possam interagir. Esses ambientes podem ser virtuais ou físicos e na maioria dos casos devem possuir recursos inteligentes que devem permitir monitorar as atividades de seus usuários e reagir em conformidade.

O projeto foi nomeado JamSession em referência às jam sessions originadas nos anos 1940, em Nova Iorque, nos Estados Unidos, em que músicos de jazz se reuniam no final da noite, depois de suas apresentações regulares, para tocar livremente. Jam é a abreviatura em inglês de "Jazz After Midnight" (jazz depois da meia-noite). Desses encontros surgiram tendências, novas formas de composição e muita inovação no plano musical.

A plataforma JamSession pode ser usada para coordenar, através de protocolos de interação, recursos computacionais existentes para desenvolver aplicações inovadoras, daí a analogia. A intenção é que a plataforma JamSession cumpra, no ambiente da tecnologia da informação, o mesmo papel que as jam sessions cumpriram no cenário musical.

\footnotetext{
${ }^{1}$ http://lidet.wordpress.com/
} 


\subsection{Motivação}

O paradigma da computação orientada a serviços (Service Oriented Computing - SOC) [40] é uma tendência na área de computação distribuída. Este paradigma utiliza serviços como elementos fundamentais para apoiar o desenvolvimento rápido, de baixo custo e de fácil composição de aplicações distribuídas em ambientes heterogêneos.

O uso de um único serviço em geral não é suficiente para lógicas de negócio complexas. A criação de serviços mais elaborados a partir de serviços já existentes necessita de mecanismos que permitam a integração dos serviços, de forma que possam ser executados de forma coordenada.

JamSession permite integrar e coordenar serviços utilizando fundações formais e declarativas. Concebido inicialmente para sistemas altamente interativos, como videogames com vários jogadores, foi estendido para gerenciar recursos computacionais genéricos. Apresenta-se como uma interessante alternativa para a integração desacoplada de recursos computacionais.

\subsection{Objetivos}

O objetivo geral deste trabalho de mestrado é o desenvolvimento da plataforma JamSession. Partindo de uma proposta conceitual existente, o objetivo é a construção e validação de uma versão computacional eficiente da plataforma para orquestração de serviços.

De forma a atingir este objetivo, o trabalho foi organizado da seguinte forma:

- Estudo dos principais conceitos e abordagens existentes na área de coordenação de serviços.

- Implementação e aperfeiçoamento da plataforma JamSession. A implementação contempla todo o processo de criação e execução dos protocolos de interação. É utilizada a plataforma . $\mathrm{NET}^{2}$ sendo o núcleo desenvolvido na linguagem de programação funcional $\mathrm{F} \#^{3}$

- Desenvolvimento de experimentos e aplicações para validar empiricamente a plataforma desenvolvida. O objetivo de tais experimentos é verificar a aplicação de JamSession em problemas concretos de integração e coordenação.

\subsection{Organização do Documento}

Neste capítulo foi apresentado o projeto JamSession e os objetivos deste trabalho.

No Capítulo 2 contextualizaremos a área na qual este trabalho está inserido por meio da apresentação de conceitos de coordenação de serviços. Abordaremos a arquitetura orientada a serviços e tecnologias relacionadas. Serão apresentados conceitos como orquestração e coreografia de serviços e os padrões mais utilizados.

No Capítulo 3 serão apresentados alguns projetos mais diretamente relacionados à abordagem apresentada neste trabalho. Tais projetos possuem características que inspiraram o desenvolvimento desta nova plataforma.

O Capítulo 4 é dedicado à plataforma teórica JamSession. Ou seja, serão apresentados todos os conceitos envolvidos, a linguagem utilizada para especificação de protocolos, as características da plataforma e seu funcionamento. Também abordaremos a análise e verificação formal dos protocolos

\footnotetext{
${ }^{2}$ http://www.microsoft.com/net

${ }^{3}$ http://fsharp.org/
} 
de interação.

O Capítulo 5 apresentará detalhes da implementação da plataforma JamSession. Serão tratados assuntos relativos à implementação e funcionamento da plataforma.

No Capítulo 6 serão apresentadas as aplicações consideradas para validar este trabalho. Apresentaremos os experimentos desenvolvidos na construção de ambientes virtuais interativos e na área de integração de workflows interorganizacionais. Também apresentaremos o projeto OpenMuseum, que tem como objetivo proporcionar aos museus físicos uma presença virtual provendo funcionalidades num ambiente de interoperabilidade entre instituições .

Finalmente, o Capítulo 7 conclui este trabalho com algumas considerações finais e propostas de trabalhos futuros. 


\section{Capítulo 2}

\section{Coordenação de serviços}

\subsection{Introdução}

Neste capítulo são apresentados conceitos relevantes relacionados à coordenação de serviços, tais como web services, arquitetura orientada a serviços (SOA - Service-Oriented Architecture) e mecanismos de coordenação.

\section{$2.2 \quad$ Web services}

Computação orientada a serviços [40] é um paradigma da computação que utiliza serviços como elementos fundamentais para o desenvolvimento de soluções e aplicações distribuídas. Web services representam a aplicação deste paradigma na Web.

Serviços podem ser definidos como entidades autônomas, independentes de plataformas, que podem ser descritas, publicadas e descobertas pela rede e são fracamente acopladas entre si [35].

O modelo de web services surgiu com o objetivo de resolver um dos principais problemas existentes na área de tecnologia da informação, que é a integração de sistemas. Um web service é um sistema de software desenvolvido para suportar interoperabilidade entre máquinas sobre uma rede, o qual pode apresentar uma interface que o descreve (WSDL).

Outros sistemas interagem com os web services por meio de mensagens SOAP, geralmente usando HTTP com serialização XML em conjunto com outros padrões relacionados a Web [23].

As características principais dos web services são as seguintes [18]:

- São autocontidos: podem ser usados pelos clientes de forma independente, sem necessidade de software adicional.

- São autodescritivos: cliente e servidor precisam conhecer apenas apenas o formato e conteúdo das mensagens de requisição e resposta. A definição do formato da mensagem viaja com a mensagem e não são necessários repositórios de metadados externos.

- São modulares: são uma tecnologia para implantar e fornecer acesso à funcionalidades de negócio através da Web. Diversas tecnologias podem ser utilizadas na implementação de web services. 
- Podem ser publicados, localizados e invocados através da Web. Os padrões utilizados para isso são:

- Simple Object Access Protocol (SOAP): protocolo baseado em XML projetado para invocar aplicações remotas através de RPC (Remote Procedure Calls - chamadas remotas de procedimento) ou trocas de mensagens em um ambiente independente de plataforma.

- Web Service Description Language (WSDL): documento baseado em XML utilizado para descrever web services funcionando como um contrato do serviço. Especifica como acessar o serviço e quais as operações ou métodos disponíveis.

- Universal Description, Discovery, and Integration (UDDI): serviço de diretório onde empresas podem registrar e procurar por serviços web.

- São independentes de linguagem: a interação requer apenas um documento WSDL para definir a interface e descrever o serviço, e de um protocolo de rede (geralmente HTTP). A comunicação não depende das plataformas ou linguagens utilizadas na implementação do web service.

- São baseados em padrões abertos: XML and HTTP são a base técnica. Independência de fornecedores e interoperabilidade são metas realistas.

- São dinâmicos: com WSDL e UDDI, a descrição e a descoberta de web services podem ser automatizadas.

- Podem ser combinados: web services simples podem ser agregados a outros mais complexos.

Os web services permitem que as empresas desenvolvam funções que podem ser utilizadas sob demanda ou utilizadas em conjunto para fornecer um serviço de negócio [10]. 


\subsection{Arquitetura Orientada a Serviços (SOA)}

Arquitetura Orientada a Serviços (SOA, em inglês) é uma abordagem de desenvolvimento de software na qual suas funções-chave são construídas como componentes reutilizáveis. Esta abordagem permite baixo acoplamento, interoperabilidade, habilidade de descobrimento, gerenciamento de alterações e operação de serviços de negócio em um ambiente bem administrado. Serviços de negócio, operando em um ambiente SOA bem organizado, podem ser compostos por processos de negócio que alinham TI com o negócio [45] [31].

O conceito de orientação a serviços baseia-se na ideia de que sistemas são construídos por meio da composição de serviços disponíveis. A arquitetura orientada a serviços não está diretamente relacionada a uma tecnologia específica. Embora outras tecnologias como CORBA e RMI também permitam implementar este tipo de arquitetura, a tecnologia mais utilizada para implementação da arquitetura SOA tem sido web services.

SOA é uma forma de arquitetura de sistema distribuído com as seguintes características [22]:

- Visão lógica: o serviço é uma abstração, uma visão lógica dos programas, banco de dados, lógica do processo de negócio, etc.

- Orientado a mensagem: o serviço é formalmente definido em termos das mensagens trocadas entre os agentes provedor e solicitante. Características internas dos agentes tais como a linguagem de implementação e estrutura de banco de dados são deliberadamente abstraídas na arquitetura SOA. Não é necessário saber como é feita a implementação do serviço por um agente. Um dos principais benefícios desta abordagem é a participação de sistemas legados. Ao evitar qualquer conhecimento da estrutura interna de um agente, pode-se incorporar qualquer componente de software apenas o envolvendo na definição formal de serviço.

- Orientado a descrição: um serviço é descrito por metadados que são publicados. A semântica de um serviço deve ser documentado, direta ou indiretamente, pela sua descrição.

- Granularidade: serviços tendem a usar um pequeno número de operações com mensagens relativamente grandes e complexas.

- Orientado a rede: serviços costumam ser usados através da rede, embora isso não seja um requisito.

- Plataforma neutra: mensagens são enviadas em um formato padrão independente de plataforma. XML é o mais utilizado.

\subsubsection{Elementos de uma arquitetura SOA}

SOA básica não é uma arquitetura apenas sobre serviços. É um relacionamento entre três tipos de participantes [40]: fornecedor de serviços, repositório de serviços e consumidor de serviços (cliente).

As interações envolvem publicação, busca e ligação. O provedor de serviços publica a descrição de seus serviços em um repositório de serviços. Esse repositório é usado pelos clientes para encontrar serviços que satisfazem determinado critério de busca. Se o repositório possui esse serviço, ele fornece ao cliente o contrato e o endereço para o serviço desejado.

Na Figura 2.1 pode-se observar a colaboração existente entre os três participantes. 


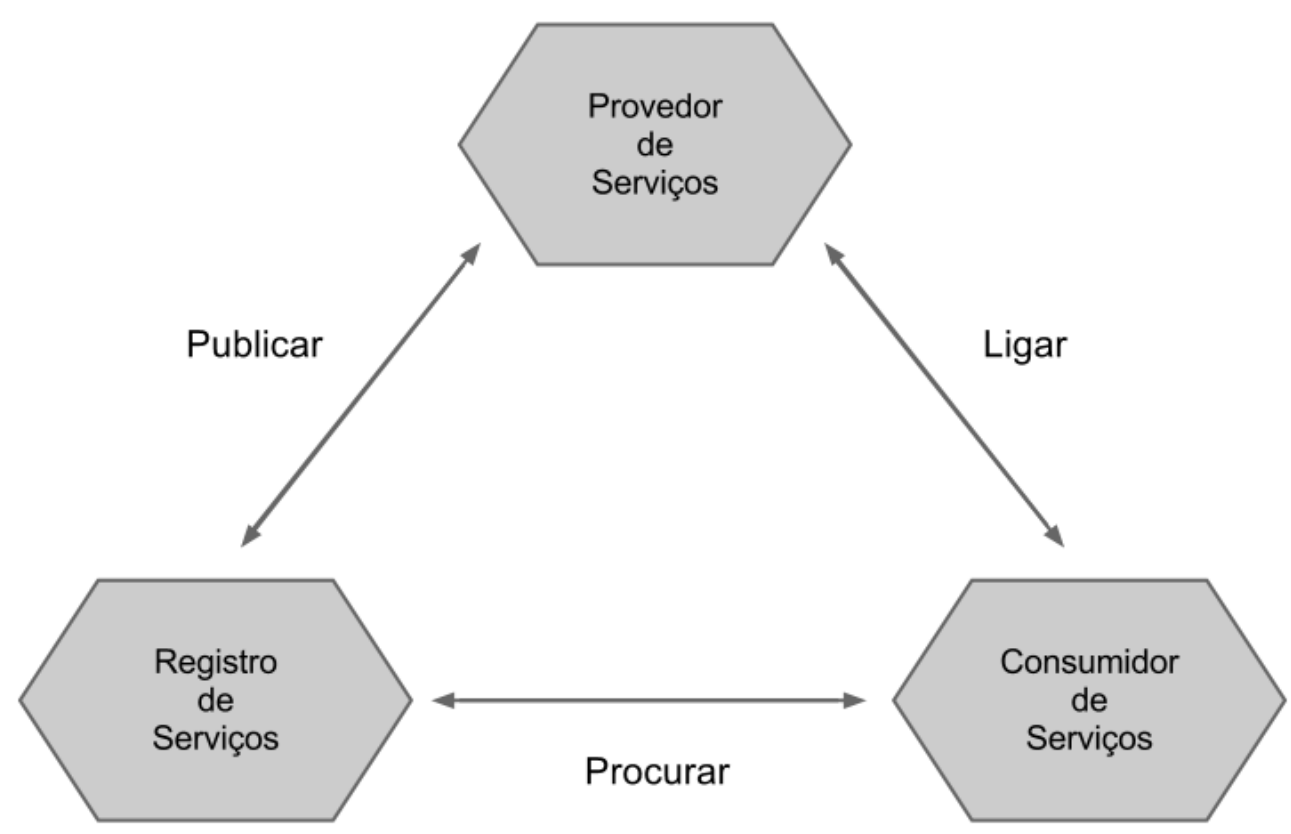

Figura 2.1: Modelo de interação $S O A$

\begin{tabular}{|lc|}
\hline Descoberta & UDDI \\
\hline Descrição & WSDL \\
\hline Troca de mensagens XML & XML-RPC, SOAP, XML \\
\hline Transporte & \\
\hline
\end{tabular}

Figura 2.2: Pilha de protocolos

A arquitetura SOA é vista com um paradigma ideal para integrar ambientes heterogêneos, pois sua unidade de desenvolvimento são os serviços. Assim, estes podem ser executados em ambientes distintos.

A aplicação de princípios SOA provê vantagens no processo de desenvolvimento de software [19]. Destacam-se::

- Serviços são reutilizáveis: independentemente de saber se existem oportunidades imediatas de reutilização, os serviços são projetados para suportar a reutilização.

- Serviços compartilham um contrato formal: para os serviços interagirem, há um contrato formal que descreve cada serviço e define as informações trocadas.

- Serviços possuem baixo acoplamento: serviços devem ser projetados para interagir de forma independente sem a necessidade de dependências fortes e conhecimento interno de sua implementação. 
- Serviços devem abstrair a lógica de negócios: somente o contrato de serviço é visível para o solicitante do serviço.

- Serviços podem ser compostos: serviços podem compor outros serviços. Esta lógica promove reusabilidade e criação de camadas de abstração.

- Serviços são autônomos: a lógica governada por um serviço reside dentro de um limite explícito e independe de um elemento externo.

- Serviços são stateless: serviços não devem gerenciar o estado das informações.

- Serviços permitem serem descobertos: serviços devem permitir que suas descrições sejam descobertas e entendidas por solicitantes de serviços.

\subsubsection{Modelo de referência para SOA}

A OASIS (Organization for the Advancement of Structured Information Standards) é um consórcio global sem fins lucrativos que impulsiona o desenvolvimento, convergência e adoção de padrões abertos na área de tecnologia da informação. A OASIS elaborou um modelo de referência [39] com o objetivo de definir os conceitos relacionados a uma arquitetura SOA e os relacionamentos entre eles. O propósito do modelo de referência é oferecer uma base conceitual comum que possa ser usada consistentemente entre diferentes implementações.

Segundo a definição da OASIS, SOA é um paradigma para organização e utilização de competências distribuídas que estão sob controle de diferentes domínios proprietários. Competência é definida como um elemento que soluciona ou dá suporte a determinado problema de negócio.

Não há uma correlação exata entre necessidades e competências. Determinada necessidade pode exigir a combinação de diversas competências enquanto uma única competência pode tratar mais de uma necessidade. A arquitetura orientada a serviços oferece um arcabouço poderoso para compatibilizar necessidades e competências e combinar competências para atender a essas necessidades.

O modelo de referência para SOA apresenta três conceitos fundamentais: visibilidade, interação e efeitos no mundo real.

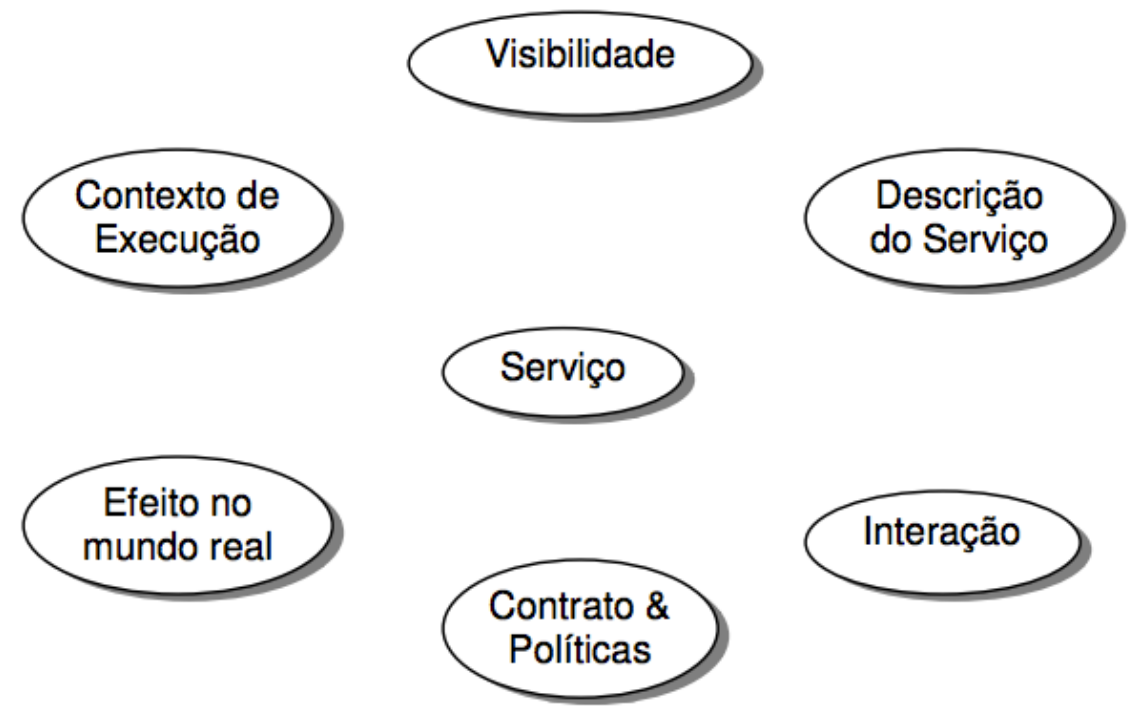

Figura 2.3: Principais conceitos do modelo de referência para SOA (OASIS) 
Visibilidade refere-se à capacidade de entidades com necessidades e entidades com competências estarem aptas a se verem mutuamente. É obtida pelo oferecimento das descrições das funções, dos requisitos técnicos, restrições, políticas e um mecanismo para conexão entre as entidades.

Interação refere-se ao ato de se utilizar uma competência. Geralmente, a interação é feita por meio de troca de mensagens entre os consumidores e fornecedores de serviços. O propósito de se utilizar uma competência é realizar um ou mais efeitos no mundo real.

O resultado de uma interação é um efeito e pode ser um retorno de informação ou uma mudança no estado de uma entidade envolvida na interação. Os efeitos esperados no mundo real determinam se uma competência atende aos requisitos de uma dada necessidade.

Na Figura 2.3 estão os principais conceitos descritos no modelo de referência. Segundo este modelo, serviço é um mecanismo pelo qual as necessidades e as competências são colocadas juntas. Trata-se do mecanismo utilizado para disponibilizar determinada competência por meio de uma interface predefinida e consistente com a descrição do serviço.

Contrato e política representam um acordo entre as partes envolvidas e condições de uso respectivamente. O contexto de execução é o conjunto de elementos técnicos e de negócios que são definidos como parte de uma interação com um serviço.

\subsection{Composição de serviços}

A principal motivação para a composição de serviços é a possibilidade de criar serviços mais complexos a partir de serviços previamente existentes. Um aspecto fundamental está relacionado a integração de negócios [36]. A composição permite que serviços de diferentes organizações sejam utilizados em conjunto na construção de novas aplicações de uma forma plug-and-play.

É comum nas organizações a utilização de serviços já existentes que funcionam de maneira independente para formar um único serviço que atenda a uma necessidade de negócio da empresa.

Uma arquitetura orientada a serviços mais desenvolvida necessita de elementos que permitam a integração dos serviços, de forma que possam ser executados de forma coordenada. Serviços sem coordenação ficam limitados a interações mais simples. Para compor serviços de software existem duas principais técnicas disponíveis: orquestração e coreografia [43]. 


\subsection{Orquestração}

Orquestração é um modelo de composição de serviços em que há a presença de um coordenador. O coordenador controla o fluxo das operações uma vez que é o responsável pela execução dos serviços participantes. Os serviços compostos tipicamente são independentes, havendo baixo acoplamento.

O coordenador é o serviço exposto que abstrai a existência dos demais serviços. Os serviços envolvidos não precisam conhecer seu papel no fluxo do processo nem a existência dos demais serviços envolvidos. Portanto, a orquestração foca no comportamento sob o ponto de vista de um único participante, agindo como um controlador de um processo e conduzindo a execução desse processo seguindo sua definição.

A orquestração representa o processo de negócio e inclui a ordem das execuções definidas a partir de fluxos que podem atravessar diferentes organizações. O diagrama abaixo ilustra a composição de serviços por orquestração:

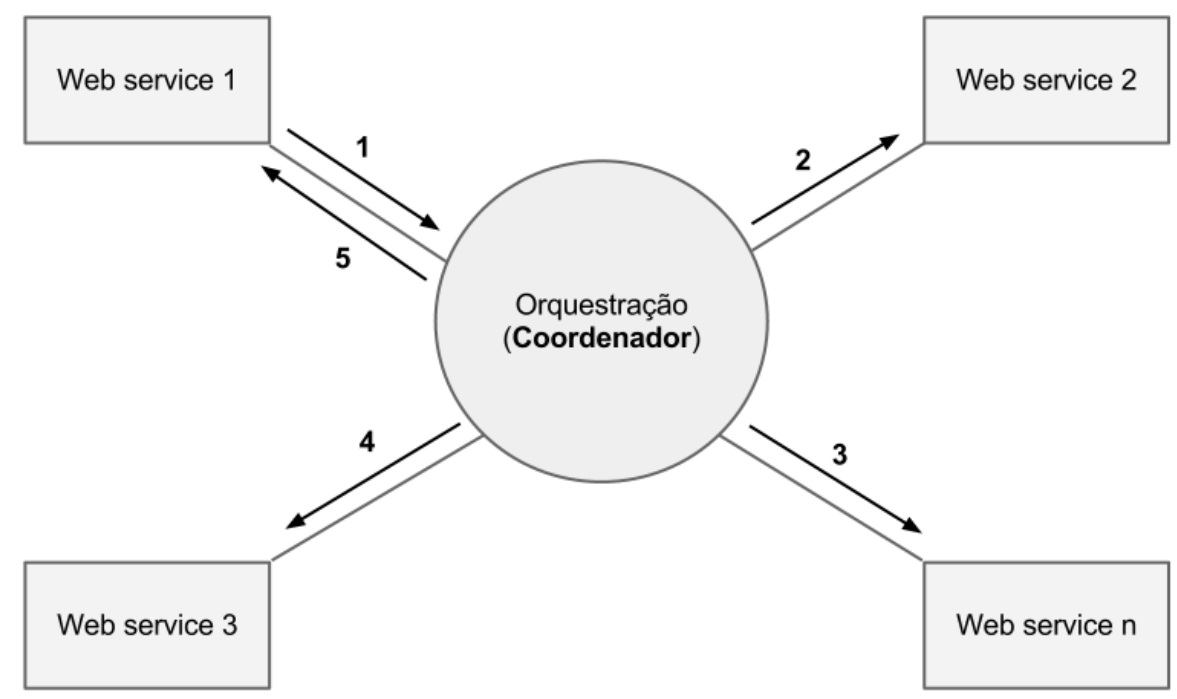

Figura 2.4: Orquestração de serviços

Trata-se de um mecanismo utilizado para agregar ou compor serviços com o objetivo de criar um novo serviço com funcionalidades mais complexas. Essa abordagem abstrai a lógica de negócio de forma transparente ao cliente. A orquestração permite desenvolver novos serviços de forma adaptável, flexível e dinâmica às necessidades de negócios que se alteram com frequência [43].

Na seção seguinte apresentaremos a linguagem BPEL, padrão mais utilizado para realizar orquestrações de serviços. 


\subsubsection{BPEL - Business Process Execution Language}

A linguagem BPEL (inicialmente denominada BPEL4WS) foi criada em 2003 numa parceria entre BEA Systems, IBM, Microsoft, SAP e Siebel Systems. Esta nova linguagem surgiu da evolução de duas linguagens para workflow XLANG [50] e WSFL [32], criadas anteriormente pela Microsoft e IBM respectivamente.

A continuidade da BPEL4WS ficou sob responsabilidade da OASIS (Organization for the Advancement of Structured Information Standards) ${ }^{1}$ e foi criado o padrão WS-BPEL (Web Services Business Process Execution Language), atualmente na versão 2.0 [28].

BPEL, que é o padrão atual para orquestrar processos de negócios, é uma linguagem baseada em XML que provê construções de controle de fluxo para a composição de web services.

O uso de BPEL em substituição a linguagens usuais, como C\# e Java, fornece uma camada de abstração e interfaces gráficas que permitem a visualização dos processos de negócio de forma que todos os passos da execução podem ser gerenciados mais facilmente.

Entre as principais características de BPEL estão [29]:

- Descrever a lógica de processos de negócios por meio da composição de serviços

- Compor processos de negócios maiores por meio de processos menores e serviços

- Lidar com chamadas de serviços síncronas e assíncronas (muitas vezes de longa duração) gerenciar os retornos que ocorrem em momentos posteriores

- Invocar serviços de forma sequencial ou paralela

- Seletivamente compensar as atividades concluídas em caso de falhas

- Manter várias atividades transacionais de longa duração, que também são passíveis de interrupção

- Encaminhar mensagens recebidas para os processos e atividades apropriados

- Executar atividades em paralelo e definir como unir fluxos paralelos baseados em condições de sincronização

Na linguagem WS-BPEL, uma composição de web services é chamada de processo (Process), cada serviço participante é chamado de parceiro (Partner) e a troca de mensagens é chamada de atividade (Activity).

\footnotetext{
${ }^{1}$ http://www.oasisopen.org/
} 
Processos de negócios podem ser descritos de duas formas em BPEL:

- Processos de negócios executáveis: especificam os detalhes exatos de processos de negócio e podem ser executados por uma engine BPEL. Na maioria dos casos, BPEL é usada para especificar processos executáveis.

- Processos de negócios abstratos: especificam apenas a troca de mensagens públicas entre as partes envolvidas, sem incluir os detalhes específicos dos fluxos do processo. Funciona como uma interface em linguagens de programação. Eles não são executáveis e são raramente utilizados.

A especificação WS-BPEL possui dois tipos de atividades: básicas e estruturadas:

- Atividades básicas: não interferem no fluxo de execução e corresponde a uma operação simples como uma invocação de uma operação WSDL de um serviço.

- Atividades estruturadas: gerenciam o fluxo do processo definindo uma orquestração das atividades básicas.

\begin{tabular}{|l|l|}
\hline Invoke & Invoca um web service \\
\hline Receive & Recebe a mensagem de um cliente. \\
\hline Reply & Envia uma resposta a um cliente \\
\hline Assign & Comando de atribuição de dados \\
\hline Throw & Usado para sinalizar erros na execução do processo \\
\hline Wait & Aguarda um tempo determinado \\
\hline Empty & Operação sem ação \\
\hline \hline
\end{tabular}

Tabela 2.1: BPEL - Atividades básicas

\begin{tabular}{|l|l|}
\hline Sequence & Executa atividades sequencialmente \\
\hline Flow & Executa atividades em paralelo \\
\hline If & Estrutura para desvio condicional \\
\hline While & Executa a atividade enquanto uma condição for satisfeita \\
\hline RepeatUntil & Executa a atividade até atingir determinada condição \\
\hline Pick & Permite associar ações a determinados eventos \\
\hline ForEach & Executa uma atividade por determinado número de vezes \\
\hline
\end{tabular}

Tabela 2.2: BPEL - Atividades estruturadas 
A Figura 2.5 mostra a sintaxe XML de uma definição um processo BPEL.

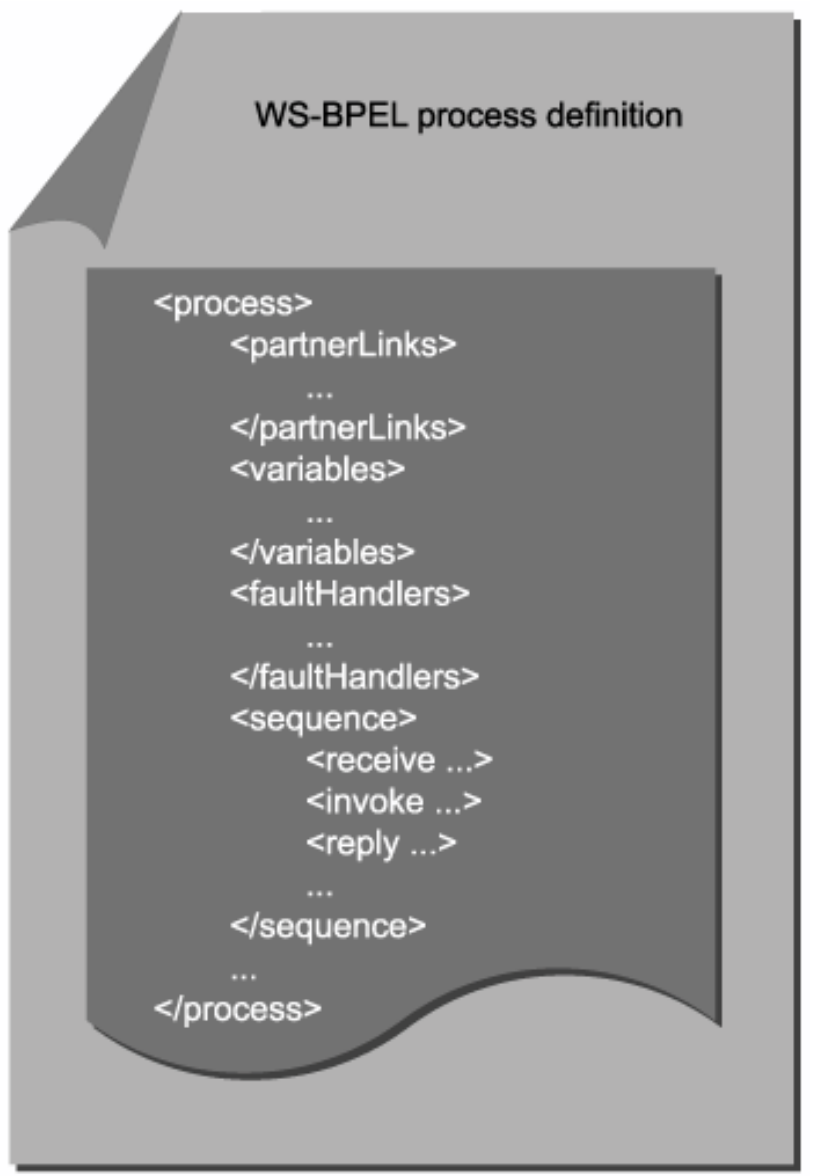

Figura 2.5: Definição de um processo WS-BPEL

Processos BPEL podem ser executados em engines (ambiente que permite a execução da BPEL) disponíveis para Java, .Net e outras plataformas. 


\subsection{Coreografia}

Na coreografia de serviços não existe a presença de um coordenador central. A coreografia descreve as relações de colaboração entre os serviços participantes. Cada serviço envolvido sabe como e quando interagir com os outros serviços.

Enquanto a orquestração foca na interação entre os serviços participantes apenas sob a perspectiva do coordenador, a coreografia trata de questões como a ordenação de mensagens e a interação sob a perspectiva de todas as partes de forma colaborativa.

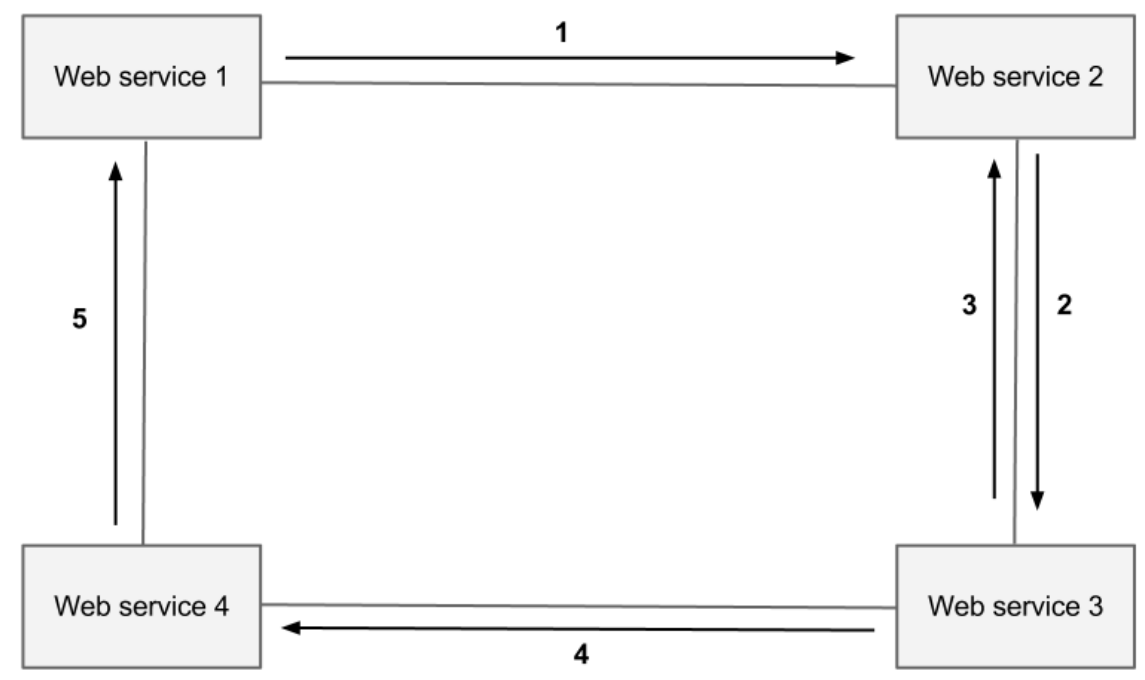

Figura 2.6: Coreografia de serviços

A coreografia não trata questões de implementação, possuindo apenas o objetivo de fornecer uma descrição das interações entre participantes. Ao contrário das linguagens de orquestração, as linguagens de coreografia de serviços representam uma definição formal das regras das interações entre os vários participantes de um ponto de vista global. 


\subsubsection{WS-CDL (Choreography Description Language)}

Web Service Choreography (WS-CDL) [30] é uma especificação baseada em XML para descrever as colaborações dos participantes envolvidos em um processo de negócio. Não existe um coordenador e os serviços têm noção da existência da composição e sabem quando devem interagir e que operações devem ser utilizadas.

Há uma visão global dos participantes de uma colaboração em um modelo peer-to-peer de web services distribuídos de forma a se chegar em um objetivo comum.

Ao contrário das linguagens de orquestração, WS-CDL não é uma linguagem executável. A função de especificar a lógica de execução de uma aplicação deve ser exercida por outras linguagens.

Entre os principais objetivos da especificação WS-CDL estão permitir:

- Reúso: a mesma definição de coreografia pode ser usada por diferentes participantes em diferentes contextos.

- Cooperação: coreografias definem a sequência de interações entre um grupo de serviços que cooperam entre si.

- Semântica: coreografias podem incluir documentação e semântica promovendo entendimento comum entre os participantes.

- Composição: novas coreografias podem ser formadas combinando coreografias existentes.

- Tratamento de exceções: coreografias podem definir como condições excepcionais ou incomuns devem ser tratadas.

- Transações: os participantes da coreografia podem trabalhar de forma transacional, coordenando o resultado das colaborações de longa duração.

\subsection{Conclusão do capítulo}

Neste capítulo contextualizamos a área na qual este trabalho está inserido por meio da apresentação dos principais conceitos relacionados à coordenação de serviços, tais como web services e arquitetura orientada a serviços (SOA).

Foram apresentadas as abordagens mais utilizadas para composição de serviços: orquestração, modelo em que há a presença de um coordenador central, e coreografia, modelo que descreve as relações de colaboração entre os serviços participantes.

Também foram apresentados os padrões BPEL para orquestração e WS-CDL para coreografia.

\subsubsection{Posicionamento da plataforma JamSession}

A plataforma JamSession emprega a abordagem de orquestração de serviços, que possui as seguintes vantagens considerando a composição de serviços para gerenciar processos de negócios [29]:

- Sabemos exatamente qual componente é o responsável pela execução de todo o processo de negócio.

- Podemos incorporar diversos serviços, mesmo os que não sabem de sua participação no processo. 
- Podemos fornecer cenários alternativos quando ocorrerem falhas.

Além de concentrar o controle e proporcionar as vantagens mencionadas acima, o mecanismo de orquestração de serviços utilizado na plataforma JamSession também facilita a verificação formal da interação, aspecto que será abordado no Capítulo 4. 


\section{Capítulo 3}

\section{Projetos Relacionados}

O desenvolvimento da plataforma JamSession foi inspirado em projetos de pesquisa existentes que representam subconjuntos específicos dos recursos esperados desta nova plataforma.

Uma arquitetura conceitual que possui várias semelhanças com a abordagem deste trabalho é a de instituições eletrônicas [20]. Instituições eletrônicas são compostas por agentes, papéis, regras normativas que caracterizam as instituições e as cenas em que os diálogos envolvendo agentes ocorrem. Para participar de um diálogo, um agente deve assumir um papel específico compatível com aquele diálogo, e para assumir um papel específico, o agente deve possuir os requisitos necessários exigidos para esse papel. Uma vez que todos os papéis necessários para um diálogo são preenchidos por agentes, o diálogo pode começar e, se todas as normas são seguidas, o diálogo pode ser executado até o fim, realizando assim uma sequência estruturada e controlada de ações linguísticas.

Interações mediadas por normas tem sido exploradas em uma variedade de iniciativas [5] [14] nas quais os protocolos de interação são fundamentados por regras normativas que especificam permissões, obrigações e proibições que os agentes devem respeitar.

LCC (Lightweight Coordination Calculus) é uma linguagem baseada em cálculo de processos utilizada para especificar a coordenação entre os vários participantes. Isso é feito definindo os papéis adotados pelos participantes e assegurando o cumprimento dos papéis através da regulação dos fluxos de mensagens entre eles. Na plataforma JamSession a noção de localização e mobilidade está explicitamente incluída.

O modelo Multilayered Multiagent Situated Systems (MMASS) [55] considera a mobilidade como uma noção central para contextualização e interações em sistemas multiagentes. Em MMASS encontramos o conceito de localizações, que são estruturadas por transições que formam um grafo de locais através dos quais os agentes podem se mover para procurar recursos específicos.

Este capítulo é dedicado a uma breve apresentação desses projetos que foram particularmente influentes na elaboração desta nova plataforma. 


\subsection{Instituições Eletrônicas}

As instituições humanas de nossa sociedade definem interações entre os indivíduos, direcionando o comportamento social e obrigando os indivíduos a agirem de acordo com as normas estabelecidas pela instituição.

O modelo de instituições eletrônicas (Electronic Institutions - EIs) [20] se inspirou nas instituições humanas para a conceber sistemas multiagentes e envolve os seguintes elementos principais:

- Agentes e papéis: Agentes são jogadores na instituição eletrônica, interagindo através de atos de fala. Qualquer agente de uma instituição eletrônica deve assumir um papel. Os papéis definem padrões de comportamento padronizado para determinado agente, determinando o conjunto de ações possíveis.

- Framework dialógico: Define o contexto ou a estrutura da interação entre os agentes de uma instituição como os objetos do mundo e a linguagem empregada na comunicação. As interações entre os agentes devem ocorrer através de atos de fala por meio de uma linguagem comum.

- Cena: Interações entre os agentes são articuladas através de reuniões de grupos de agentes, chamadas de cenas, que seguem um protocolo de comunicação bem definido.

- Estrutura performativa: Cenas podem ser conectadas, compondo uma rede que define as transições de agentes dentro de uma instituição.

- Regras normativas: As ações de um agente no contexto de uma instituição podem ter consequências que podem limitar ou ampliar as possibilidades de ações subsequentes. Essas consequências podem impor obrigações aos agentes que afetam os caminhos possíveis dentro da estrutura performativa.

Por meio da utilização de ambientes de instituições eletrônicas é possível especificar sistemas baseados em agentes cujas interações são reguladas através de regras normativas. Esta noção de interações mediadas por normas avançou e assume papel central em outras abordagens [15] [52]. 


\subsection{OpenKnowledge}

OpenKnowledge [2] é um projeto da União Europeia, coordenado pela Universidade de Edinburgh, que tem por objetivo proporcionar uma nova forma de compartilhamento de conhecimento em ambientes abertos.

O objetivo do projeto é fornecer um framework aberto para interação e coordenação de agentes em ambientes ricos em conhecimento. O framework fornece uma infraestrutura distribuída, que permitem peers encontrar e coordenar outros, publicando, descobrindo e executando modelos de interação. A principal novidade da abordagem é que nenhum acordo a priori ou conhecimento dos peers da conversação é necessário para ter interações significativas.

O projeto se baseia na ideia que a World Wide Web tem sido bem-sucedida numa escala global devido ao custo da participação. Custos em um nível básico são baixos e o benefício individual da participação é imediato, aumentando rapidamente à medida que aumenta o número de participantes. Assim, OpenKnowledge se concentra na semântica relacionada à interação que poderia ser adquirida a baixo custo (participação) e poderia ser usada sem que sejam necessários acordos semânticos a priori.

As áreas de bioinformática e gerenciamento de emergências compõem os experimentos da pesquisa. Até agora, vários resultados foram alcançados, como a definição de uma linguagem para modelar as interações e um protótipo funcional.

OpenKnowledge permite que peers em uma rede peer-to-peer possam interagir de forma produtiva uns com os outros sem qualquer acordos globais ou conhecimento anterior sobre quem interage com quem ou como as interações vão prosseguir. Qualquer tipo de serviço (por exemplo, um serviço WSDL) pode tornar-se um peer e usuários podem facilmente criar seus próprios peers compartilhando código previamente existente ou escrever seus próprios.

Nesta abordagem as coreografias são publicadas em um repositório compartilhado. Participantes buscam as coreografias apropriadas quando precisam realizar uma atividade que requer a atividade coordenada de outros participantes. As coreografias são compatíveis com as capacidades dos participantes: os participantes selecionam a coreografia que melhor se encaixa e anuncia a sua intenção de desempenhar um papel neles. Se todos os papéis são preenchidos, a interação pode ser iniciada.

\section{Modelos de interação}

O conceito básico é o modelo de interação compartilhado (shared interaction models - IM), realizado por diferentes aplicações e fornecedores de serviços. Esses atores são os participantes, chamados peers, das interações e eles desempenham papéis. Em uma interação todos os papéis têm o mesmo peso. O comportamento de todos os peers e em particular sua troca de mensagens são especificados.

Modelos de interação são escritos em Lightweight Coordination Calculus (LCC) [47] e publicados pelos autores em um serviço de descoberta distribuído com uma descrição baseada em palavraschave.

Um modelo de interação em $L C C$ é um contrato que define interfaces de comportamento dos papéis que os participantes podem assumir na interação: um modelo de interação é um conjunto de cláusulas do papel. Participantes em uma interação assumem seu papel inicial e segue o desdobramento da cláusula especificada usando combinações do operador de sequência (então) ou operador de escolha (ou) para conectar as mensagens e as alterações do papel. 
Mensagens são enviadas e recebidas de outro participante em determinado papel. Um participante pode assumir, durante uma interação, mais papéis e pode assumir recursivamente o mesmo papel (por exemplo, quando o processando uma lista). Mensagens de entrada/saída ou mudança de papel são controladas por restrições. Na sua definição, $L C C$ não estabelece o método utilizado para resolver as restrições - participantes diferentes podem trabalhar com diferentes revolvedores de restrições.

\section{Lightweight Coordination Calculus (LCC)}

No núcleo do sistema OpenKnowledge está a linguagem LCC (Lightweight Coordination Calculus) na qual as interações entre os participantes são descritas.

$L C C$ é uma linguagem baseada em cálculo de processos utilizada para especificar a coordenação entre os vários participantes. Isso é feito definindo os papéis adotados pelos participantes durante a interação, onde os papéis são executados de forma independente (de acordo com a definição das cláusulas) e sincronizados através da troca de mensagens. $L C C$ assegura o cumprimento dos papéis dos participantes através da regulação dos fluxos de mensagens entre eles, ou seja, as mensagens que devem ser enviadas e recebidas e quais restrições devem ser satisfeitas antes que uma mensagem possa ser manipulada.

Trata-se de uma linguagem de especificação declarativa, compacta e executável num estilo familiar aos programadores de linguagens lógicas. Variáveis e estruturas de dados são tratados de maneira semelhante ao Prolog.

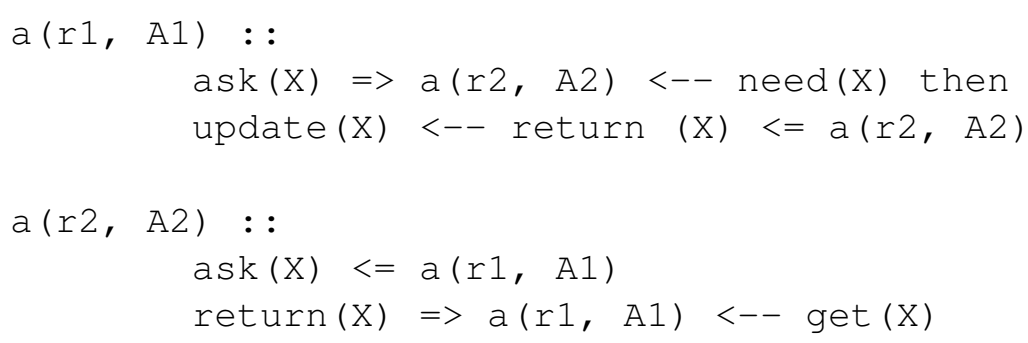

Figura 3.1: Trecho de modelo de interação especificado em LCC. Setas duplas (=>, <=) indicam passagem de mensagens, setas simples (->, <-) indicam pré-condiçôes.

Uma interação básica descrita com $L C C$ é mostrada acima. O agente $A_{1}$ desempenhando o papel $r_{1}$ verifica se precisa da informação $X$ (pré-condição need $(X)$ ). Se sim, $A_{1}$ solicita $X$ para o agente $A_{2}$ desempenhando o papel $r_{2}$ enviando a mensagem $\operatorname{ask}(X) . A_{2}$ recebe a mensagem $\operatorname{ask}(X)$ de $A_{1}$ e obtém a informação $X$ (pré-condição $\operatorname{get}(X)$ ) antes de enviar de volta uma resposta para $A_{1}$ através da mensagem $\operatorname{return}(X)$. Depois de ter recebido a mensagem $\operatorname{return}(X), A_{1}$ atualiza seu estado (pós-condição update $(X)$ ). 


\section{Ciclo de vida}

Um peer que deseja executar alguma tarefa procura por modelos de interação publicados para a tarefa que deseja realizar enviando uma consulta baseada em palavras-chave para o $D D S$. O DDS recolhe os modelos de interação que correspondem à descrição (as palavras-chave são estendidas adicionando sinônimos para melhorar a busca) e envia a lista de volta para o peer, que então precisa escolher um para se inscrever.

Uma vez que o peer tenha selecionado um modelo de interação, ele se inscreve para o seu papel na descoberta de serviços. Quando todos os papéis são preenchidos, o serviço de descoberta escolhe aleatoriamente um peer na rede como coordenador para a interação, e entrega o modelo de interação juntamente com a lista dos participantes envolvidos, a fim de executá-lo.

O primeiro coordenador pede a cada peer para selecionar os peers que desejam interagir, formando um grupo de peers compatíveis entre si para as respostas. Todos os participantes recebem a lista de peers inscritos em todos os papéis, e eles podem verificar as assinaturas, selecionando as preferenciais. A estrutura oferece somente a interface para o método de seleção e a sua implementação é delegada ao desenvolvedor da aplicação.

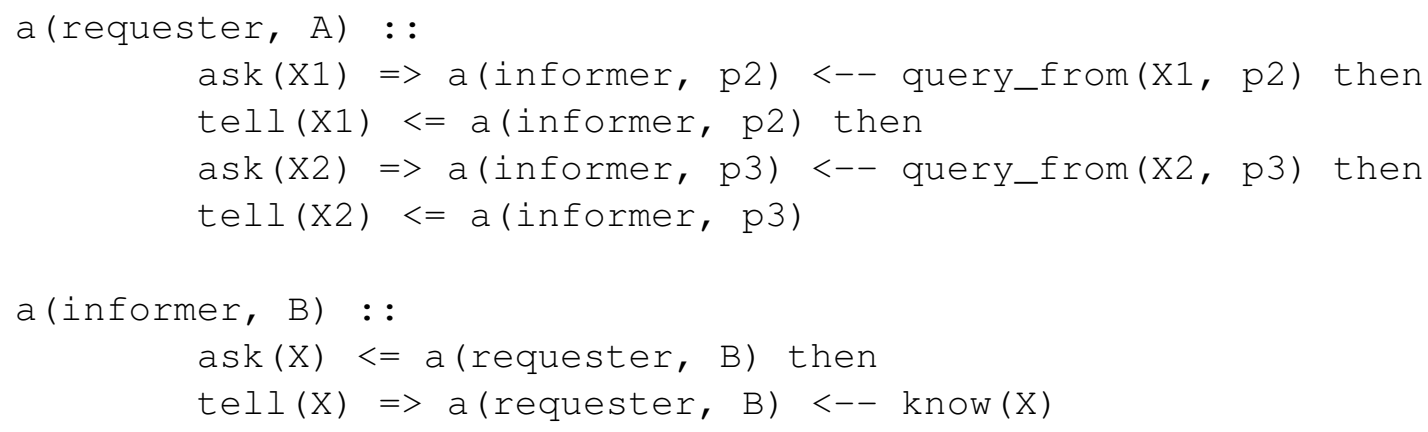

Figura 3.2: Exemplo de modelo de interação informante/solicitante

Existem três aspectos principais em um modelo de interação:

\section{- Papéis:}

Modelos de interação devem consistir de dois ou mais papéis, onde cada papel descreve as ações necessárias para um dos peers que irão participar da interação. Identificadores do papel têm a forma (papel, ID). Por exemplo, no modelo acima, o primeiro papel é solicitante, e isso vai ser assumido por um peer com ID $A$. $A$ é uma variável que será instanciada com o ID do peer apropriado quando este é conhecido.

Seria possível fazer esse ID constante e, portanto, o papel só seria assumido pelo peer específico identificado por essa constante, mas isso é contrário ao ideal de reutilização de modelos de interação e por isto geralmente não é tão incentivado.

\section{- Mensagens:}

As mensagens são indicadas pela seta dupla. À esquerda da seta dupla está a mensagem que está a sendo enviada e à direita está o papel para o qual a mensagem está sendo enviada. Setas duplas apontando para a direita (para o papel) indicam mensagens indo para esse papel, e vice-versa. 
Dentro de um modelo de interação, a maioria das mensagens irá conter uma ou mais variáveis que não são determinadas pelo modelo de interação. Por exemplo, no modelo de interação acima, o valor da variável $X$ é determinado apenas em tempo de execução: portanto, o modelo de interação é reutilizável em diferentes situações.

Qualquer mensagem que é enviada em um modelo de interação também deve ser recebido pelo papel apropriado dentro desse modelo de interação, e, portanto, todas as mensagens aparecem duas vezes, uma vez como uma mensagem enviada em papel do remetente e uma vez como uma mensagem recebida no papel do destinatário. Quando há apenas dois papéis, isso torna a passagem de mensagens nesses papéis completamente simétrica.

\section{- Restrições:}

As restrições são colocadas em mensagens, aparecendo à direita delas em um modelo de interação e apontando para a mensagem relevante com uma seta única, e têm duas funções:

- Explicar como as variáveis nas mensagens devem ser instanciadas.

- Limitar as circunstâncias sob as quais uma mensagem pode ser enviada: ela só pode ser enviada se a restrição puder ser satisfeita pelo peer desempenhando o papel.

Por exemplo, em tempo de execução, a variável $X$ deve ser instanciada com um valor adequado. Isto é feito através da restrição query $(X)$. Assim, o peer que faz o papel de solicitante deve ser capaz de satisfazer essa restrição, e, ao fazê-lo, ele irá instanciar a variável $X$ para quem quiser.

Qualquer peer é capaz de transmitir qualquer mensagem desde que as restrições necessárias estejam satisfeitas. Portanto, a capacidade de desempenhar um papel especial é equivalente à capacidade de satisfazer todas as restrições sobre as mensagens nesse papel.

OpenKnowledge está desenvolvendo experimentos em vários domínios, com foco em duas áreas: bioinformática e gerenciamento de emergências. 


\subsection{Multilayered Multiagent Situated Systems (MMASS)}

No contexto de sistemas multiagentes, o modelo denominado Multilayered Multiagent Situated Systems (MMASS) [55] permite a representação explícita da estrutura do ambiente onde os agentes estão situados, e fornece o comportamento dos agentes dependentes da localização e mecanismos de interação.

Esse modelo considera a mobilidade como a noção central para contextualização e interações em sistemas multiagentes. Em MMASS encontramos a noção de localizações, que são estruturadas por vias formando um grafo de locais através dos quais os agentes podem se mover para procurar recursos específicos para realizar seus objetivos.

Vizzari [55] propõe um modelo de interação explorando informações espaciais a fim de fornecer mecanismos de interação que são conscientes do contexto em que as entidades envolvidas estão posicionadas. O modelo proposto é um framework formal e computacional para a definição de sistemas multiagentes caracterizado pela representação explícita do ambiente dos agentes e mecanismos de interação que dependem de características espaciais desse ambiente e do contexto da interação.

\subsubsection{Agentes situados}

Agentes MMASS são situados, ou seja, eles têm uma determinada posição no ambiente. Essa posição e, mais genericamente, o contexto espacial em que os agentes estão situados, determina sua possibilidade de perceber, agir e interagir com outras entidades.

\subsubsection{Ambiente multicamadas}

O ambiente de agentes MMASS é multicamadas, ou seja, é composto de várias estruturas espaciais interconectadas, possivelmente relacionadas com diferentes aspectos do ambiente. Por exemplo, abstrações de um espaço físico, mas também topologia com base em uma noção não física de adjacência.

Agentes colocados em uma camada podem influenciar outras entidades, tanto aquelas posicionadas na mesma camada como também aquelas situadas em outras que podem ser alcançadas por seus sinais, de acordo a estrutura espacial do ambiente. 


\subsection{Conclusão do capítulo}

Neste capítulo foram apresentados projetos de pesquisa com características que inspiraram o desenvolvimento da plataforma JamSession.

Em JamSession, o conceito de papel existente nas instituições eletrônicas é substituído por uma noção equivalente de localização. Os agentes devem se deslocar para locais específicos a fim de participar de ações colaborativas e permitir acesso a determinados recursos.

Outra semelhança entre instituições eletrônicas e JamSession é que ambos levam em conta questões relativas à usabilidade. Instituições eletrônicas foram usadas como base para a construção de sistemas amigáveis, com base em interfaces de usuário que recorrem a animações interativas como meio de trazer aos usuários a experiência de interagir com os serviços como numa interação com funcionários humanos em um ambiente simulado virtual [6].

Na plataforma JamSession, o conceito de interações mediadas por normas é simulado por meio de protocolos de interação associados a localizações específicas.

O conceito de localizações existente em MMASS influenciou fortemente a plataforma JamSession. Intuitivamente, temos agentes em um ambiente, cujos recursos são bloqueados ou liberados para uso, dependendo das localizações em que eles estão situados. Quando um usuário precisa de um serviço específico, ele deve se certificar de que o agente que tem a capacidade de fornecer o serviço em um local específico realmente está na localização apropriada. Localizações são, portanto, abstrações de grupos de serviços cuja disponibilidade é controlada por agentes em locais específicos. 


\section{Capítulo 4}

\section{Plataforma Teórica}

JamSession é uma plataforma para integração e coordenação de recursos computacionais. Foi concebido inicialmente para sistemas altamente interativos, como videogames com vários jogadores, e mais tarde estendido para gerenciar recursos computacionais genéricos. As principais características do JamSession são:

- Alto desempenho computacional, para fornecer os meios para a coordenação e integração de componentes de software em sistemas de tempo real.

- Usabilidade, para garantir que os usuários novatos são capazes de integrar e coordenar recursos heterogêneos com um esforço minimizado.

- Fundações formais e declarativas, para fornecer os meios para o desenvolvimento formal, análise e verificação de protocolos de coordenação.

- Integração desacoplada de recursos computacionais heterogêneos, para garantir a sua independência.

\subsection{O conceito de localização}

Um dos conceitos fundamentais na plataforma JamSession é o de localização. Intuitivamente, temos serviços distribuídos em um ambiente, que estão bloqueados ou liberados para uso, dependendo da localização de agentes. Agentes estão associados a recursos, que podem ser ativados quando eles atingem localizações específicas. Sempre que precisamos de um serviço específico, temos de nos certificar que aquele agente que tem a capacidade de fornecer o serviço em um local específico realmente se moveu para essa localização.

Formalmente, temos um grafo dirigido para especificar as localizações e suas conexões. Os nós do grafo são as localizações e as setas indicam as transições que os agentes podem realizar para se mover para outras localizações.

JamSession pode ser encarado como um coordenador de recursos externos. As construções na linguagem utilizada foram projetadas para fornecer os meios adequados para coordenar e regular o acionamento dos recursos disponíveis. A ferramenta conceitual para realizar esta coordenação e controle dos recursos é o movimento de agentes entre as localizações. 


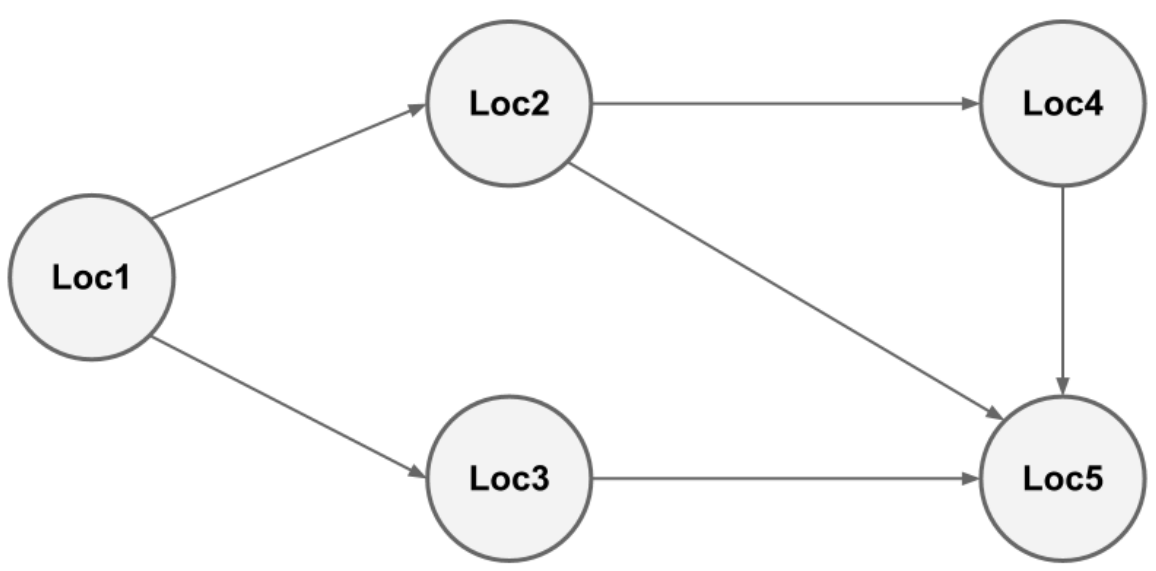

Figura 4.1: Grafo de localizações. Os agentes podem se mover, por exemplo, da localização 1 para a localização 2, mas eles não podem passar da localização 3 para a localização 4.

\subsection{Agentes}

Agentes são entidades que habitam localizações. Um agente permanece em uma localização até que que receba um ordem para se deslocar para uma localização diferente. Uma ordem para um agente se mover é uma tripla da forma:

\section{move(Agente, Localização , Localização $_{2}$ )}

$\mathrm{Na}$ ordem acima, temos que o agente Agente está na Localização $o_{1}$ e está sendo solicitado para se deslocar para a Localização2.

Uma ordem para mover pode ser avaliada, caso em que uma tentativa de execução deve ser realizada e um valor verdade correspondente será atribuído a ela, dependendo do sucesso da execução. Se o agente Agente está de fato na Localização $o_{1}$ e há um caminho da Localização $o_{1}$ para a Localização $o_{2}$ então o Agente é movido da Localizaçãoo $o_{1}$ para a Localização $o_{2}$ e a ordem é avaliada para $\top$ (verdadeiro). Caso contrário, Agente permanece onde estava e e a ordem é avaliada para $\perp$ (falso). 


\subsection{Predicados}

Recursos externos são chamados de predicados no JamSession. Cada predicado está associado a um par [Agente, Localização]. Um predicado possui parâmetros de entrada e saída e tem a seguinte forma:

$$
\left[A g, \text { Loc]predicado }\left(\left(I_{1}, \ldots, I_{n}\right),\left(O_{1}, \ldots, O_{n}\right)\right)\right.
$$

onde $A g$ é um agente, $L o c$ é uma localização, $I_{i}$ são termos de entrada e $O_{j}$ são variáveis de saída.

Predicados são definidos durante o projeto de um sistema, especificando quais os recursos e serviços podem ser acionados por quais agentes em quais localizações. Durante a execução de um sistema, predicados são usados para realmente disparar recursos e serviços, obedecendo as especificações dadas.

Um predicado pode ser acionado, ou seja, pode haver uma tentativa de avaliá-lo. Predicados podem ser usados para consumir recursos externos e chamar serviços externos.

Os termos de entrada do predicado são sintaticamente e semanticamente verificados e também é verificado se o agente $A g$ está localizado na localização $L o c$. Se todas as verificações forem bemsucedidas, os recursos e serviços são ativados, possivelmente instanciando as variáveis de saída e o predicado é avaliado para $\top$ ou $\perp$, dependendo do comportamento programado.

Se os parâmetros de entrada não forem consistentes ou se $A g$ não está localizado em $L o c$, ou se $A g$ não tem permissão para acionar o predicado em $L o c$, então o predicado é bloqueado e os recursos correspondentes não podem ser ativados. Neste caso, o predicado é avaliado para $\perp$ e as variáveis de saída não são instanciadas.

\subsection{Protocolos}

Predicados e movimentos são combinados usando protocolos de interação baseados em conhecimento (knowledge-based interaction protocols - KBIPs). Um KBIP é uma estrutura de entidades que especifica sua ordem de avaliação.

Entidades podem ser de três tipos:

1. Ordem para mover um agente

2. Predicados

3. Recursivamente, outros KBIPs

KBIPs estão associados a localizações. Uma solicitação para acionar um KBIP pode resultar nas seguintes situações:

- O KBIP solicitado não está definido para a localização especificada. Neste caso, o valor verdade obtido é $\perp$.

- O KBIP solicitado está definido para a localização especificada. Neste caso, a especificação do $K B I P$ é recuperada e avaliada, com base nas regras algébricas que determinam o comportamento dos conectivos usados na especificação do $K B I P$. O resultado da avaliação determina o valor verdade que deve ser atribuído ao $K B I P$, que pode ser $\top$ ou $\perp$. 
Um KBIP é denotado da seguinte forma:

$$
[\operatorname{Loc}] \operatorname{KBIP}\left(\left(I_{1}, \ldots, I_{m}\right),\left(O_{1}, \ldots, O_{n}\right)\right)
$$

Na expressão acima, Loc é a localização na qual o $K B I P$ está associado, $I_{i}$ são os termos de entrada e $O_{j}$ são as variáveis de saída. A utilização esperada dos termos e variáveis na especificação dos KBIPs é a passagem de parâmetros através de predicados e KBIPs auxiliares.

Um KBIP assume a forma de uma fórmula na forma normal disjuntiva, nas quais os átomos são as entidades mencionadas acima, ou seja, as ordens para movimentar os agentes, os predicados e os KBIPs.

Mais formalmente, a especificação de um $K B I P$ tem a seguinte forma:

- $[L o c] K B I P\left(\left(I_{1}, \ldots, I_{m}\right),\left(O_{1}, \ldots, O_{n}\right)\right)::=\bigvee_{i=1}^{k} F_{i}$.

- $F_{i}::=\bigwedge_{i=1}^{r_{i}} e_{j}$

- $e_{j}::=$ Move|Predicado|KBIP.

- Move $:=\operatorname{move}\left(A g, L o c_{1}, L o c_{2}\right)$

- Predicado ::= $[$ Ag, Loc $]$ predicado $\left(\left(I_{1}, \ldots, I_{n}\right),\left(O_{1}, \ldots, O_{n}\right)\right)$

- $K B I P::=[\operatorname{Loc}] K B I P\left(\left(I_{1}, \ldots, I_{m}\right),\left(O_{1}, \ldots, O_{n}\right)\right)$

As disjunções e conjunções são consideradas não comutativas, e portanto a ordem em que as entidades aparecem nos KBIPs podem alterar sua avaliação.

KBIPs são usados para especificar, implementar e executar as interações entre os usuários de sistemas de informação com base na integração e coordenação dos recursos. Protocolos de interação também são empregados para especificar, implementar e executar as interações de sistemas de informação entre si mesmos.

Agentes, localizações e todas as entidades que compõem o KBIPs são os recursos conceituais utilizados para caracterizar as interações desejadas tanto em tempo de projeto como em tempo de execução. KBIPs comportam-se como mediadores entre os recursos computacionais e asseguram que os recursos heterogêneos estão desacoplados.

Protocolos de interação podem ser acionados concorrentemente. Mais de um protocolo e mais de uma instância de um mesmo protocolo podem estar executando ao mesmo tempo. O projetista do sistema deve assegurar que o grupo concorrente de protocolos gera comportamentos que estão em conformidade com os requisitos especificados para cada aplicação. A caracterização declarativa dos protocolos de interação no JamSession, no entanto, fornece os meios para análise formal e verificação de protocolos. 


\subsection{Representação gráfica}

Uma linguagem gráfica foi concebida com o objetivo de simplificar a especificação dos KBIPs.

A conjunção é representada com uma linha conectando duas entidades e a disjunção é representada por um círculo preto. As três entidades básicas que compõem um KBIP (movimento, predicados e outros $K B I P s$ ) são representadas como mostrado na figura abaixo:
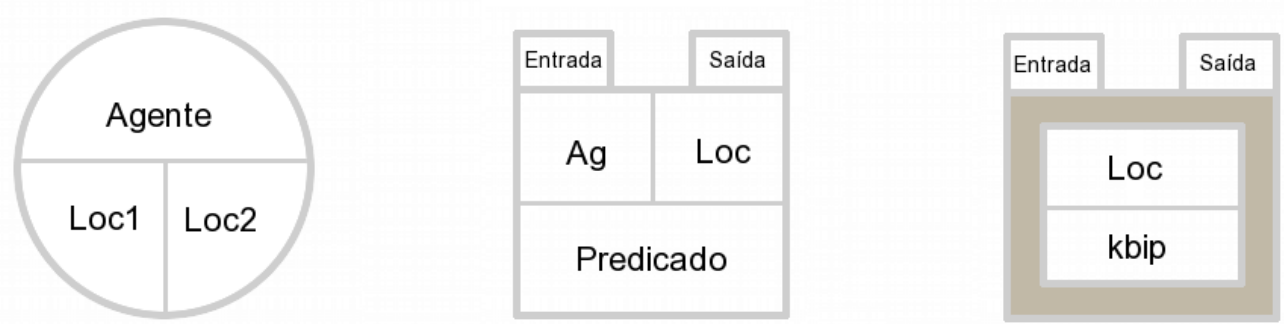

Figura 4.2: Representações gráficas das entidades (movimento, predicado e KBIP)

Por exemplo, o seguinte $K B I P$

$$
\begin{aligned}
& {\left[\operatorname{Loc}_{1}\right] K B I P_{1}((I),(O))::=} \\
& {\left[A g, \text { Loc }_{1}\right] \operatorname{Pred}_{1}((I),(O)) \vee\left(\text { move }\left(A g, \operatorname{Loc}_{1}, \operatorname{Loc}_{2}\right) \wedge\left[A g, \operatorname{Loc}_{2}\right] \operatorname{Pred}_{2}((I),(O))\right.}
\end{aligned}
$$

pode ser representado em diagrama como exibido na figura 4.3:

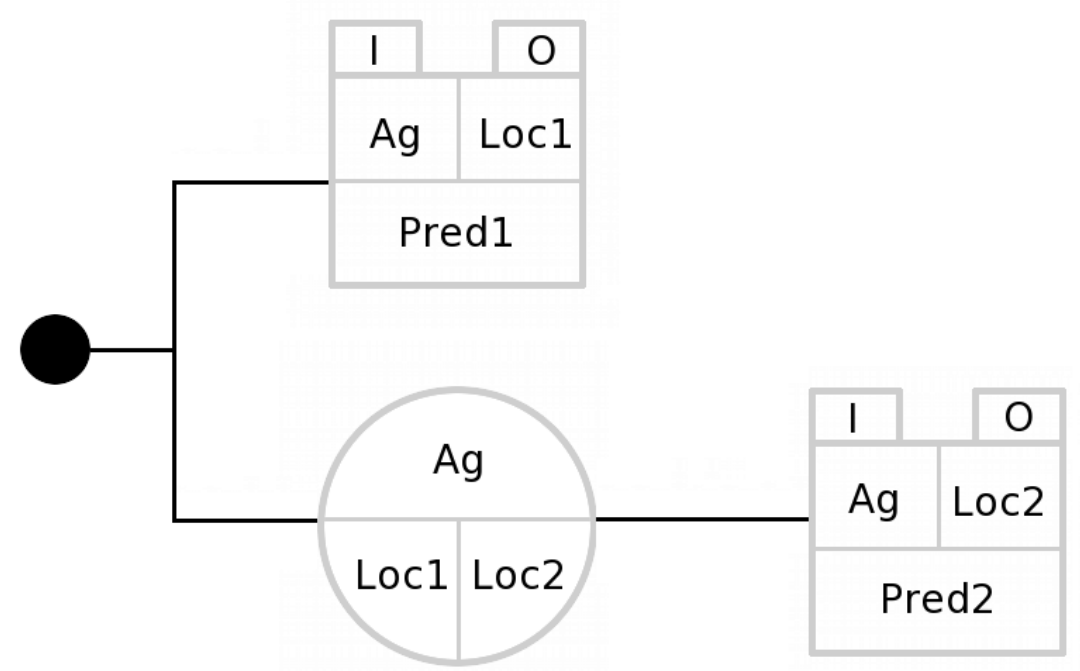

Figura 4.3: Representação gráfica de um KBIP simples

A especificação deve ainda ser complementada com a informação sobre quais recursos pertencem a quais localizações e agentes, as conexões entre as localizações e a configuração inicial dos agentes.

Por exemplo, poderíamos ter: 
- $\left[A g, \operatorname{Loc}_{1}\right] \operatorname{Pred}_{1}((I),(O))::=($ especificação do comportamento associado à Pred 1 )

- $\left[A g, \operatorname{Loc}_{2}\right] \operatorname{Pred}_{2}((I),(O))::=\left(\right.$ especificação do comportamento associado à Pred $\left._{2}\right)$

- Estrutura de localizações e localização inicial do agente $A g$ como mostrado na figura 4.4

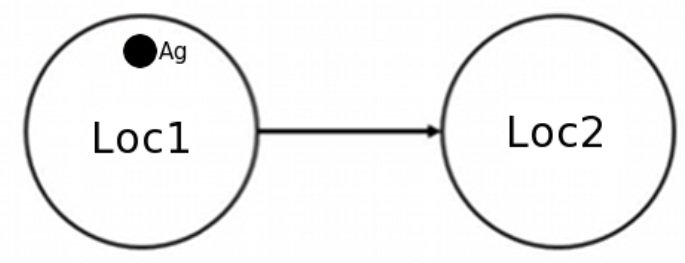

Figura 4.4: Configuração inicial 


\subsection{Análise formal}

Como mencionado anteriormente, a caracterização declarativa dos protocolos de interação na plataforma JamSession fornece meios para verificação e análise formal do comportamento do sistema. Nesta seção descrevemos como os protocolos de interação do JamSession podem ser verificados.

Importante destacar que JamSession pode ser usado em diferentes níveis de abstração, ou seja, é possível desenvolver protocolos sofisticados utilizando recursos externos simples como também é possível desenvolver protocolos triviais com acesso a recursos externos mais complexos. Portanto, a análise do sistema deve considerar esta flexibilidade existente na composição dos protocolos.

\subsubsection{Análise de configurações}

Uma forma de verificação dos protocolos em JamSession é realizar uma análise de configuração. É possível verificar se um conjunto de protocolos em JamSession sempre termina com sucesso analisando todas as possíveis saídas destes protocolos.

Poderíamos estar interessados, por exemplo, em verificar se uma determinada configuração pode ser alcançada ou se uma mensagem de erro pode ser gerada dado um conjunto de valores de entrada. Verificações desta natureza podem ser desenvolvidas em protocolos JamSession baseadas na análise de configurações.

\subsubsection{Redes de Petri}

A rede de Petri [37] é um modelo matemático com representação gráfica que permite especificar, simular e avaliar formalmente a estrutura, propriedades e o comportamento dinâmico de sistemas concorrentes. A análise das propriedades da rede Petri apresenta informações importantes que podem ser usadas para avaliar a modelagem do sistema levando a melhorias ou mudanças no sistema projetado.

Redes de Petri têm sido cada vez mais aplicadas para modelar sistemas distribuídos e móveis [56] [34]. Redes de Petri e mais especificamente as redes de Petri coloridas [27] e suas variações também têm sido utilizadas para especificar e analisar formalmente workflows interorganizacionais [46]

A natureza declarativa dos protocolos JamSession possibilitam a análise e verificação formais destes protocolos. É possível traduzir esses protocolos para redes de Petri coloridas para simular o comportamento da interação e identificar os possíveis estados de conflitos e falhas. Esta técnica também pode ser utilizada visando a otimização dos protocolos utilizando os agentes de forma mais eficaz.

Em [53] é apresentada uma proposta de semântica formal para a linguagem utilizada na plataforma JamSession, que pode ser utilizada na análise, simulação e verificação de protocolos de interação. Inicialmente é apresentada a sintaxe da linguagem e regras semânticas de seu processo computacional. Na sequência é mostrado como o comportamento dinâmico de seu mecanismo de coordenação pode ser modelado utilizando redes de Petri aninhadas [33].

Na plataforma JamSession os agentes são entidades passivas que gerenciam os recursos locais e os protocolos são os componentes ativos que coordenam a interação dos agentes. Os protocolos de interação podem ser compostos, aninhados e recursivamente definidos. Dessa forma, o ambiente 
que define o sistema (agentes, localizações e movimentos de agentes) pode ser representado usando um conjunto de cores e as transições da rede representam a execução dos predicados e protocolos, assim como os operadores de conjunção e disjunção.

Em [53] o comportamento de um sistema desenvolvido com JamSession foi modelado como um Workflow Net [51] e foi definida uma propriedade para sua corretude, que pode ser utilizada para a detecção de interações conflitantes.

\subsubsection{SPIN}

Em [54] é estudado como o verificador de modelos SPIN (Simple Promela INterpreter) [26], que é uma das ferramentas mais bem-sucedidas para simulação e verificação de sistemas concorrentes e distribuídos, pode ser usado para verificar protocolos de interação em JamSession.

\subsection{Conclusão do capítulo}

Neste capítulo foram abordados os principais conceitos e características da plataforma JamSession. Foram introduzidas as entidades que compõem os protocolos de interação e suas representações gráficas. Foi definida formalmente a linguagem utilizada para a especificação de protocolos e apresentados mecanismos de análise e verificação.

A realização computacional da base teórica apresentada neste capítulo, ênfase deste trabalho, será detalhada no Capítulo 5. 


\section{Capítulo 5}

\section{Implementação}

JamSession foi desenvolvido na plataforma .NET sendo o núcleo da plataforma desenvolvido na linguagem de programação funcional $\mathrm{F}^{1}{ }^{1}$ [44] [48]. A plataforma desenvolvida atualmente é composta por:

- Coordenador: trata-se do núcleo do JamSession, responsável pelo mecanismo de avaliação de protocolos. Gerencia as localizações dos agentes, assim como os clientes e seus correspondentes protocolos de interação.

- Editor de protocolos: ferramenta para especificar protocolos e predicados.

- Aplicativo de testes: ferramenta desenvolvida para testes que permite executar protocolos e predicados.

- Unity Demo: aplicativo de exemplo ilustrando o uso do JamSession em ambientes virtuais.

JamSession pode ser executado de três maneiras diferentes: em uma única máquina, em rede local ou na internet, por exemplo utilizando a plataforma de computação em nuvem Windows Azure ${ }^{2}$, na qual foram realizados alguns experimentos.

$\mathrm{Na}$ implementação desenvolvida, o coordenador armazena e gerencia as localizações dos agentes, assim como os clientes e seus correspondentes KBIPs. Sempre que um cliente se inscreve ao coordenador, ele exporta para o coordenador sua coleção de interfaces para seus protocolos localmente armazenados.

Cada cliente pode disparar um protocolo enviando uma requisição para o coordenador, que então verifica a validade da requisição e, caso a requisição seja válida, faz uso da correspondente interface do protocolo e envia uma requisição para o cliente apropriado, isto é, aquele que hospeda o protocolo desejado para efetivamente acioná-lo.

Além dos protocolos, clientes também hospedam a implementação dos predicados cujas avaliações são solicitadas pelo servidor no curso da execução dos protocolos. Efeitos colaterais da avaliação de predicados tais como atualizações de arquivos e interações com recursos computacionais externos também são implementados localmente nos clientes.

Predicados podem ser especificados nas linguagens C\# ou F\#. Eles são compilados independentemente para bibliotecas de vínculo dinâmico $(D L L s)$.

\footnotetext{
${ }^{1}$ http://www.fsharp.net/

${ }^{2}$ http://www.windowsazure.com/
} 


\subsection{Espaço de tuplas}

O conceito de espaço de tuplas vem dos meados dos anos 80, quando foram introduzidas pela primeira vez por Gelernter e Carriero da Universidade de Yale em conjunto com a linguagem de coordenação Linda [8]. Neste modelo, há uma arquitetura cliente-servidor com uma comunicação baseada exclusivamente em listas ordenadas de dados primitivos, chamadas tuplas.

Os clientes podem escrever e tomar tuplas do servidor e não precisam ter informações sobre os outros clientes. Eles se comunicam apenas por meio do servidor sem que seja necessário resolver qualquer endereço de outro cliente. Espaços de tuplas são uma maneira elegante e fácil de criar sistemas de software distribuídos que são robustos e modulares, uma vez que são fracamente acoplados.

JamSession utiliza o conceito de espaço de tuplas para gerenciar as localizações dos agentes. A implementação atual utiliza a implementação SQLSpaces ${ }^{3}$, que foi desenvolvida pelo grupo de pesquisa Collide da Universidade de Duisburg-Essen.

\subsection{Coordenador}

O coordenador implementa a especificação do núcleo do JamSession atuando como coordenador de recursos externos.

É responsável por gerenciar a lista de clientes conectados assim como predicados e protocolos implementados em cada cliente. Também é responsável por manter o espaço de tuplas onde são armazenados os mundos e localizações dos agentes.

O núcleo do JamSession contém funções que permitem avaliar predicados e protocolos de acordo com a especificação definida no capítulo anterior. Também contém funções para o gerenciamento de mundos e agentes como incluir mundos, verificar se um agente está em determinado mundo e movimentar agentes de acordo com as regras de movimentação (grafo de transições possíveis).

A comunicação com os clientes é feita por meio de web services. Ao receber uma solicitação de execução de um predicado ou protocolo (chamada de web service), o coordenador solicita que algum cliente que possua a implementação execute. Caso a execução tenha sucesso, a lista de variáveis de saída é devolvida para o cliente que inicialmente solicitou a execução.

\footnotetext{
${ }^{3}$ http://sqlspaces.collide.info/
} 


\subsection{Comunicação}

Windows Communication Foundation (WCF) [9] é o modelo unificado de programação da $M i$ crosoft para criação de aplicações orientadas a serviços. WCF possui bindings predefinidos para diversos casos. Para a implementação dos web services, JamSession utiliza o binding NetTcpBinding.

NetTcpBinding usa o protocolo TCP para o transporte, codificação binária para as mensagens SOAP e permite comunicação duplex. Um serviço duplex mantém um canal de callback que permite o serviço fazer chamadas para o cliente.

Ambos serviço e cliente expõem contratos do serviço, que especificam as operações que cada um deles expõe para o outro.

A Figura 5.1 ilustra a arquitetura da plataforma:

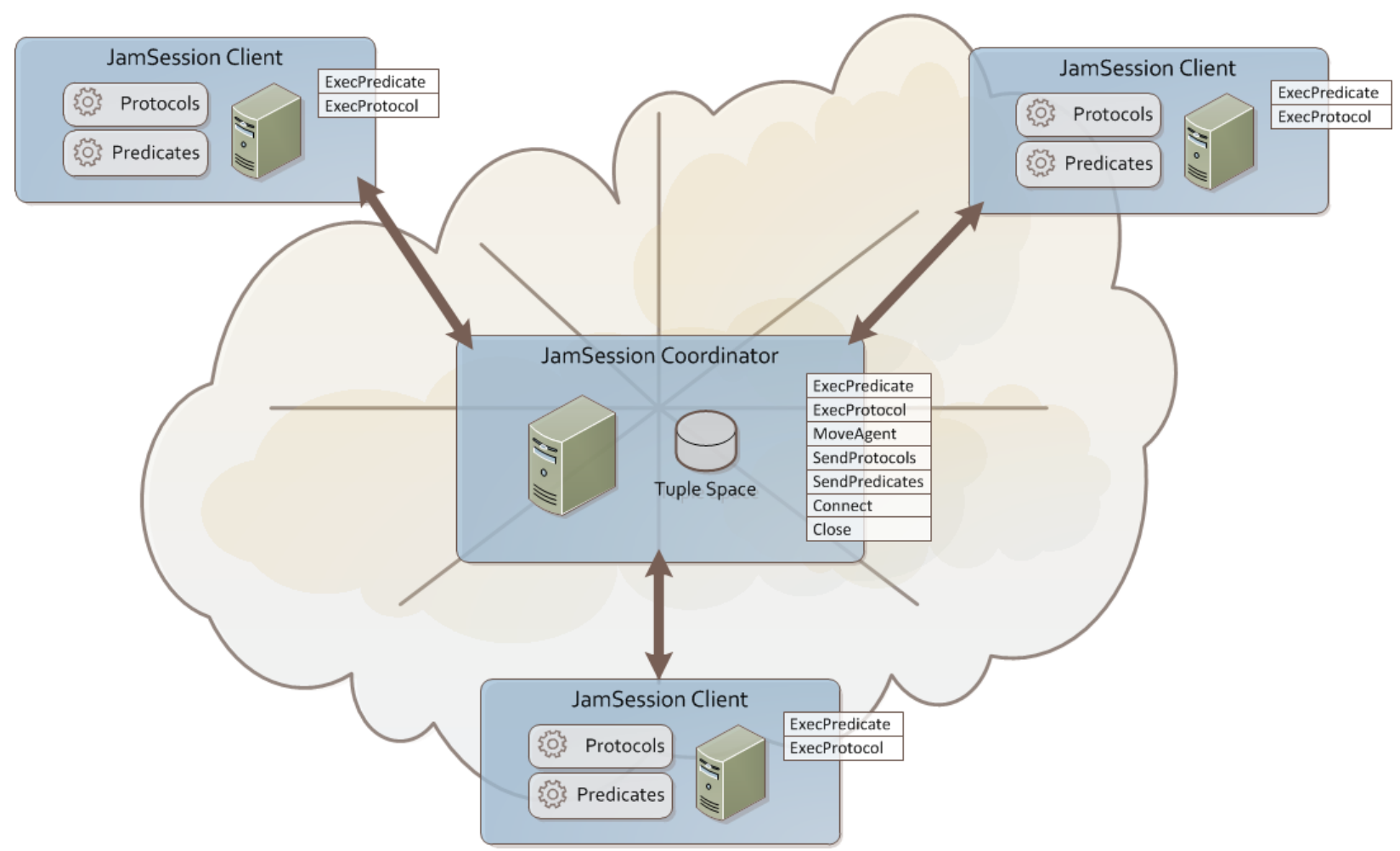

Figura 5.1: JamSession - Arquitetura 


\subsubsection{Operações}

Como ilustrado na Figura 5.1, a comunicação entre os participantes é feita por meio de operações específicas.

\section{Coordenador}

Abaixo estão as operações atualmente disponibilizadas pelo coordenador que podem ser disparadas pelos clientes.

\begin{tabular}{|l|l|}
\hline ExecPredicate & Avalia um predicado. \\
\hline ExecProtocol & Avalia um protocolo. \\
\hline MoveAgent & Altera a localização de um agente. \\
\hline SendProtocols & Utilizada pelo cliente para enviar os protocolos implementados. \\
\hline SendPredicates & Utilizada pelo cliente para enviar os predicados implementados. \\
\hline Connect & Conecta o cliente com o coordenador. \\
\hline Close & Fecha a conexão. \\
\hline
\end{tabular}

Tabela 5.1: JamSession - Operações implementadas pelo coordenador

\section{Clientes}

Cada cliente JamSession pode implementar predicados e protocolos específicos. Os predicados e protocolos que estão implementados são informados para o coordenador e ficam acessíveis para os demais clientes.

Portanto, os clientes também atuam como servidores, recebendo solicitações de execução de predicados/protocolos.

Operações implementadas atualmente:

\begin{tabular}{|l|l|}
\hline ExecPredicate & Avalia um predicado implementado no cliente. \\
\hline ExecProtocol & Avalia um protocolo implementado no cliente. \\
\hline
\end{tabular}

Tabela 5.2: JamSession - Operações implementadas pelos clientes

\subsection{Interface IJamSessionService}

Na listagem a seguir é apresentado o código em F\# que define o contrato das operações expostas como serviços pelo coordenador. 


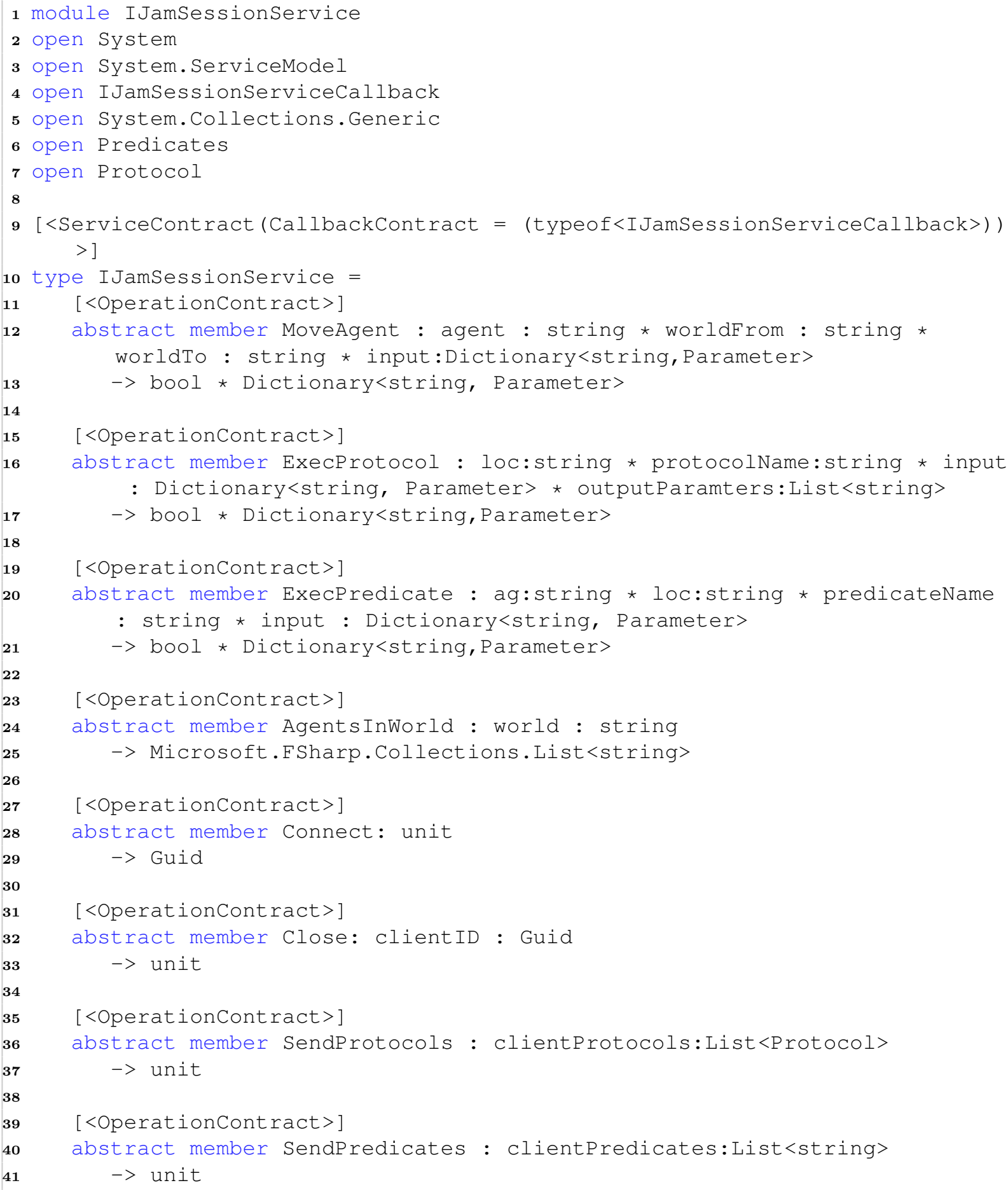

\subsection{Definição dos mundos e agentes}

Como mencionado anteriormente, todo sistema JamSession deve possuir uma configuração inicial de agentes e localizações. A especificação dos agentes e localizações, chamadas de mundos, atualmente é feita em um arquivo de configuração XML(Extensible Markup Language).

A configuração define os mundos, os agentes situados em cada mundo e transições possíveis entre os mundos. 
Mostramos a seguir um exemplo de arquivo de configuração que define os agentes e as localizações:

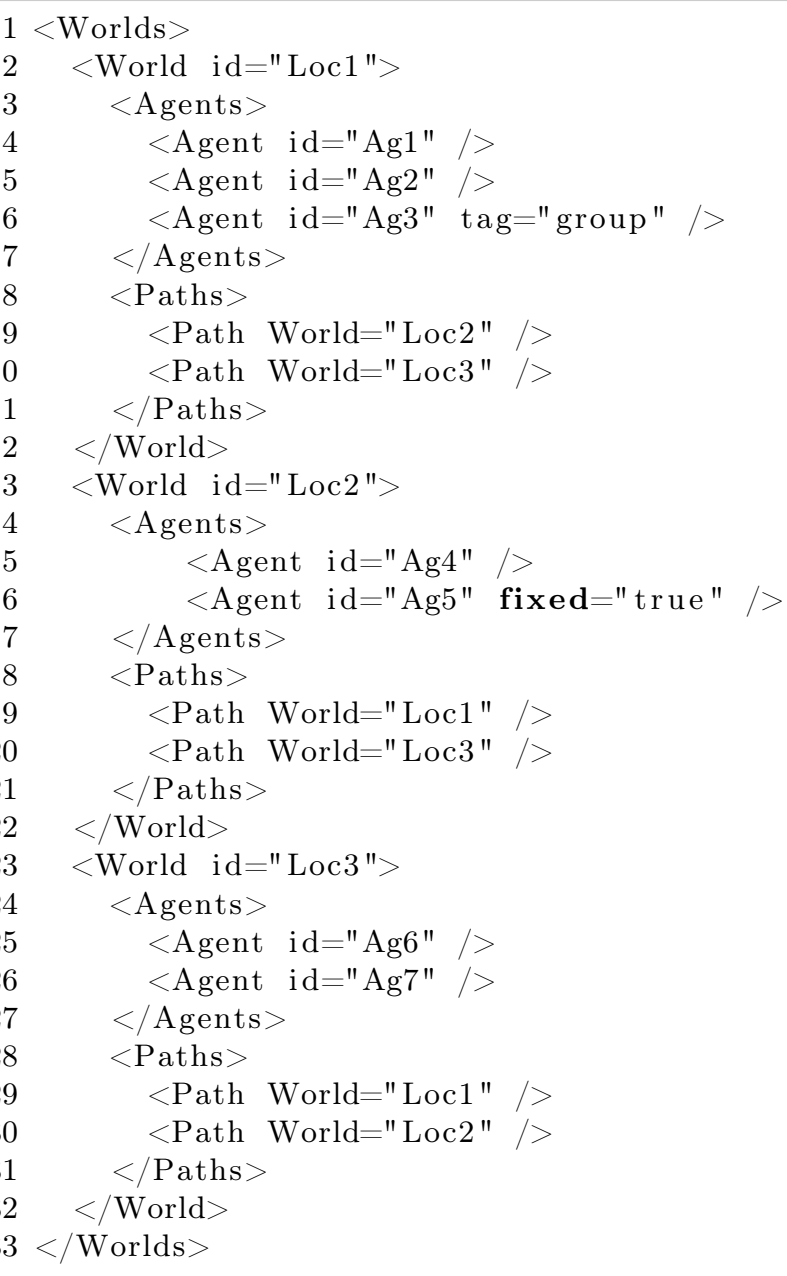

É possível associar rótulos ao definir um agente. O uso de rótulos permite distinguir entre diferentes grupos de agentes. Por exemplo, podemos definir os agentes da seguinte forma:

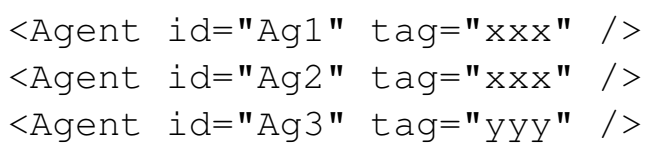

e podemos nos referir aos agentes como Any (agentes Ag1, Ag2, Ag3), Any : xxx (agentes Ag1 e Ag2) ou Any : yyy (Ag3) na especificação dos protocolos. 


\subsection{Implementação de protocolos}

É possível implementar protocolos utilizando a linguagem gráfica apresentada anteriormente. Para esta finalidade foi desenvolvido um editor de protocolos que permite especificar um protocolo por meio de diagramas.

\section{Protocolos predefinidos}

Protocolos como True (sempre avaliado como verdadeiro), Fail (sempre avaliado como falso) e alguns predicados para obter dados das localizações e agentes estão disponíveis para uso na implementação dos protocolos.

\subsection{Editor de Protocolos}

O editor de protocolos foi desenvolvido na linguagem C\#. Para o desenvolvimento dos diagramas, é utilizada a biblioteca de código aberto openDiagram ${ }^{4}$.

Os seguintes elementos podem ser inseridos:

- Movimento:

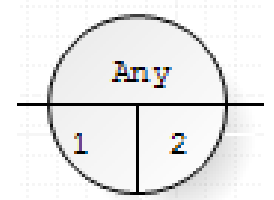

- Predicado:

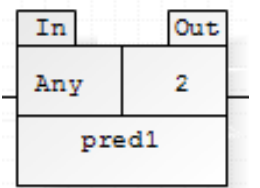

- Protocolo:

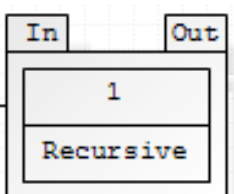

- Disjunção:

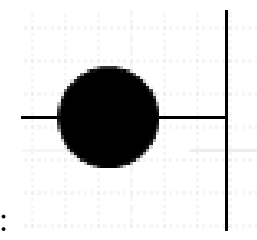

A conjunção é representada pela linha que conecta os elementos e é automaticamente inserida ao incluir os elementos. A posição dos elementos é usada para estabelecer a ordem de execução. A fórmula gerada a partir do diagrama também é exibida no editor.

É possível usar o mesmo nome de protocolo para diferentes localizações. Por exemplo, é possível definir os protocolos $[$ Loc1] kbip e [Loc2]kbip com especificações diferentes.

A ferramenta permite salvar e recuperar os diagramas especificados.

\footnotetext{
${ }^{4} \mathrm{http}: / /$ opendiagram.codeplex.com
} 


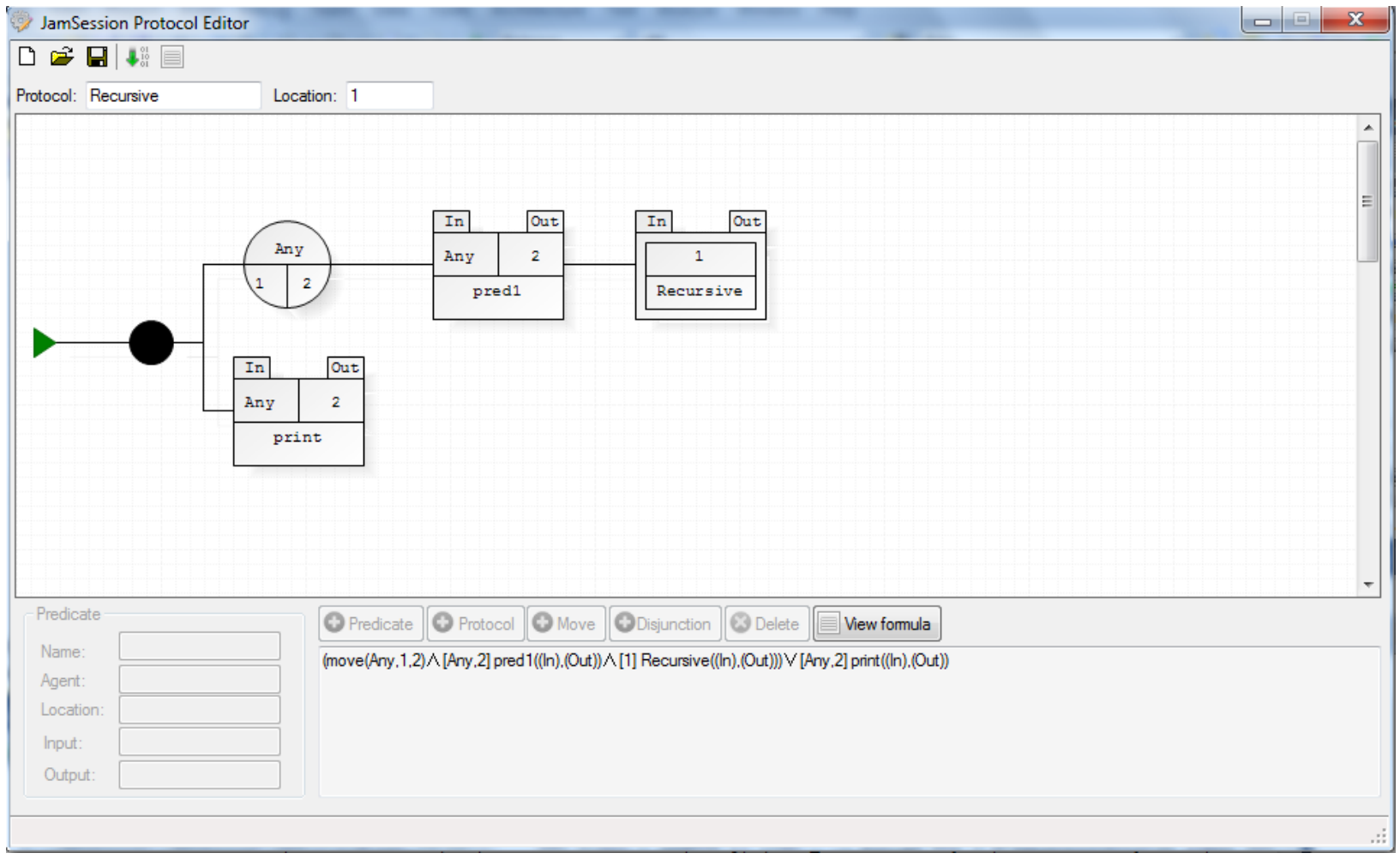

Figura 5.2: Editor de protocolos.

\subsection{Geração de código}

A partir do diagrama, é gerado código $\mathrm{F} \#$ que então é compilado em uma biblioteca de vínculo dinâmico $(D L L)$. Os protocolos compilados e habilitados ficam disponíveis para os demais clientes.

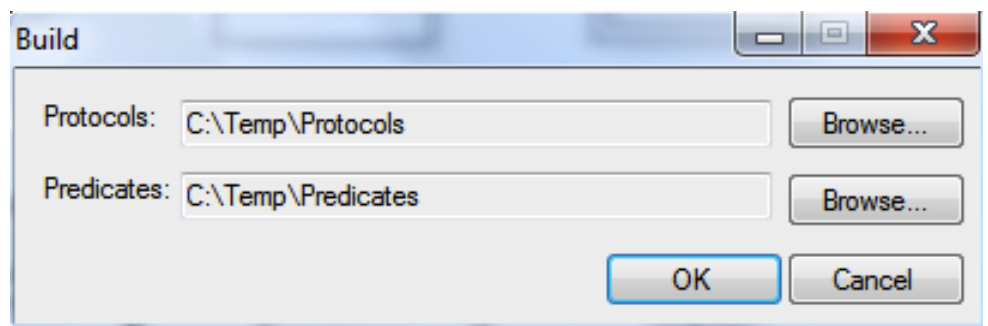

Figura 5.3: Editor de protocolos: Compilação.

A compilação é feita a partir do editor de protocolos utilizando a biblioteca F\# PowerPack ${ }^{5}$.

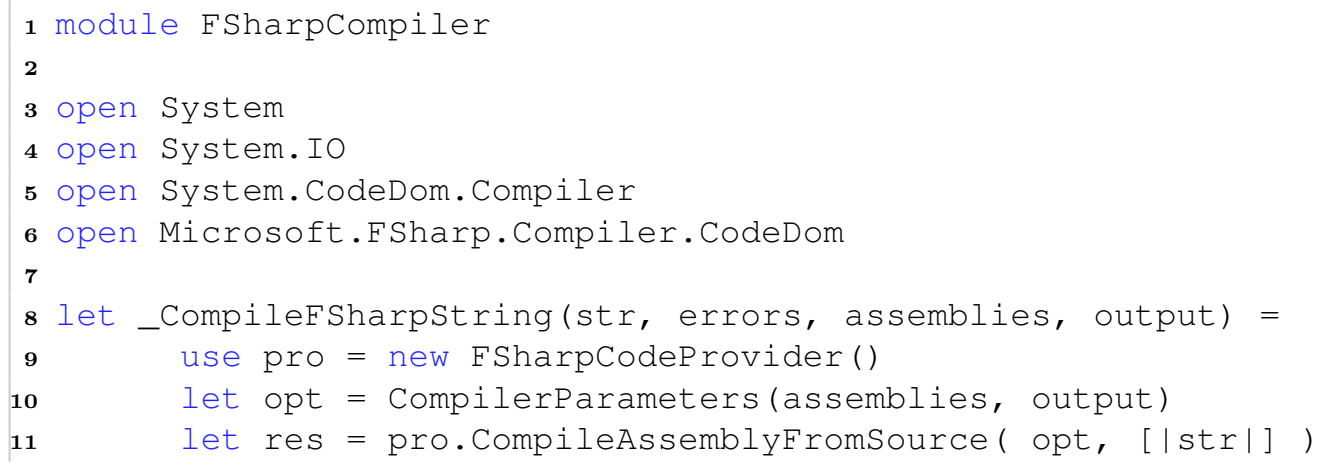

${ }^{5}$ http://fsharppowerpack.codeplex.com/ 


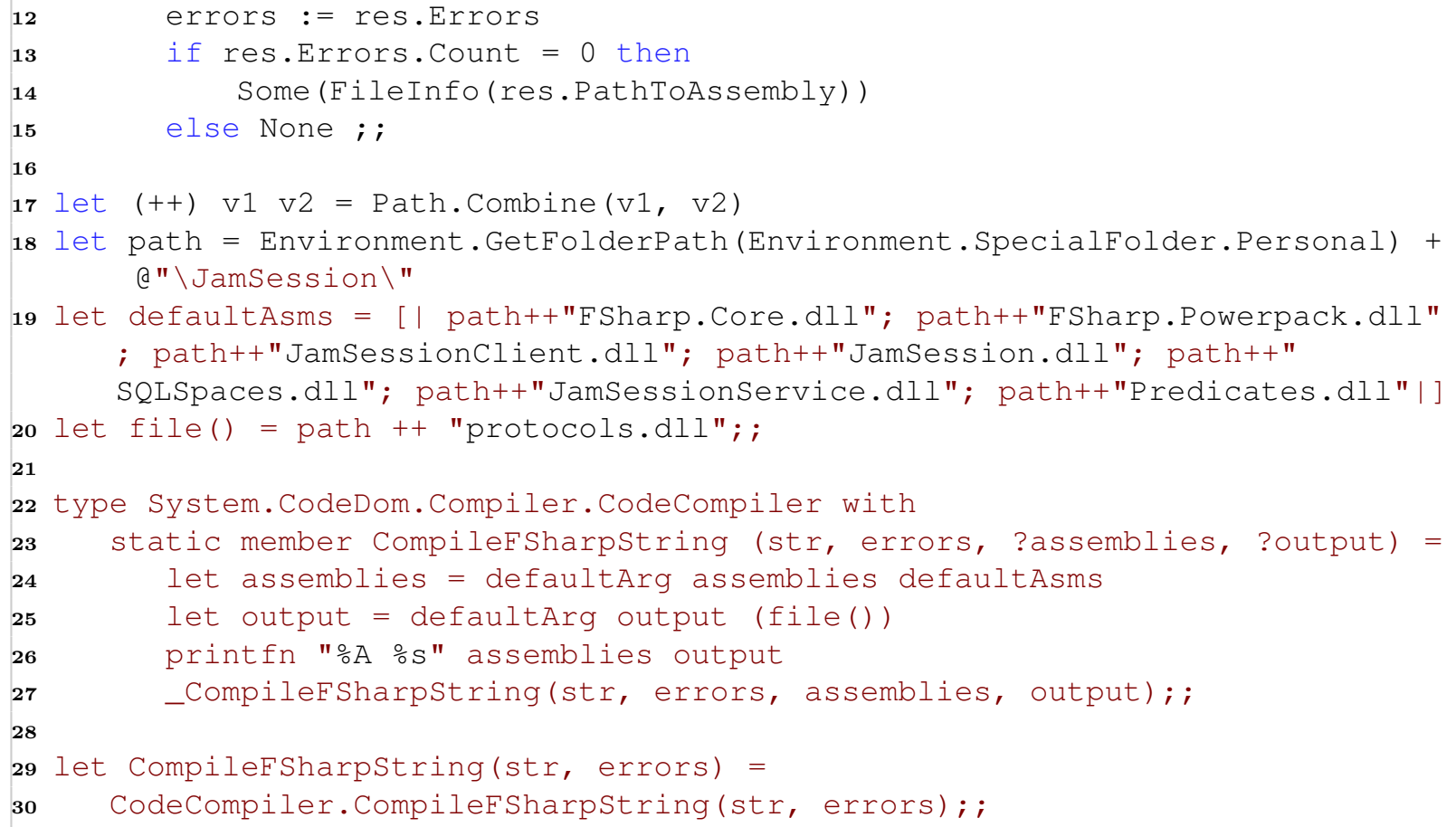




\subsection{Avaliação dos protocolos}

Protocolos são avaliados de forma sequencial. Cada conjunção de uma fórmula na forma normal disjuntiva é avaliada até que uma seja avaliada como verdadeira. Se isto acontece, então o KBIP é avaliado como verdadeiro. Caso contrário, é avaliado como falso. Dentro de cada conjunção, cada elemento também é avaliado sequencialmente, até que um deles seja avaliado como falso. Se isto acontece, a conjunção é avaliada como falsa. Se todos os elementos são avaliados como verdadeiros, então a conjunção também é avaliada como verdadeira.

A entrada do primeiro predicado em uma conjunção é a mesma entrada do protocolo sendo avaliado. A entrada de qualquer outro predicado ou $K B I P$ é a saída do último predicado ou KBIP avaliado como verdadeiro na mesma conjunção. Se um protocolo é avaliado como verdadeiro, então sua saída é a mesma do último predicado ou $K B I P$ na última conjunção avaliado como verdadeiro. Caso contrário, a saída do protocolo é indefinida.

\subsection{Variáveis}

\subsubsection{Parâmetros de entrada e saída}

Ao inserir um predicado ou protocolo no editor, é possível definir todas as variáveis de entrada e variáveis de saída. As variáveis podem ser então utilizadas em outros elementos na sequência da avaliação do protocolo.
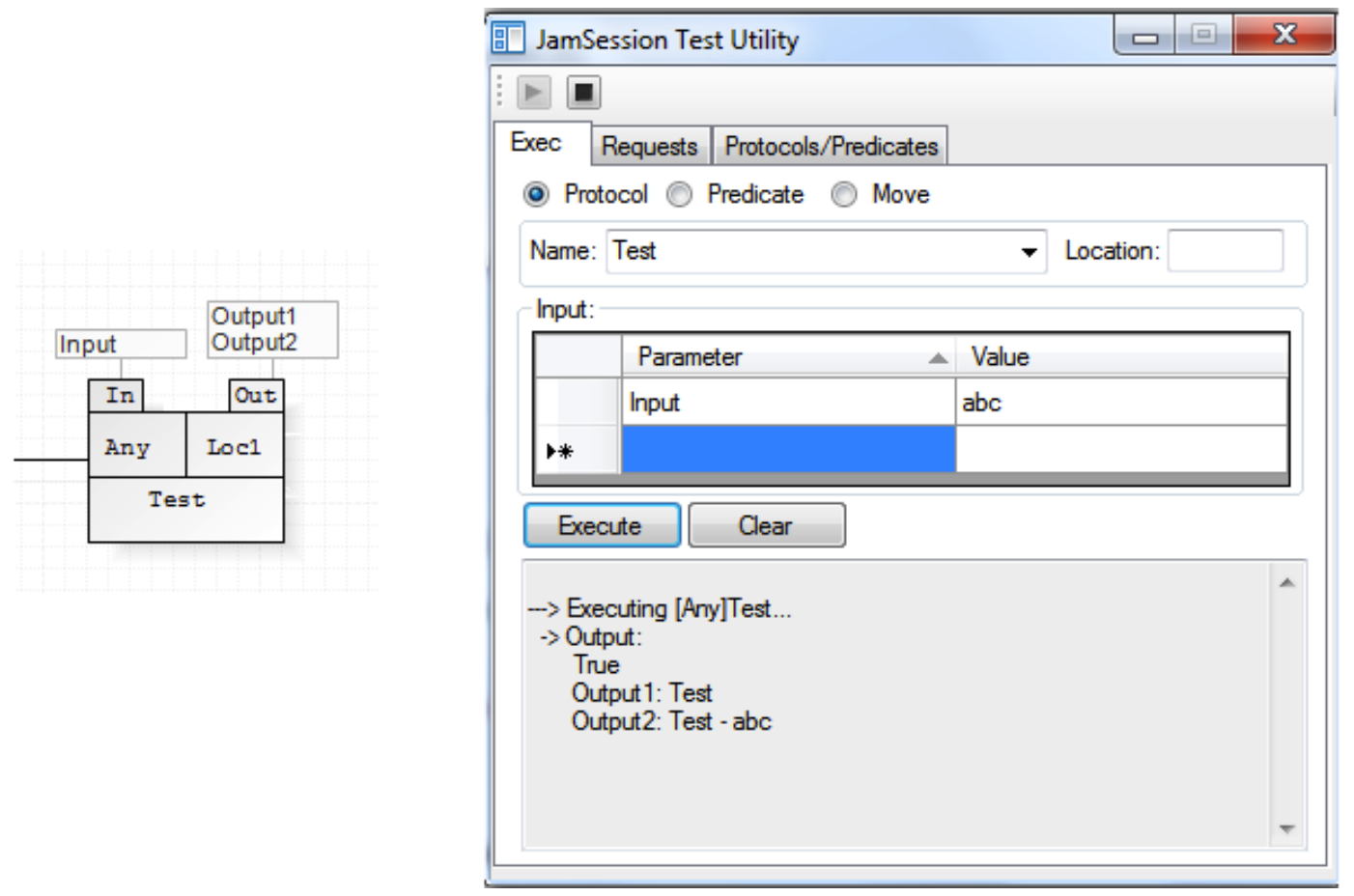

Figura 5.4: Ilustração do uso de variáveis. 


\subsection{Localizações e agentes}

É possível utilizar variáveis para localizações e agentes na especificação do protocolo. Essas variáveis também podem ser instanciadas (é usado o sinal - para indicar que a variável deve ser instanciada e + para obter seu valor), como no exemplo abaixo: a variável A é instanciada com o primeiro agente da localização 1 .

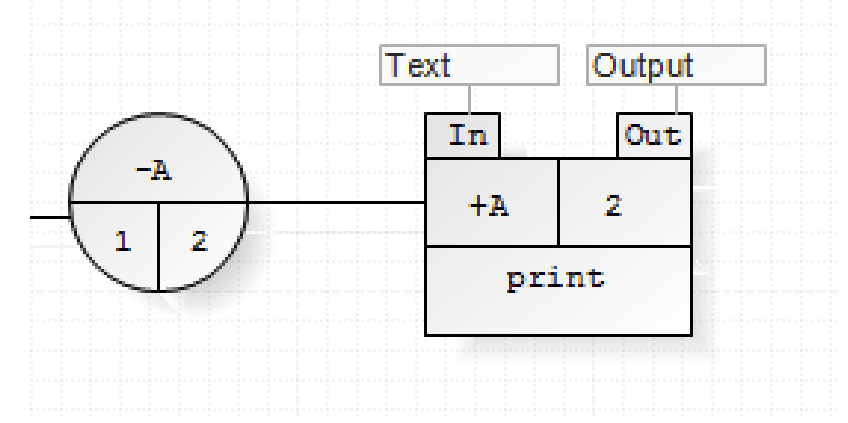

Figura 5.5: Ilustração do uso de variáveis.

\subsection{Variável Any}

A variável Any é tratada de forma especial e possui um comportamento diferente. Se em vez de $-A$, usarmos Any significa que todos os elementos devem ser movidos. Também é possível usar Any : tag para mover todos os agentes com determinado rótulo.

O uso de variáveis traz muitas possibilidades e enriquece bastante a linguagem.

\subsubsection{Uso de variáveis para movimentar agentes}

Na notação utilizada a seguir, o símbolo + indica que o argumento está instanciado e o símbolo - indica uma variável que deverá ser instanciada.

Seja move $\left(A, L_{1}, L_{2}\right)$ um movimento de agentes tal que $\mathrm{A}$ é o agente, $L_{1}$ é a localização de origem e $L_{2}$ é localização de destino. Abaixo está o comportamento esperado em cada situação:

- move $\left(-A,-L_{1},-L_{2}\right)$ : Deve falhar

- move $(A n y, A n y,+L)$ : Todos os agentes situados em localizações que são predecessoras diretas de L devem ser movidos para $\mathrm{L}$

- move $\left(-A,-L_{1},+L_{2}\right)$ : Deve falhar

- move $\left(\right.$ Any $\left.,+L_{1},+L_{2}\right)$ : Todos os agentes em $L_{1}$ devem ser movidos para $L_{2}$

- move $\left(-A,+L_{1},+L_{2}\right)$ : O primeiro agente em $L_{1}$ deve ser movido para $L_{2}$

- move $\left(\right.$ Any $\left.,+L_{1},-L_{2}\right)$ : Todos os agentes em $L_{1}$ devem ser movidos para $L_{2}$ (primeiro movimento possível no grafo de transições)

- move $\left(-A,+L_{1},-L_{2}\right)$ : Primeiro agente em $L_{1}$ deve ser movido para $L_{2}$ (primeiro movimento possível no grafo de transições)

- move $\left(+A,+L_{1},+L_{2}\right)$ : A agente $A$ deve ser movido de $L_{1}$ para $L_{2}$ 
- move $\left(+A,+L_{1},-L_{2}\right)$ : A variável $L_{2}$ é instanciada com primeiro movimento possível no grafo de transições e então ocorre a avaliação

- move $\left(+A,-L_{1},+L_{2}\right)$ : A variável $L_{1}$ é instanciada com a localização do agente $A$ e então ocorre a avaliação

- move $\left(+A,-L_{1},-L_{2}\right)$ : A variável $L_{1}$ é instanciada com a localização do agente $A$, a variável $L_{2}$ é instanciada com o primeiro movimento possível no grafo de transições e então ocorre a avaliação

\subsubsection{Uso de variáveis para avaliar predicados/protocolos}

Seja $[A, L]$ pred uma chamada de predicado tal que $A$ é o agente e $L$ é localização. Temos as seguintes situações possíveis na avaliação do predicado:

- $[+A,+L]$ pred: $\mathrm{O}$ predicado é avaliado somente se o agente $A$ estiver na localização $L$

- $[+A,-L]$ pred: A variável $L$ é instanciada com a atual localização de $A$ antes da avaliação

- $[$ Any, Any $]$ pred: Sempre é avaliado.

- $[+A$, Any $]$ pred: É avaliado se $A$ é um agente válido.

- $[$ Any, $+L]$ pred: É avaliado somente se existir algum agente na posição $L$

- $[-A,+L]$ pred: É avaliado somente se existir algum agente na posição $L$. Antes da avaliação, $A$ é instanciado com o primeiro agente situado em $L$.

- [-A, -L]pred: Deve falhar.

\subsection{Implementação de predicados}

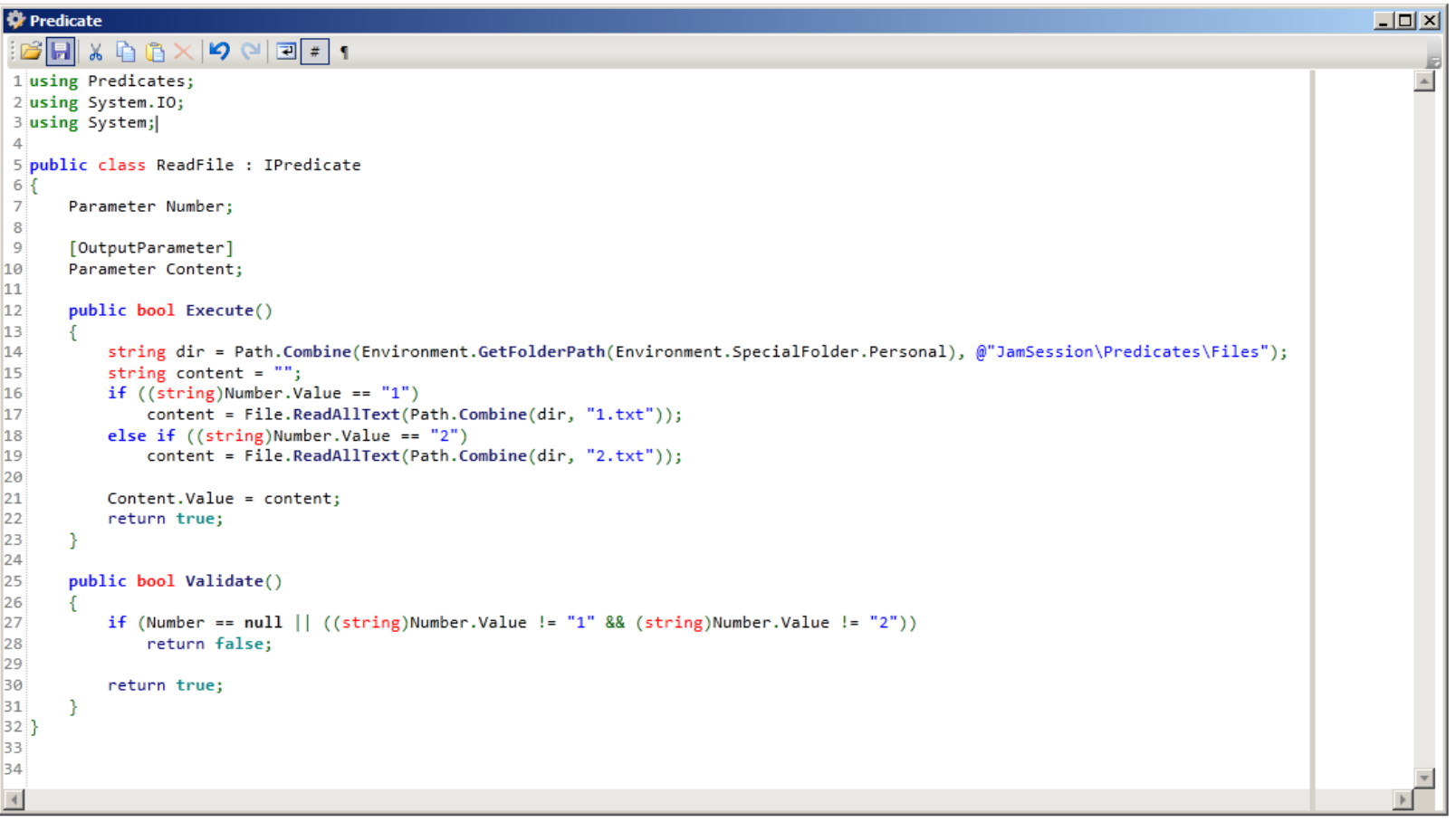

Figura 5.6: Editor de predicados 
Há predicados predefinidos, mas também existe a possibilidade do usuário da plataforma desenvolver seus próprios predicados, que representam os recursos/serviços que serão disponibilizados.

Aproveitamos a interoperabilidade das linguagens de programação na plataforma .NET e possibilitamos que os predicados sejam desenvolvidos tanto na linguagem $\mathrm{F} \#$ quanto na linguagem $\mathrm{C \#}$.

Os predicados criados então podem ser utilizados na composição dos protocolos criados.

\subsection{Interface IPredicate}

Um predicado é criado por meio de uma classe que deve implementar a interface IPredicate. Os métodos que devem ser implementados são:

- Validate: Executado antes da execução do método Execute. Execute só é executado se Validate devolve true.

- Execute: método que de fato define o comportamento do predicado. Recebe os parâmetros de entrada, processa e preenche a lista de parâmetros de saída. Deve devolver um valor booleano.

\subsection{Utilização de parâmetros}

Os parâmetros utilizados no predicado são especificados por meio da classe Parameter. Os parâmetros de entrada são instanciados de forma transparente antes da execução do predicado. Os parâmetros de saída são identificados com o atributo OutputParameter e podem ser instanciados durante a execução do predicado.

\subsubsection{Acesso ao agente e à localização}

O predicado pode ter acesso ao agente e a localização relacionados à determinada chamada.

A implementação do predicado pode incluir as variáveis agent e location, que serão instanciadas com os valores apropriados antes da execução do método Execute do predicado. É possível então utilizar essas variáveis para escrever código com tratamentos diferenciados. 
Abaixo está um exemplo de predicado desenvolvido na linguagem $\mathrm{F} \#$.

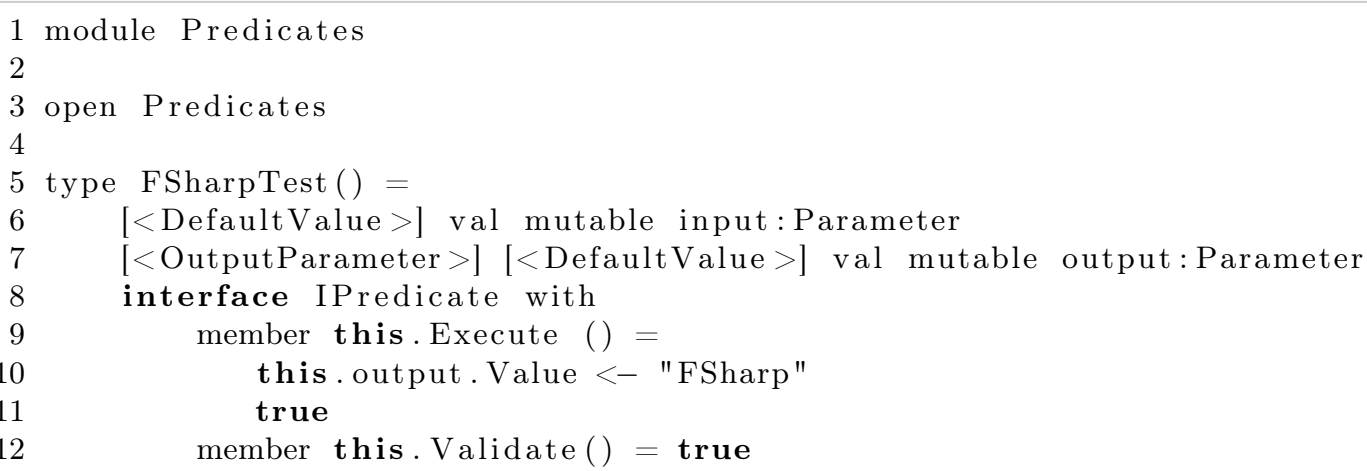




\subsection{Utilitário de testes}

Para verificar o funcionamento dos protocolos e predicados especificados, foi desenvolvido um aplicativo de testes, que permite movimentar agentes, avaliar predicados e protocolos. Este aplicativo é um cliente do JamSession. É possível definir as variáveis de entrada e visualizar o resultado da avaliação. Todas as requisições recebidas pelo cliente também podem ser exibidas.

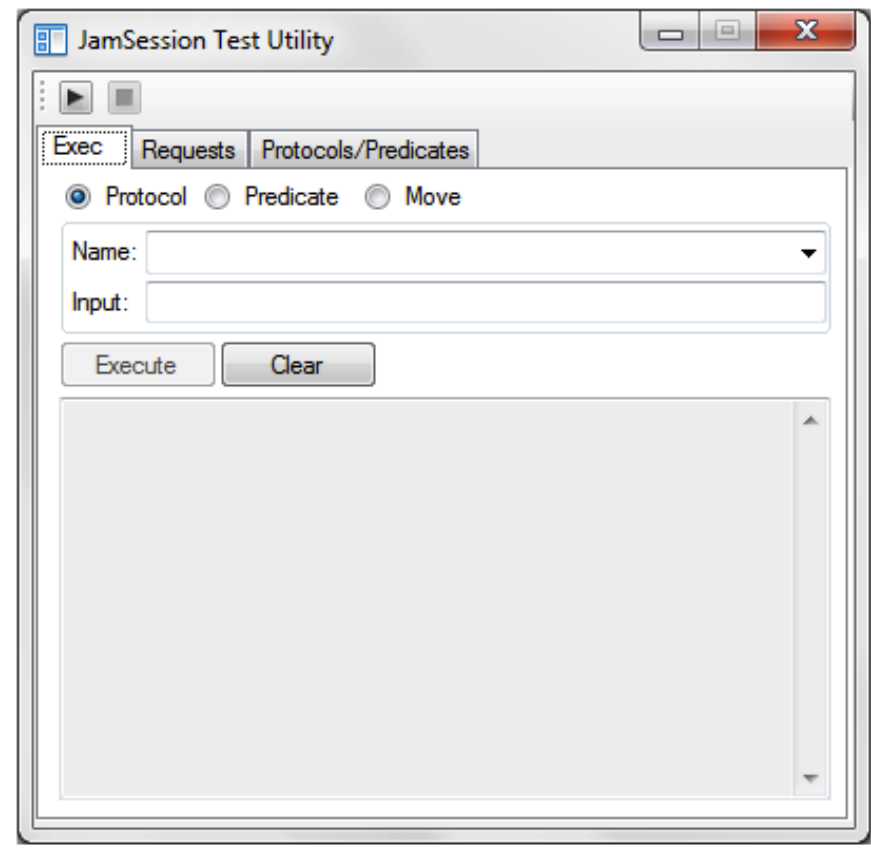

Figura 5.7: Utilitário de testes: Tela principal.

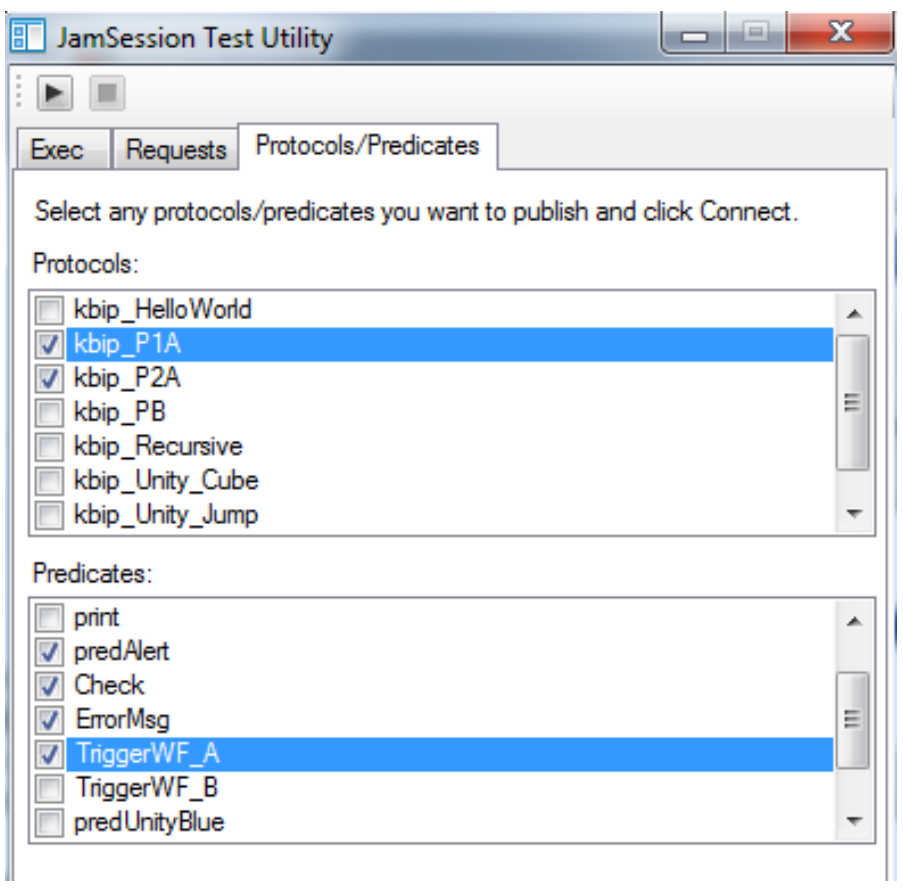

Figura 5.8: Utilitário de testes: Protocolos e predicados habilitados. 


\subsection{Conclusão do capítulo}

Neste capítulo foi apresentada a versão computacional da plataforma JamSession. Abordamos o funcionamento da plataforma e os aspectos mais relevantes da implementação, execução, componentes e ferramentas.

No próximo capítulo serão apresentados experimentos realizados para validar a plataforma desenvolvida. 


\section{Capítulo 6}

\section{Aplicações}

JamSession pode ser usado em uma variedade de cenários atuando como coordenador de recursos. Neste capítulo apresentaremos alguns experimentos que vem sendo realizados com a plataforma JamSession. O foco do trabalho são experimentos envolvendo integração de workflows e coordenação de recursos multimídia em aplicações interativas.

O objetivo é assegurar a expressividade da linguagem e avaliar empiricamente a plataforma através da construção e análise desses sistemas.

\subsection{Integração de workflows}

Workflows [25] podem ser coordenados usando JamSession como um mediador. Neste experimento ilustramos como implementar um padrão de integração de workflows [11] usando protocolos de interação.

\section{Workflow hierárquico}

Num modelo hierárquico, a colaboração entre organizações é feita por meio de um workflow raiz pertencente à organização principal. Neste primeiro nível, as atividades do workflow podem ser definidas como sub-workflows. A hierarquia pode conter vários níveis, formando uma rede de workflows encadeados. Neste padrão de colaboração, o domínio de execução de cada workflow pertence a diferentes organizações.

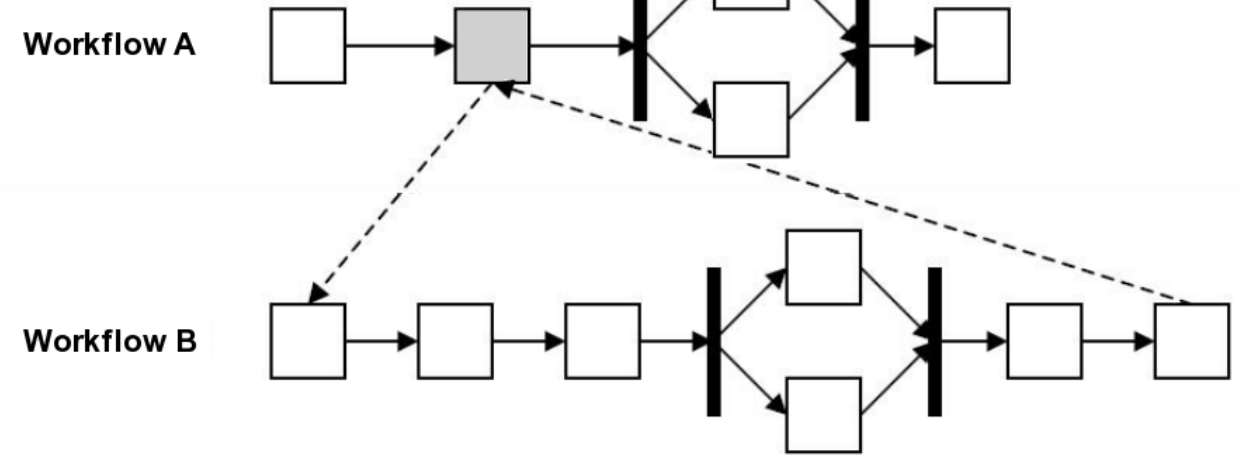

Figura 6.1: Workflow hierárquico

Na figura acima, o workflow $A$, pertencente à organização $A$, dispara uma instância completa do workflow $B$, pertencente à organização $B$, e aguarda o término do workflow $B$ para continuar 
sua execução.

Foram construídos protocolos de interação baseados em conhecimento para mediar a interação entre o workflow $A$ e o workflow $B$. Este padrão pode ser implementado usando 3 protocolos de interação. Também foi incluído um controle adicional que limita o número de instâncias concorrentes do workflow $B$ de forma que tenhamos no máximo 3 instâncias simultâneas.

A configuração inicial é exibida na imagem abaixo. Foram utilizados 5 agentes e 2 localizações.

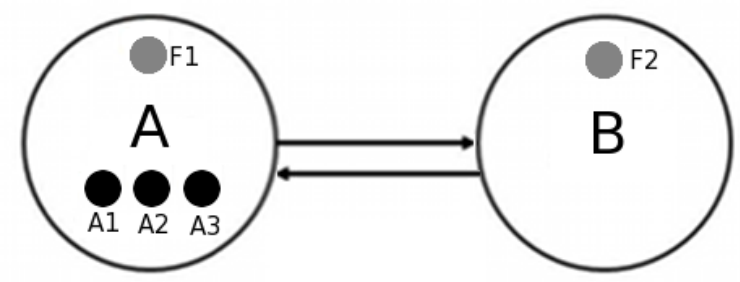

Figura 6.2: Configuração inicial para o padrão de integração hierárquico. Círculos pretos representam agentes que se movem entre as localizações e círculos cinzas representam agentes fixos. 


\subsubsection{Protocolos de interação}

Foram implementados os seguintes protocolos:

- Protocolo $P_{1}^{A}$ : Pertence à organização $A$ e é disparado pela atividade destacada no workflow $A$. Esta atividade fornece um conjunto de valores para o protocolo $P_{1}^{A}$. Se os valores são consistentes, o protocolo tenta mover um dos agentes móveis da localização $A$ para a localização $B$. Desta maneira, é controlado o número de instâncias do workflow $B$ que estão ativas. Se todas as entidades são avaliadas como $T$, então o protocolo $P^{B}$ é disparado.

- Protocolo $P^{B}$ : Pertence à organização $B$ e é disparado pelo protocolo $P_{1}^{A}$ e recebe os mesmos valores de entrada que $P_{1}^{A}$. Se todos os valores são consistentes, então é executado o predicado responsável por disparar o workflow $B$. Quando o workflow $B$ completa a execução, o conjunto de valores de saída é capturado e enviado como entrada para o protocolo $P_{2}^{A}$.

- Protocolo $P_{2}^{A}$ : É disparado pelo protocolo $P^{B}$ e recebe de $P^{B}$ a saída do workflow $B$. Se os valores são consistentes, um dos agentes móveis é movido da localização $B$ para a localização $A$, liberando assim o uso de uma nova instância do workflow $B$.

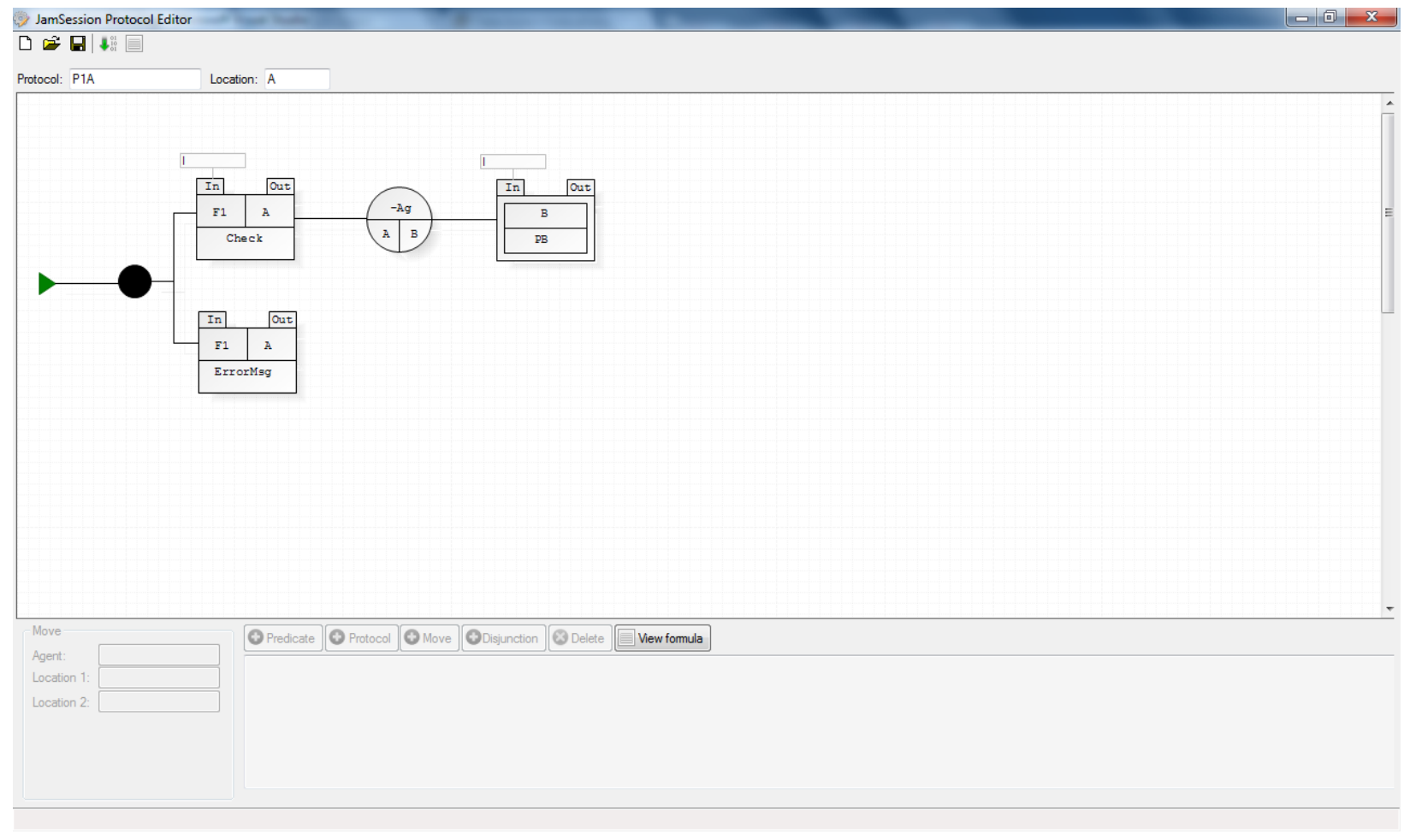

Figura 6.3: Protocolo $P_{1}^{A}$ 


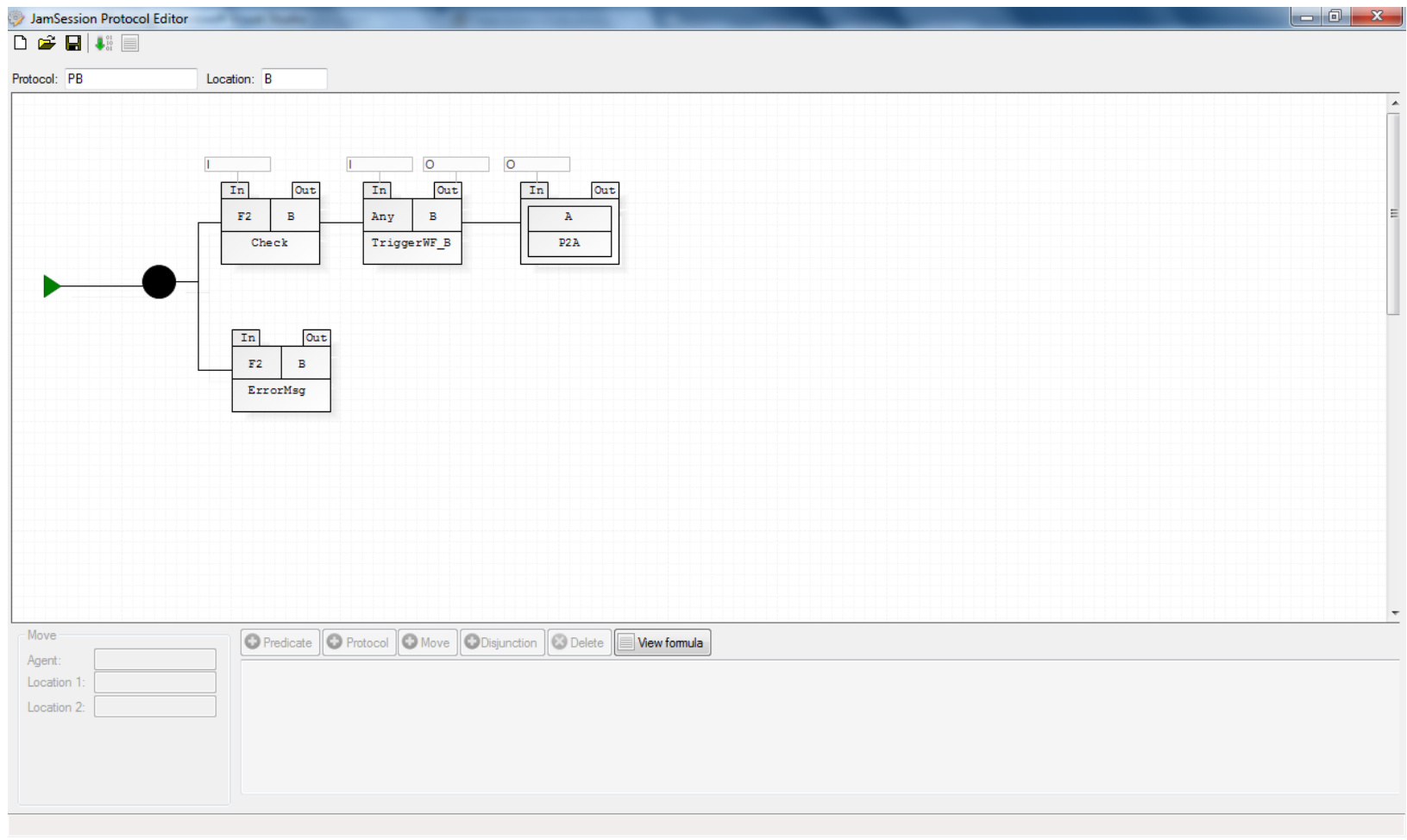

Figura 6.4: Protocolo $P^{B}$

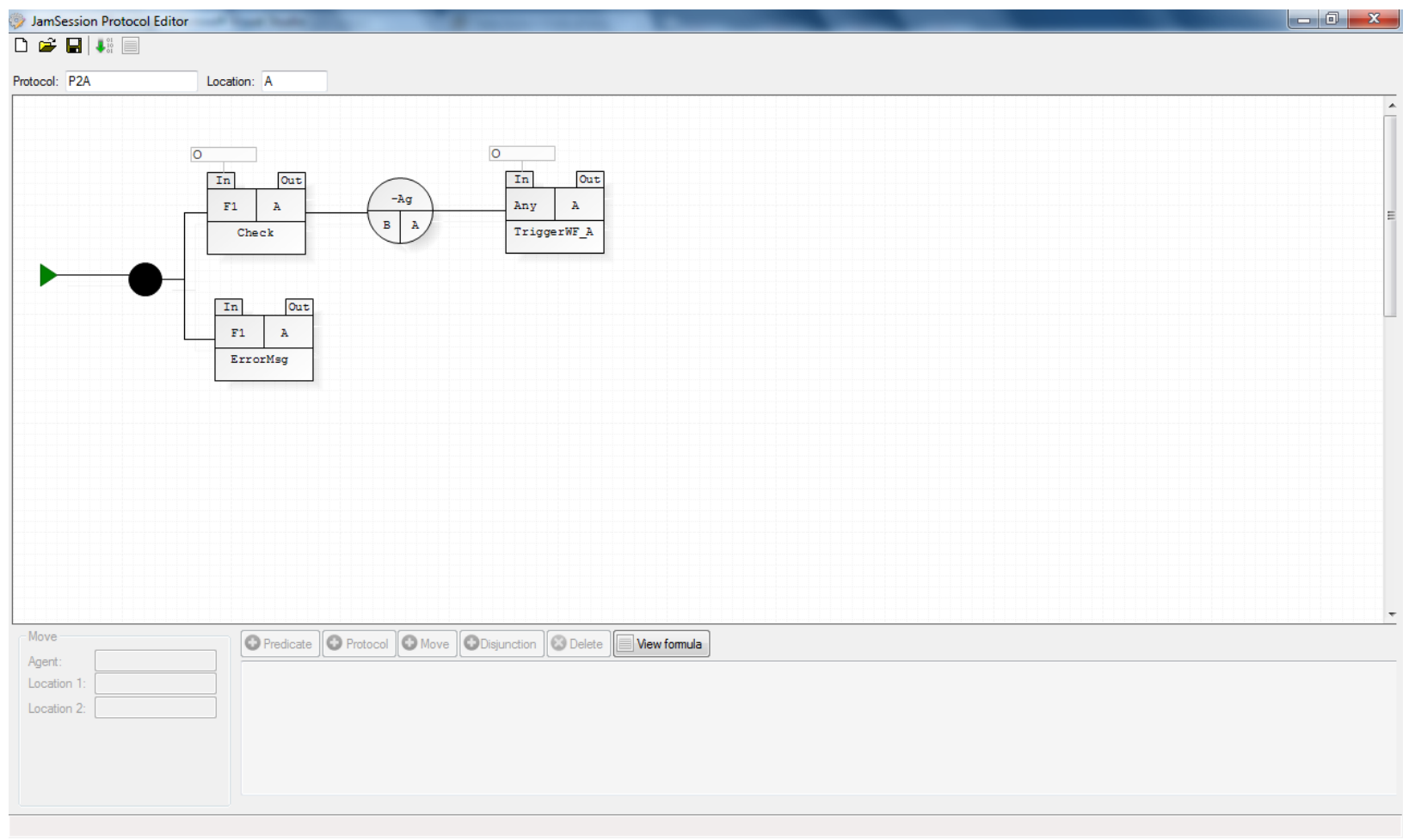

Figura 6.5: Protocolo $P_{2}^{A}$ 
Os experimentos foram realizados usando o sistema de workflows de código aberto Bonita Open Solution ${ }^{1}$.

\subsubsection{Avaliação de um protocolo a partir de uma etapa do workflow}

Bonita possui connectors que podem ser vinculados às etapas do workflow. A ferramenta fornece uma variedade de opções, tais como executar consultas em banco de dados, enviar e-mails, executar web services, criar eventos em calendários, enviar mensagens pelo twitter, etc. Entre as opções disponíveis está a execução de uma classe Java, que foi a maneira utilizada para realizar a comunicação com o JamSession. No atual estágio de desenvolvimento da plataforma, para realizar esta integração, foi criado um connector que executa um aplicativo auxiliar que recebe comandos para execução de protocolos por meio da entrada padrão. Outros mecanismos de integração estão em estudo.

Na figura 6.6 é exibido o Connector criado para possibilitar a execução de protocolos.

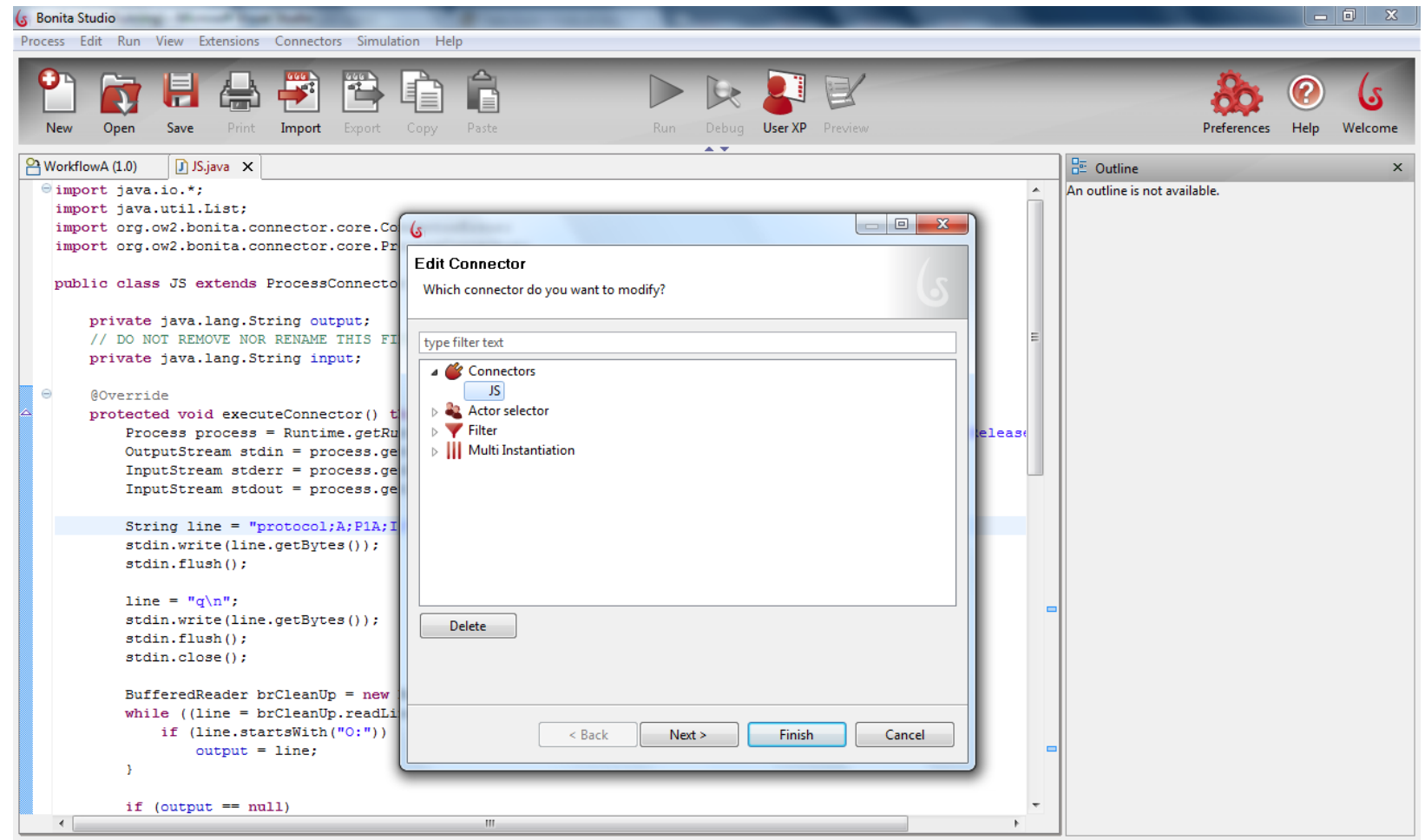

Figura 6.6: Connector implementado.

\footnotetext{
${ }^{1}$ http://www.bonitasoft.com/
} 


\subsubsection{Execução de um workflow do Bonita a partir de um predicado}

Para que seja possível integrar o JamSession com sistemas de workflow é preciso que o sistema exponha algum mecanismo para gerenciamento de seus workflows, permitindo iniciar novas instâncias, obter informações sobre o estado da execução, acesso às variáveis, etc.

O Bonita possui uma API sofisticada para obter informações e gerenciar os workflows. A maneira utilizada para realizar a integração a partir do código C\# do predicado foi utilizar a API REST [1] disponibilizada pelo Bonita.

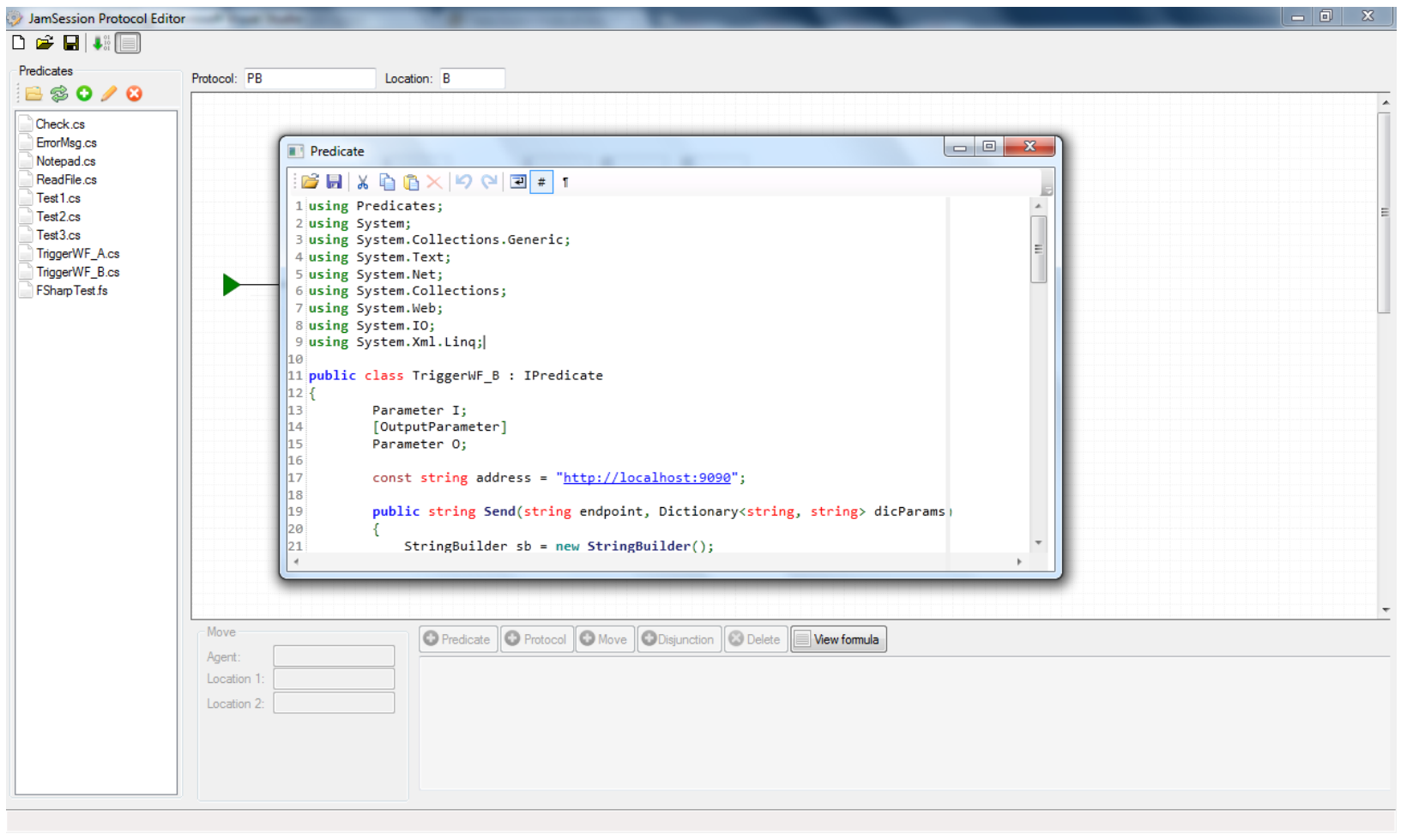

Figura 6.7: Integração de workflows: Predicado implementado

Abaixo está um exemplo de código utilizado no experimento:

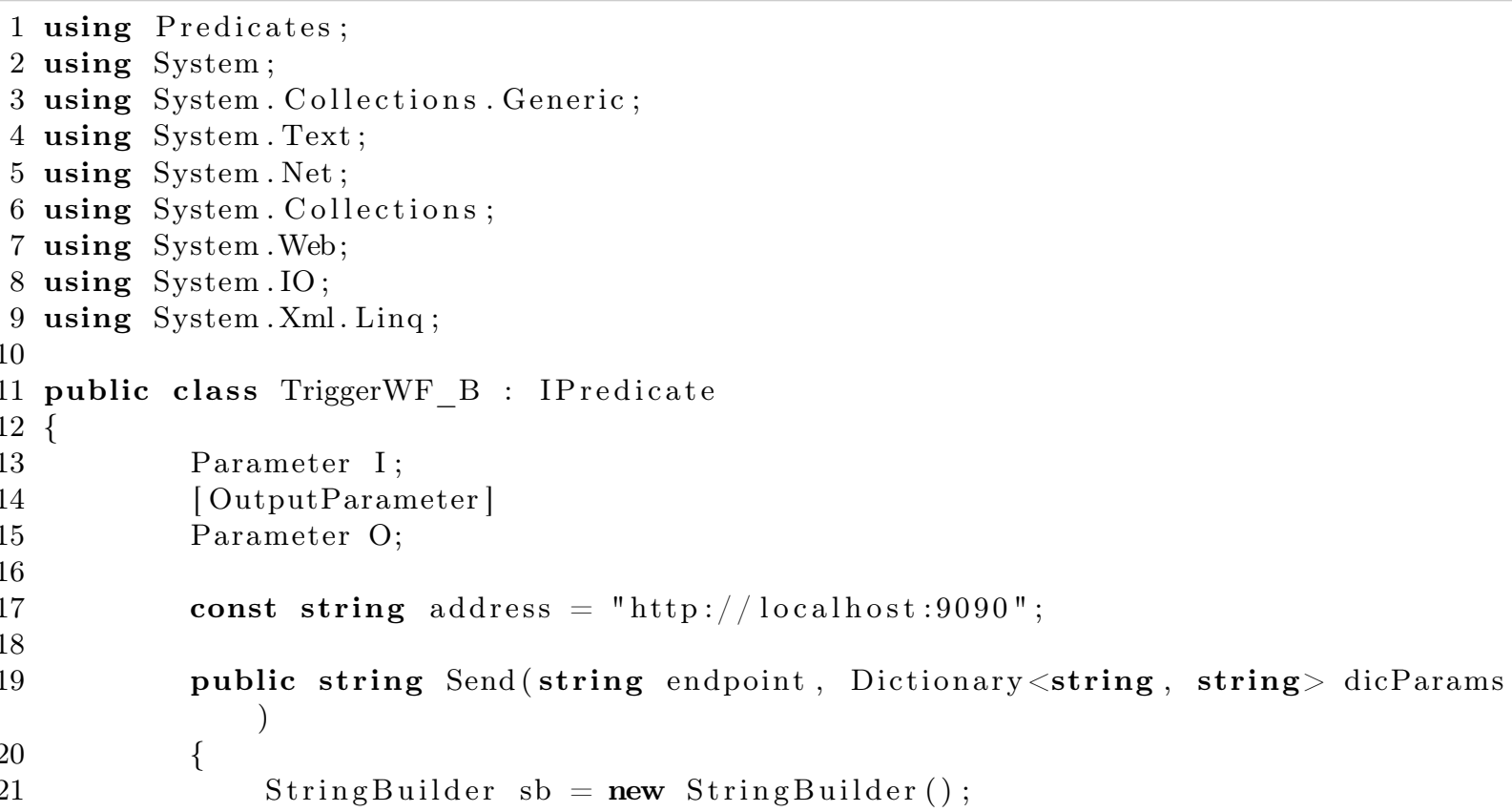


int $\mathrm{i}=0$;

foreach (var param in dicParams)

\{

sb. AppendFormat ( $\{0\}=\{1\} "$, param.Key, HttpUtility. UrlEncode ( param. Value));

if $(\mathrm{i}<\operatorname{dicParams}$. Count -1$)$

byte [] bytes = Encoding.UTF8. GetBytes (sb.ToString ());

string response = " ;

HttpWebRequest request $=($ HttpWebRequest $)$ WebRequest. Create (endpoint) ;

request. ContentLength $=$ bytes. Length;

request. ContentType $=$ "application $/ \mathrm{x}-$ www-form-urlencoded " ;

request. Credentials = new NetworkCredential("restuser", "restbpm"); request. Method $=$ "POST";

using (var requestStream = request. GetRequestStream ()) requestStream. Write (bytes, 0, bytes. Length);

using (HttpWebResponse httpWebResponse = (HttpWebResponse) request. GetResponse ())

\{

if (httpWebResponse. StatusCode $=$ HttpStatusCode.OK)

Stream responseStream = httpWebResponse.GetResponseStream (); StreamReader $\mathrm{sr}=$ new StreamReader (responseStream); 
82

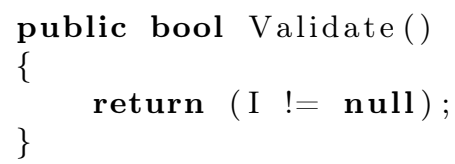

O predicado acima dispara o Workflow $B$ e preenche a variável $O$ com a saída do workflow. O método Send é um método auxiliar utilizado para realizar a chamada apropriada à API REST.

No código acima é utilizada a runtimeAPI ${ }^{2}$ e a queryRuntimeAPI ${ }^{3}$. Essas APIs também disponibilizam as operações necessárias para outros cenários de integração.

O controle feito pelos protocolos do JamSession garante que existam apenas 3 instâncias simultâneas do workflow B. Abaixo está a caixa de entrada do Bonita User Experience, que é um portal que permite administrar os processos em uma interface semelhante à de um webmail, exibindo instâncias do workflow $B$.

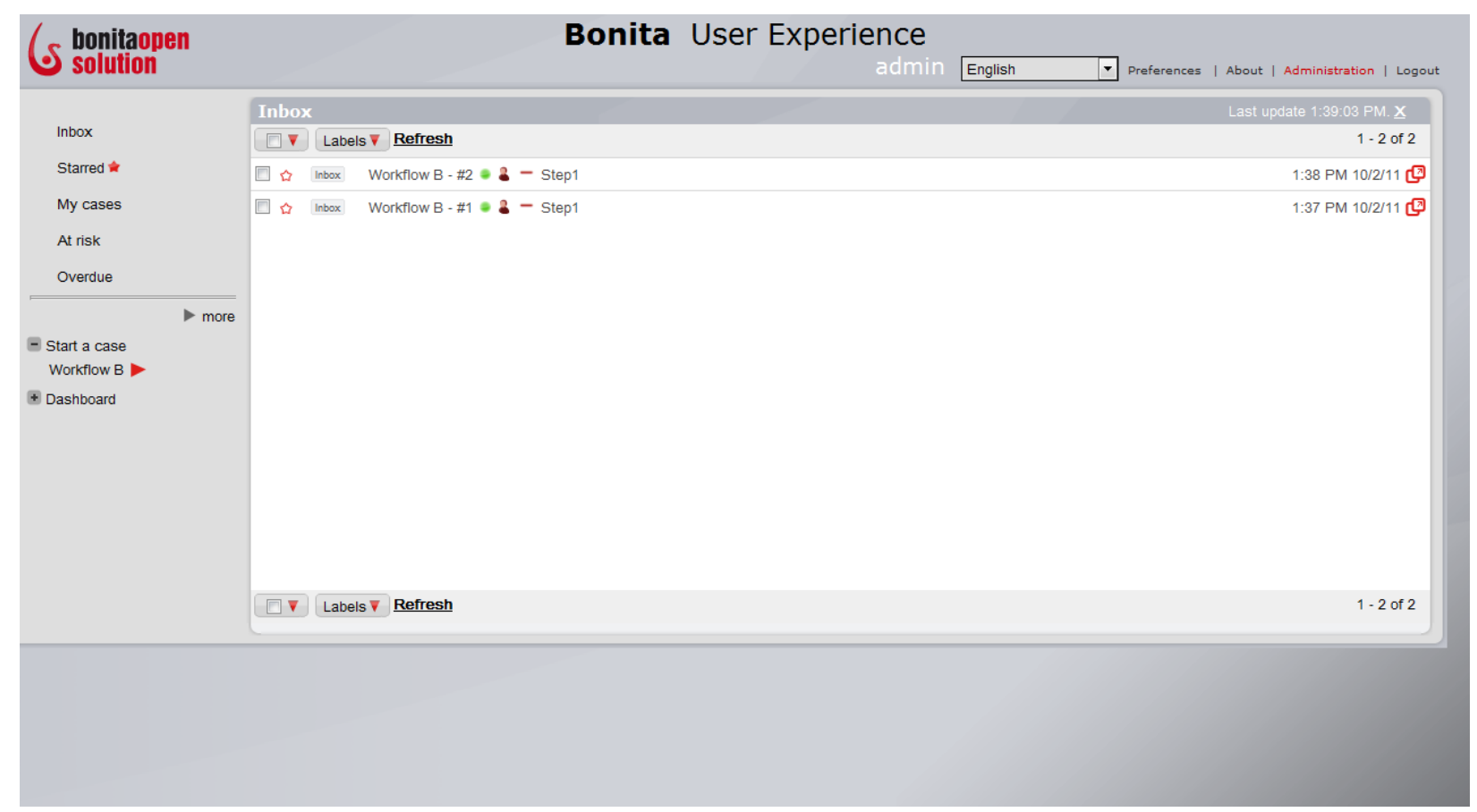

Figura 6.8: Instâncias do workflow $B$ em execução

\footnotetext{
${ }^{2}$ http://www.bonitasoft.org/docs/javadoc/rest/5.3/API/runtimeAPI/

${ }^{3}$ http://www.bonitasoft.org/docs/javadoc/rest/5.3/API/queryRuntimeAPI/
} 
Na figura 6.9 é exibido o workflow especificado no Bonita.

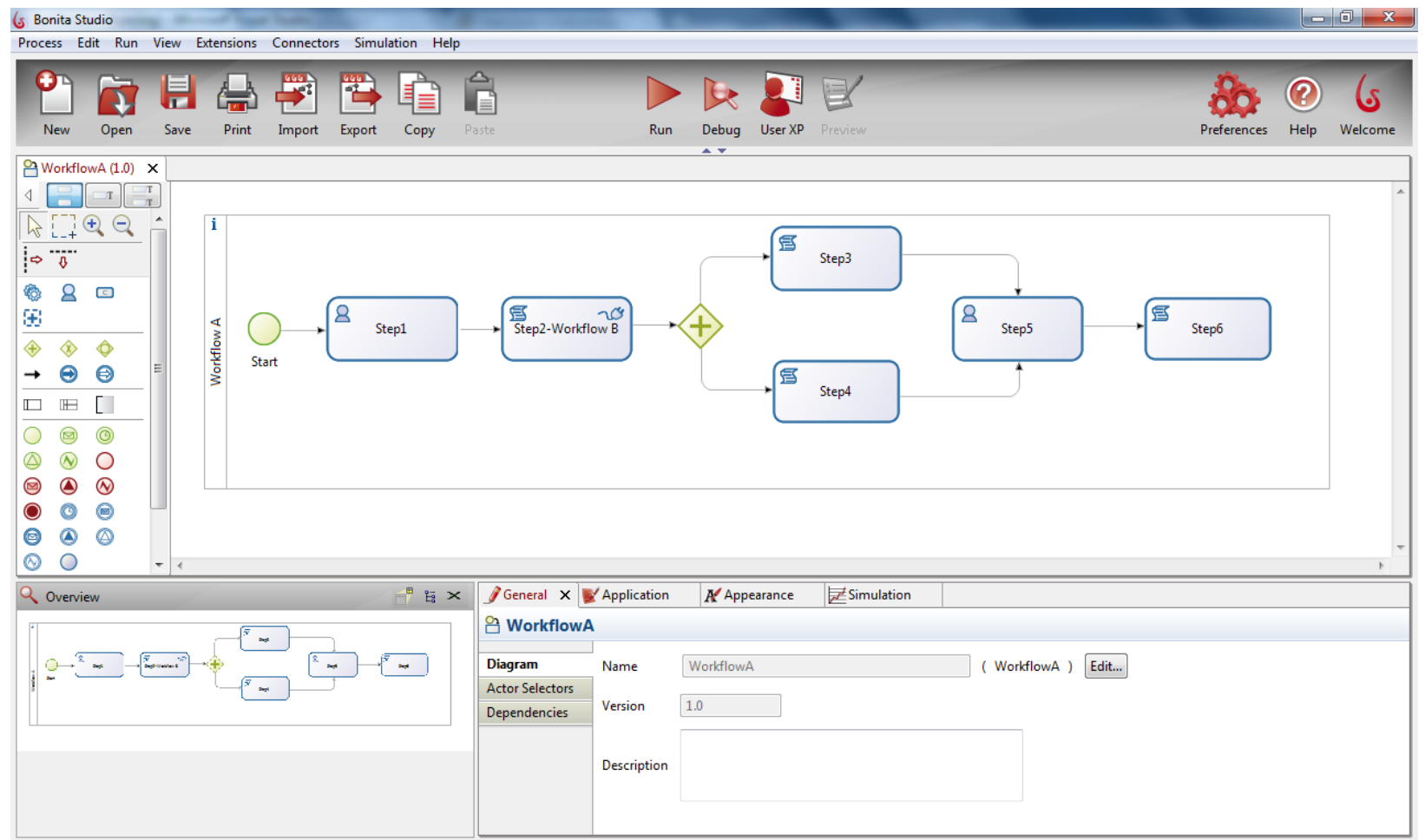

Figura 6.9: Workflow A. 


\subsection{Unity $3 D$}

Como mencionamos anteriormente, JamSession foi concebido inicialmente como uma ferramenta para coordenar sistemas altamente interativos, como videogames com vários jogadores. Embora a plataforma tenha sido estendida para gerenciar recursos computacionais genéricos, também é possível utilizá-la como um mecanismo para coordenar sistemas interativos.

Desenvolvemos um aplicativo de exemplo para ilustrar o uso do JamSession num contexto de ambientes virtuais. Para esta finalidade foi utilizado o Unity $3 D^{4}$.

Unity $3 D$ é um sistema integrado para criação de jogos tridimensionais ou outros ambientes virtuais interativos. Consiste tanto de um editor para desenvolvimento do jogo como do motor de jogo para sua execução.

Abaixo está a captura de tela do aplicativo desenvolvido:

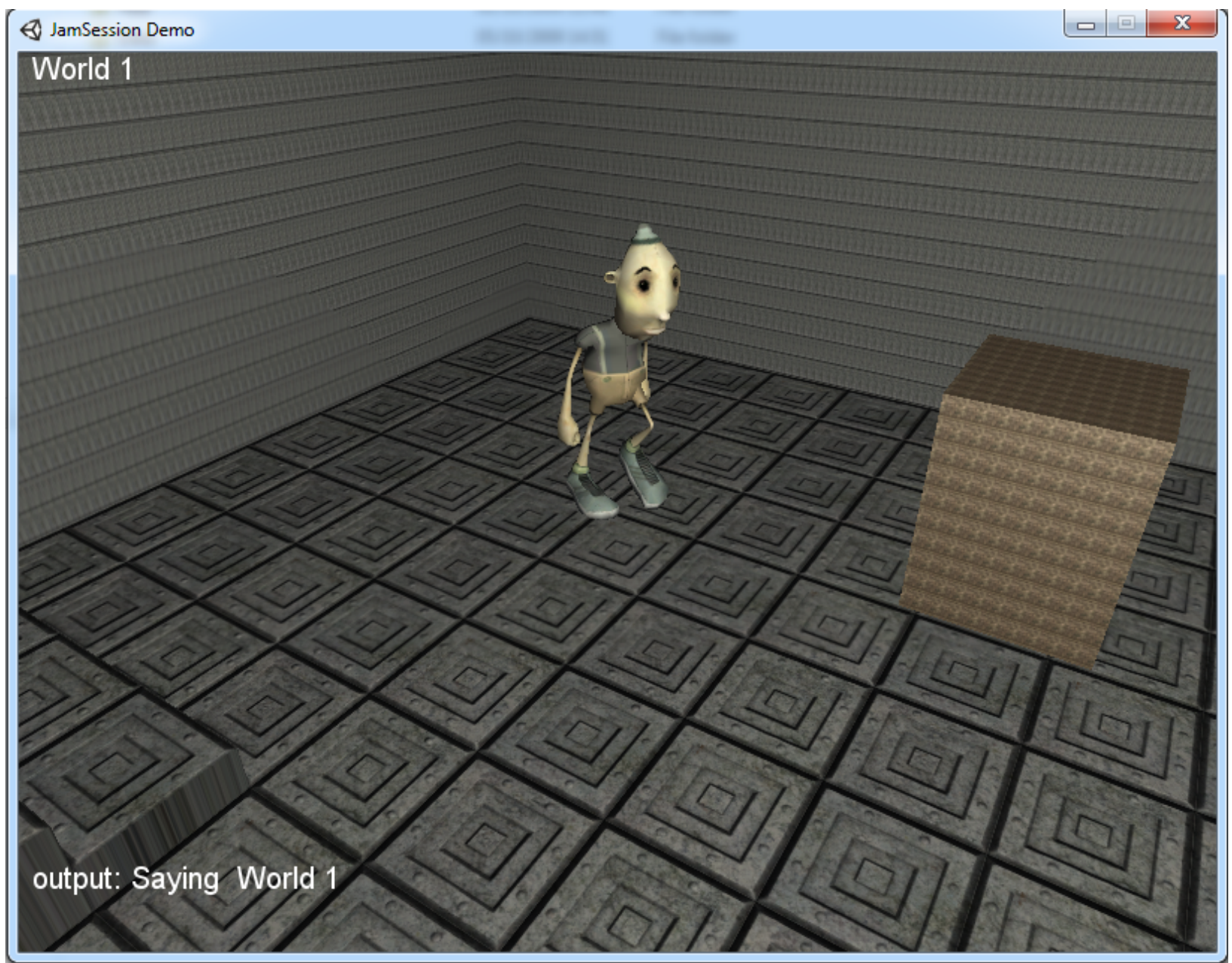

Figura 6.10: Aplicativo de exemplo ilustrando o uso do JamSession num contexto de ambientes virtuais

\footnotetext{
${ }^{4}$ http://unity3d.com/
} 
O aplicativo é uma prova de conceito mostrando a execução de protocolos de interação JamSession a partir de ações realizadas pelo usuário (jogador).

São disparados determinados protocolos quando o jogador colide com o cubo presente no cenário, quando o jogador pula ao pressionar determinada tecla ou está em determinada parte do cenário. De acordo com o retorno do protocolo executado, também são feitas alterações no ambiente, como por exemplo alteração na cor do cubo.

Neste exemplo, também foi implementado um predicado utilizando síntese de voz por meio da tecnologia Microsoft Speech. O predicado recebe um texto como entrada e tem a fala deste texto como efeito colateral de sua avaliação. 


\subsection{OpenMuseum}

Iniciamos a elaboração desta prova de conceito com uma pesquisa sobre a definição e o propósito de um museu. A definição de museu tem sido modificada em conformidade com a evolução da sociedade. Atualmente, segundo o Conselho Internacional de Museus ${ }^{5}$, organismo ligado à Organização das Nações Unidas para a Educação, a Ciência e a Cultura (UNESCO) ${ }^{6}$, o atual conceito de museu é o seguinte:

uma instituição permanente sem fins lucrativos, a serviço da sociedade e de seu desenvolvimento, aberto ao público, e que adquire, conserva, estuda, expõe e transmite o patrimônio material e imaterial da humanidade e de seu ambiente para fins de estudo, educação e apreciação.

Lado a lado com o patrimônio monumental, as coleções dos museus constituem a maior parte do que é universalmente conhecido como patrimônio cultural. A finalidade principal do museu é a de proteger, salvaguardar e preservar o patrimônio tangível e intangível. Para isso, realiza estudos científicos para compreender e estabelecer tanto o seu significado quanto a sua posse. Museus também têm uma missão educativa, que ajuda na preparação de uma ética global baseada na prática para a conservação, proteção e difusão dos valores do patrimônio cultural. Um museu apresenta as interações entre cultura e natureza: um número crescente de museus está concentrando seu interesse na ciência e na tecnologia. Finalmente, voltado para o seu público, os museus comunitários estão atentos para a mudança social e cultural e nos ajudam a apresentar nossa identidade e diversidade em um mundo em constante mudança.

Segundo a UNESCO, algumas questões importantes são:

- O patrimônio cultural reflete a vida da comunidade, sua história e sua identidade. Sua preservação ajuda a reconstruir as comunidades destruídas, restabelecer suas identidades, e vincular o seu passado com seu presente e futuro.

- Objetos culturais móveis e os museus em que são conservados constituem repositórios de diversidade cultural. Como pontos de acesso para o conhecimento sobre as culturas e centros de educação, museus também contribuem para a compreensão mútua e coesão social, bem como para o desenvolvimento econômico e humano.

- A estratégia da UNESCO concentra-se nos museus e coleções que melhor contribuem para uma compreensão integrada do patrimônio e da sua contribuição potencial para o desenvolvimento econômico, social e humano das comunidades locais e dos grupos desfavorecidos. Esta estratégia é implementada através de atividades de formação que envolvem técnicas simples e eficientes para salvaguardar objetos, com uma ênfase especial na criação de ferramentas pedagógicas; desenvolvimento de museus através do reforço das redes profissionais e de parcerias; melhoria dos conteúdos educativos e acesso ao conhecimento através de ações de sensibilização e atividades educativas; e promoção do retorno, restituição e melhoria do acesso aos bens culturais por meio de sensibilização e atividades de consultoria e parcerias inovadoras.

Tendo reconhecido que este contexto dos museus é importante para toda a sociedade, verificamos mais profundamente o funcionamento dos museus e suas interações entre si e com seus usuários.

\footnotetext{
${ }^{5}$ http://icom.museum/

${ }^{6}$ http://www.unesco.org
} 


\subsubsection{Prova de conceito}

A interoperabilidade entre os museus é fundamental para o desempenho de suas funções. Ela diz respeito principalmente ao compartilhamento de informações sobre suas obras de arte, eventuais empréstimos de obras e montagem conjunta de exposições de suas obras.

É fundamental que os museus possuam uma definição clara do conceito que compartilham. No caso, o conceito diz respeito às obras de arte dentro de seus acervos e participantes de exposições. Envolve ainda outras organizações como, por exemplo, as instituições culturais que realizam exposições destas obras e colecionadores de obras de arte que podem ceder suas obras para exposições específicas. Do outro lado, estão os visitantes (usuários) destas organizações que querem conhecer estas obras de arte e, para tanto, visitam exposições que apresentam estas obras. Aqui também se identifica a interoperabilidade entre museu e visitante.

Este projeto contou com a participação de membros do LIDET (Laboratory of Interactivity and Digital Entertainment Technology) ${ }^{7}$. O museu com o qual realizamos uma parceria nesta pesquisa foi o Museu de Arte Contemporânea da Universidade de São Paulo.

\section{O Museu de Arte Contemporânea da Universidade de São Paulo (MAC USP)}

O Museu de Arte Contemporânea da Universidade de São Paulo tinha interesse em desenvolver um ambiente virtual, no site do MAC USP ${ }^{8}$, para exposições virtuais, que fosse inovador e não meramente a reprodução do espaço expositivo real.

Este ambiente virtual da exposição não significa uma visita virtual às galerias do MAC USP, mas sim um espaço no qual o visitante do museu possa ter acesso a outras camadas de leitura e de aprofundamento da compreensão das obras que estão sendo exibidas no espaço do museu.

A partir desse pressuposto, identificamos algumas ferramentas de grande utilidade e contribuição para a sociedade, que estão alinhadas com questões de interoperabilidade:

- Criação de exposições virtuais: permitir que os usuários (profissionais de arte, educadores, alunos e leigos) possam selecionar obras disponíveis nos acervos de museus (associados ao sistema) e possivelmente em outros sites de arte, e criar suas próprias exposições de arte virtuais.

- Cruzamento de informações sobre obras e artistas: cruzamento de informações sobre obras e artistas, disponíveis em web sites de museus, galerias e exposições.

- Recuperação de comentários sobre obras, disponíveis em redes sociais: particularmente, após criar sua própria exposição virtual, o usuário pode clicar em uma das obras em exposição e recuperar comentários sobre estas obras, que foram apresentados em algumas redes sociais predefinidas.

O interesse do MAC alinhado com trabalhos desenvolvidos pelo LIDET, foi a fonte real de informações necessárias para concretizar esta prova de conceito: o sistema OpenMuseum.

\footnotetext{
${ }^{7}$ http://lidet.wordpress.com/

${ }^{8}$ http: //www.mac.usp.br
} 


\subsubsection{Objetivos}

O objetivo do OpenMuseum é proporcionar aos museus, associados ao sistema, uma presença virtual que possa ser acessada mundialmente. Estes museus virtuais têm as seguintes características:

- Espaço e armazenamento de exposições de obras de arte

- Exposições educacionais

- Catálogo de coleções (acervo)

- Ferramentas de pesquisa

Para tanto, o sistema OpenMuseum, em desenvolvimento, deve fornecer as seguintes funcionalidades:

- Armazenamento de todas as informações sobre o acervo, incluindo imagens de alta resolução e informações detalhadas de cada obra, e registro de todas as exposições que incluíram estas obras.

- O espaço virtual do museu conta com uma representação 2D ou 3D do espaço de exposição e a ferramenta proporciona a facilidade de criar uma exposição com todas (ou algumas) as obras de seu acervo. Essa funcionalidade pode ser usada por curadores que podem planejar a exposição antes de sua criação física; por professores que podem planejar uma exposição de acordo com seu tema de aula; e por estudantes que podem planejar uma exposição de acordo com uma atividade de aula.

- Interoperabilidade entre museus, para o intercâmbio de obras, de informações sobre exposições e outras questões relevantes.

- Navegação através do espaço virtual do museu. Este projeto tem um modelo geral de interoperabilidade entre as instituições e a interação com os usuários. Os problemas de interoperabilidade são orquestrados pela plataforma JamSession. O objetivo é permitir a reutilização e o compartilhamento do conhecimento para atingir a interoperabilidade entre as instituições. Portanto, neste projeto estão sendo consideradas abordagens ontológicas e técnicas relacionadas para estabelecer um sistema baseado no conhecimento através do uso de padrões. Um padrão recomendado na literatura é o Modelo de Referência Conceitual CIDOC [17], que fornece uma ontologia extensível para conceitos e informações em documentação do patrimônio cultural e de museus. 
Visão geral (prova de conceito)

A Figura 6.11 sintetiza a prova de conceito definida.

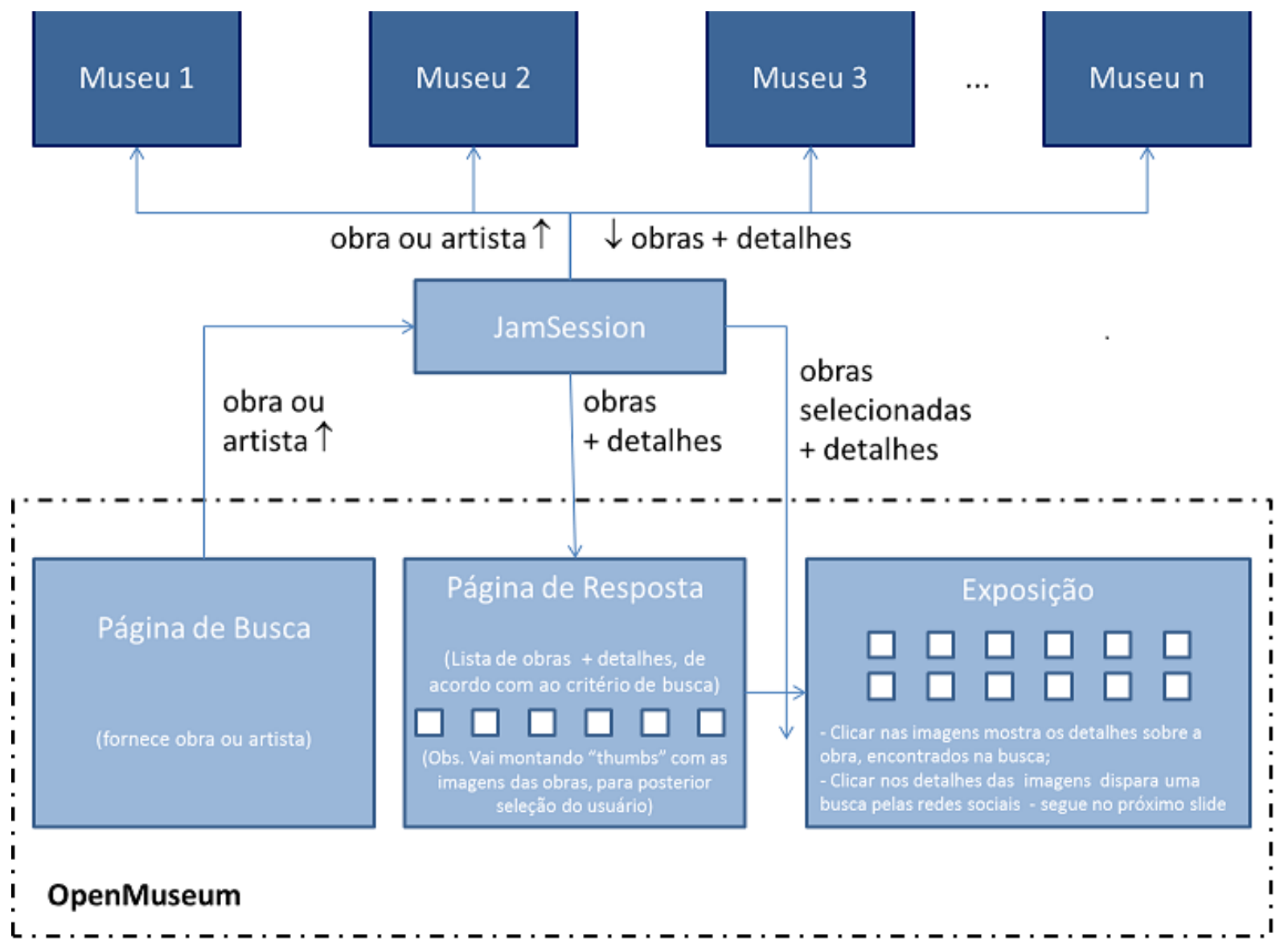

Figura 6.11: OpenMuseum - Visão Geral 


\subsubsection{Modelagem com JamSession}

\section{Visão geral (arquitetura)}

A Figura 6.12 identifica os componentes do sistema que vem sendo desenvolvido, apontando os recursos do JamSession que serão utilizados no sistema:

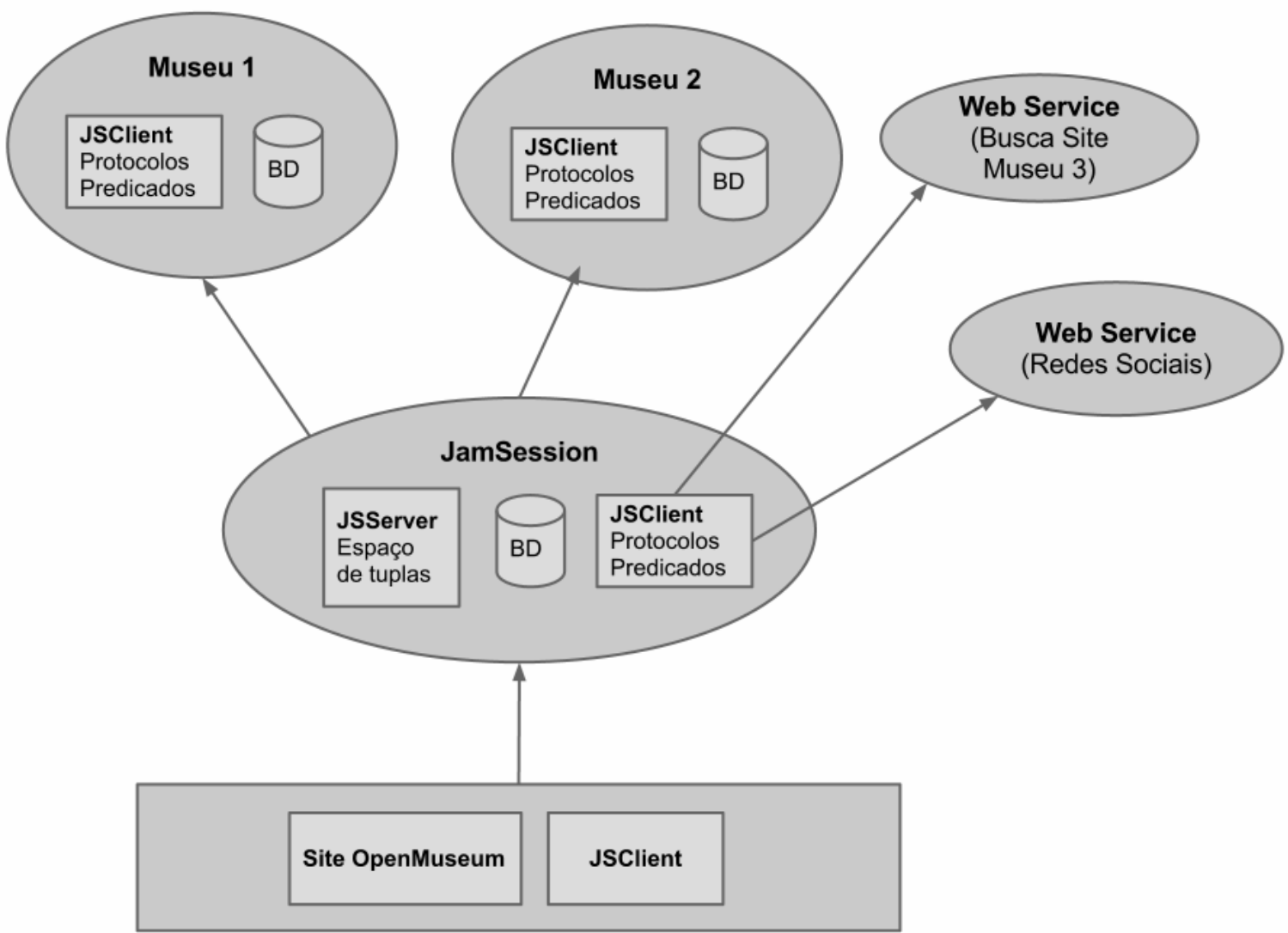

Figura 6.12: OpenMuseum - Arquitetura

\section{Localizações e agentes}

O objetivo nesta seção é mostrar como JamSession pode ser usado para orquestrar o consumo de recursos neste sistema.

Neste sistema temos 7 localizações e um agente para cada usuário. Dependendo de qual localização o agente está, diferentes protocolos e predicados estão disponíveis. Além das 7 localizações citadas, cada museu participante também possui uma localização.

Podemos considerar que o sistema imita as interações físicas reais que um usuário poderia passar para criar uma exposição. Por exemplo, cada localização pode ser vista como uma simulação de uma atividade específica desenvolvida por um funcionário. Quando o agente se desloca para um local diferente, o usuário pode ter a sensação de ter se mudado para uma etapa diferente no processo de criação da exposição.

O sistema também pode ser encarado como um jogo, no qual o usuário está resolvendo um enigma que é construído para que, como efeito colateral, uma vez que é resolvido, o usuário possa 
obter a informação que ele precisa para atingir seu objetivo.

Em ambos os casos, a ideia é construir uma interface amigável cuja utilização permite quebrar os obstáculos que os usuários podem enfrentar para ter acesso a serviços complexos.

- Localização 1 - Início - Boas vindas

- Localização 2 - Criando exposições

- Localização 3 - Visualizando exposições

- Localização 4 - Selecionando obras

- Localização 5 - Finalizando a exposição

- Localização 6 - Autorização de obra com direito autoral

- Localização 7 - Exposição criada

As 7 localizações são organizadas como um grafo, como representado na Figura 6.13.

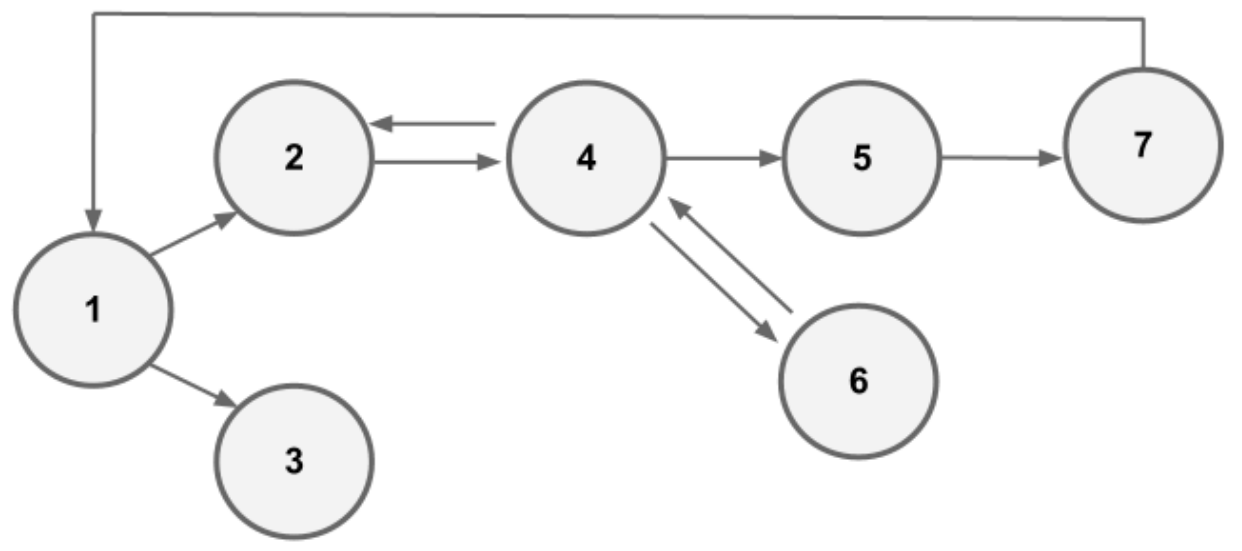

Figura 6.13: OpenMuseum - Estrutura de localizações

A localização 1 é a porta de entrada para o sistema. Quando um usuário começa a usar o sistema, o agente é colocado em um local, que também abriga um predicado que pode desencadear um recurso que dá boas vindas ao usuário, fornece informações sobre como o sistema funciona e capta alguma entrada inicial.

Dependendo da resposta do usuário, o agente é direcionado para a localização 2 ou localização 3. Uma vez em um desses novos locais, o agente pode desencadear os predicados que são hospedados por esses locais, que devem fornecer ao usuário informações adicionais e solicitar respostas adicionais. Deste modo, como agente salta de localização para localização, diferentes estados do sistema são caracterizados, diferentes recursos são liberados e diferentes comportamentos do sistema podem ser percebidos pelo usuário. 
(Exibe mensagem de boas vindas e aguarda opção)

1. Criar exposição

(Exibe busca e aguarda parâmetros)

(Busca por obras em todos os museus)

1.1 Obra (s) encontrada (s)

(Exibe obras encontradas e aguarda seleção)

(Configurar dados da obra)

(Obra selecionada possui direito autoral?)

1.1.1 Possui direito autoral

( Solicitar autorização)

1.1.2. Não possui direito autoral

(Finalizar?)

1.1.3 Sim

(Configurar dados da exposição)

(Salvar exposição)

(Mensagem de término)

1.1.4 Não. Buscar mais obras

(Volta para 1)

1.2 Nenhuma obra encontrada

(Mensagem)

(Volta para 1)

2. Ver exposição

(Exibe busca e aguarda parâmetros)

(Busca exposições)

2.1 Exposições encontrada

(Exibe exposições encontradas e aguarda seleção)

(Obter a exposição com dados das permissões para cada obra)

(Iniciar exposição)

(Aguarda comando)

2.2 Nenhuma exposição encontrada

(Mensagem)

(Volta para 2)

\section{Protocolos e predicados}

Os seguintes predicados podem ser usados na implementação deste sistema.

- [Ag,1]predBoasVindas ((),(OpcaoSelecionada)): aciona o recurso que contém uma animação que cumprimenta o usuário, fornece informações iniciais a ele e capta a entrada inicial.

- [Ag,1]predCompara $((X, Y),())$ : compara dois valores e devolve verdadeiro se eles são idênticos ou falso caso contrário.

- [Ag,2]predExibeBuscaObras((),(ParametrosBusca)): exibe interface para busca de obras e devolve os parâmetros fornecidos.

- [Ag,2]predObraNaoEncontrada((),()): avisa que nenhuma obra foi encontrada.

- [A,L/predVerificaConsistencia((ParametrosBusca),()): verifica a consistência dos parâmetros de busca.

- $[A, L / p r e d B u s c a O b r a s N o M u s e u((P a r a m e t r o s B u s c a),(R e s u l t a d o B u s c a)))$ : busca obras na base de dados do museu.

- $[A, L / p r e d E r r o((),())$ : devolve mensagem de erro.

- [Ag,4lpredSelecaoObra((ResultadoBusca),(ObraSelecionada)): exibe obras encontradas e aguarda seleção de uma obra. 
- [Ag.4lpredPossuiDireitoAutoral((Obra),()): indica se a obra possui direito autoral.

- [Ag,4]predConfiguracaoObra((ObraSelecionada),(ObraConfigurada)): solicita dados de configuração da obra na exposição.

- [Ag.4/predFinalizar((),()): verifica se o usuário deseja finalizar a seleção das obras.

- [Ag,5]predDadosExposicao((),(DadosExposicao)): obter dados da exposição.

- [Ag,5/predSalvarExposicao((Obras,DadosExposicao),()): salvar exposição.

- $[$ Ag, '7]predTermino((),()): exibe a confirmação da criação da exposição.

- [Ag, 2/predIsEmpty((L),()): verifica se a lista L está vazia.

- [Ag,2/predCopy((L1),(L2)): contrói uma cópia da lista L1 em L2.

- [Ag,2]predHeadTail((L), $(H, T))$ : dada uma lista $\mathrm{L}$, devolve a cabeça(H) e o resto da lista $(\mathrm{T})$.

- [Ag,2]predAppend((L1, L2), (LApp)): concatena as lista L1 e L2.

Abaixo a definição dos protocolos para controle do processo de criação de exposições:

[1] protInicio ()$::=[\mathrm{Ag}, 1]$ predBoasVindas $((),($ OpcaoSelecionada $))$ ^ [1] protCriacaoOuExibicao (( OpcaoSelecionada), ())

[1] protCriacaoOuExibicao (( OpcaoSelecionada), ()) ::= [Ag, 1] predCompara (( OpcaoSelecionada, "Criação"), ()) ^ (move $(\mathrm{Ag}, 1,2)$ ^ [2] protCriarExposicao (() ,()) $) \mathrm{V}(\operatorname{move}(\mathrm{Ag}, 1,3) \wedge[3]$ protExibirExposicao $((),()))$

[2] protCriarExposicao (( ObrasJaSelecionadas ) , ()) ::= [Ag, 2] predExibeBuscaObras (() $,($ ParametrosBusca $))$ ^ $[2]$ protBuscaObras ((ParametrosBusca, LocalizacoesMuseus , ()), (ResultadoBusca) ) (move $(\mathrm{Ag}, 2,4) \wedge[4]$ protSelecionarObras ( ResultadoBusca, ObrasJaSelecionadas $),(())) \mathrm{V}[\mathrm{Ag}, 2]$ predObraNaoEncontrada ((), () )

[2] protBuscaObras ((ParametrosBusca, LocalizacoesMuseus, ResultadoParcial), ( ResultadoBusca) $)::=[\mathrm{Ag}, 2]$ predIsEmpty ((LocalizacoesMuseus $),()) \wedge[\mathrm{Ag}, 2]$ predCopy ((ResultadoParcial), (ResultadoBusca)) V [Ag, 2] predHeadTail (( LocalizacoesMuseus $),(\mathrm{H}, \mathrm{T})) \wedge[\mathrm{H}]$ protBuscaObrasNoMuseu (( ParametrosBusca), ( ResultadoBuscaNoMuseu) ) ^ $[\mathrm{Ag}, 2]$ predAppend (( ResultadoParcial , ResultadoBuscaNoMuseu)), (ResultadoParcialAtualizado))

[2] protBuscaObras (( ParametrosBusca, T, ResultadoParcialAtualizado),( ResultadoBusca))

[L] protBuscaObrasNoMuseu ((ParametrosBusca), (ResultadoBuscaNoMuseu ) $::=([\mathrm{A}, \mathrm{L}]$ predVerificaConsistencia (( ParametrosBusca),()$) \wedge[\mathrm{A}, \mathrm{L}]$ predBuscaObrasNoMuseu $(($ ParametrosBusca $),($ ResultadoBuscaNoMuseu )) ) V [A,L] predErro ((), ())

[4] protSelecionarObras (( ResultadoBusca, ObrasJaSelecionadas ) , () ) ::= [Ag, 4] predSelecaoObra ((ResultadoBusca $),($ ObraSelecionada $)) \wedge[[\mathrm{Ag}, 4]$ predConfiguracaoObra ((ObraSelecionada $),($ ObraConfigurada $)))$ ^ ([Ag.4] predPossuiDireitoAutoral ((ObraConfigurada),()$) \wedge(\operatorname{move}(\mathrm{Ag}, 4,6) \wedge[6]$ protAutorizacaoDireitoAutoral ((ObraConfigurada), () ) ) $[\mathrm{Ag}, 4]$ predAppend $(($ ObrasJaSelecionadas, ObraConfigurada), ObrasSelecionadas ) ([Ag.4] predFinalizar $((),()) \wedge(\operatorname{move}(\mathrm{Ag}, 4,5) \wedge[5]$ protSalvarExposicao $(($ ObrasSelecionadas ),( ) ) V (move $(\mathrm{Ag}, 4,2)$ - [2] protCriarExposicao ( ObrasSelecionadas ), ()) ) 
[5] protSalvarExposicao (( ObrasSelecionadas $),())::=[\mathrm{Ag}, 5]$ predDadosExposicao $((),($ DadosExposicao $)) \wedge[\mathrm{Ag}, 5]$ predSalvarExposicao ((ObrasSelecionadas , DadosExposicao $),()) \wedge \operatorname{move}(\mathrm{Ag}, 5,7) \wedge[5]$ protExposicaoSalva $((),())$

[6] protAutorizacaoDireitoAutoral ((Obra), () ) ::= $\mathrm{Ag}, 6]$ predInformacoesDireitoAutoral ((Obra), ( ) ) ^ $[\mathrm{Ag}, 6]$ predAutorizacaoDireitoAutoral ((Obra), () ) move $(\mathrm{Ag}, 6,4)$

[7] protExposicaoSalva ((),()) ::= [Ag, 7] predTermino $((),()) \wedge \operatorname{move}(\mathrm{Ag}, 7,1)$

\subsubsection{Integração com redes sociais}

Mencionamos anteriormente a possibilidade de recuperar comentários sobre determinada obra disponíveis em redes sociais. Nesta seção mostraremos como implementar um predicado do JamSession com esta funcionalidade.

O Twitter ${ }^{9}$ é uma rede social e servidor para microblogging que permite que usuários enviem e recebam mensagens, chamadas tweets. Assim como muitas outras aplicações na Web, o Twitter disponibiliza uma API REST ${ }^{10}$ para que seja possível buscar tweets de forma automatizada.

A API de busca do Twitter é um serviço REST [21] que permite que os usuários utilizem determinada URL para recuperar tweets que satisfaçam os critérios especificados na URL.

Por exemplo, a seguinte URL pode ser usada para procurar por tweets em português com o termo "USP":

http://search.twitter.com/search.atom?lang=pt\&q $=U S P$

No exemplo acima, o parâmetro "q", abreviação de query, é obrigatório e indica o termo pesquisado. O parâmetro "lang" especifica o idioma do tweet (português).

A extensão ".atom" significa que os resultados da busca serão retornados no formato Atom [38]. Atom é um formato de documento baseado em XML que descreve listas de informações relacionadas conhecidas como feeds. Os feeds são formados por vários itens com um conjunto extensível de metadados anexados. Outros formatos disponíveis para o resultado da busca são JavaScript Object Notation (JSON) e RSS.

Em JamSession, podemos criar um predicado para abstrair essa funcionalidade. O predicado recebe um parâmetro de busca e recupera os comentários do Twiiter:

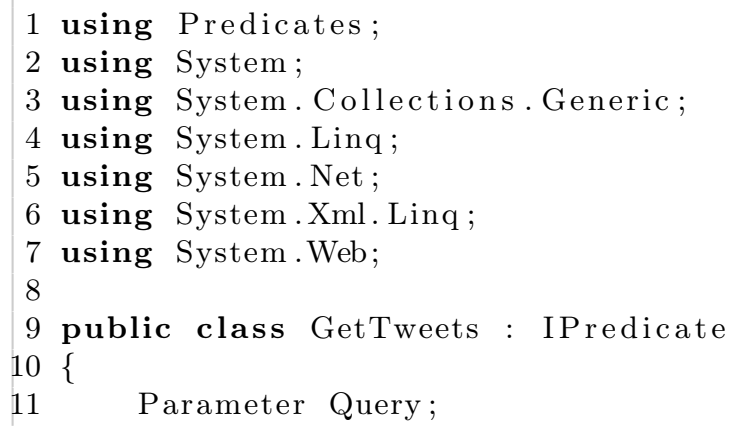

\footnotetext{
${ }^{9}$ http://twitter.com/

${ }^{10}$ https://dev.twitter.com/docs/api
} 
[ OutputParameter]

Parameter Tweets;

public bool Execute ()

\{ using (WebClient web $=$ new WebClient ()$)$ \{

string url = string.Format("http://search.twitter.com/search. atom? lang $=\mathrm{pt \& q}=\{0\} "$, HttpUtility . UrlEncode (Query) ); WebClient client $=$ new WebClient () ;

XDocument doc $=$ XDocument. Load $($ url $)$;

XNamespace $\mathrm{ns}=$ "http://www.w3.org/2005/Atom";

List $<$ string $>$ tweets $=$ (from item in doc.Descendants $(n s+$ "entry" )

select new

$$
\{
$$

Published $=$ DateTime. Parse (item. Element $(\mathrm{ns}+"$ published"). Value),

Title $=$ item. Element $($ ns + "title" $)$. Value,

Content $=$ item. Element $(\mathrm{ns}+$ "content" $)$. Value

Author $=$ item. Element $(\mathrm{ns}+$ "author" $)$. Element ( ns + "name"). Value

\}. ToXml()) . ToList ();

Tweets. Value $=$ tweets

\}

return true;

\}

public bool Validate ()

\{

return ! String. IsNullOrEmpty (Query);

\}

Outras funcionalidades relacionadas às redes sociais podem ser implementadas por meio da construção de predicados que utilizem serviços disponibilizados por essas aplicações. 


\subsubsection{Aplicações}

Abaixo estão imagens do sistema em desenvolvimento:

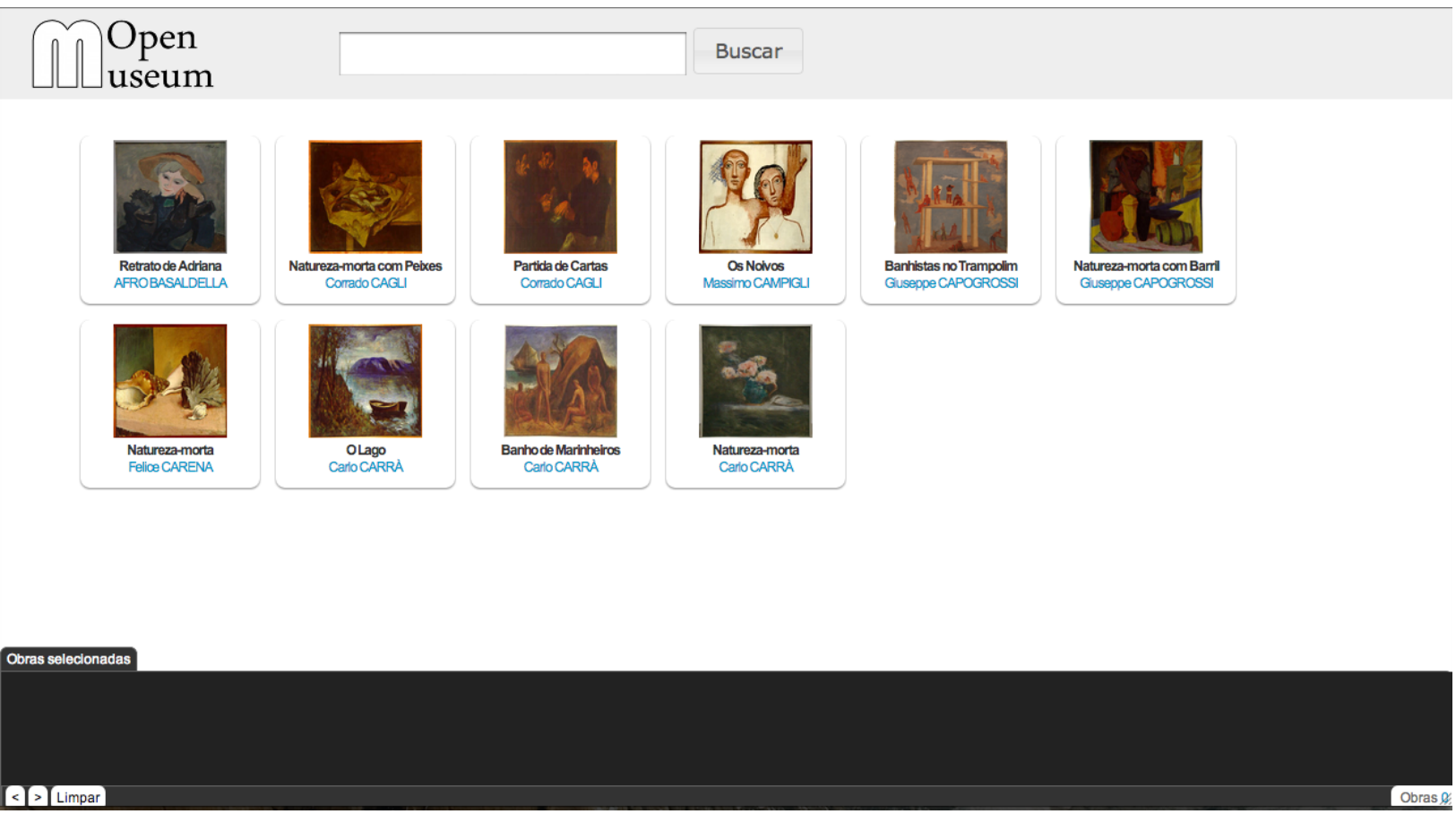

Figura 6.14: OpenMuseum - Busca de obras

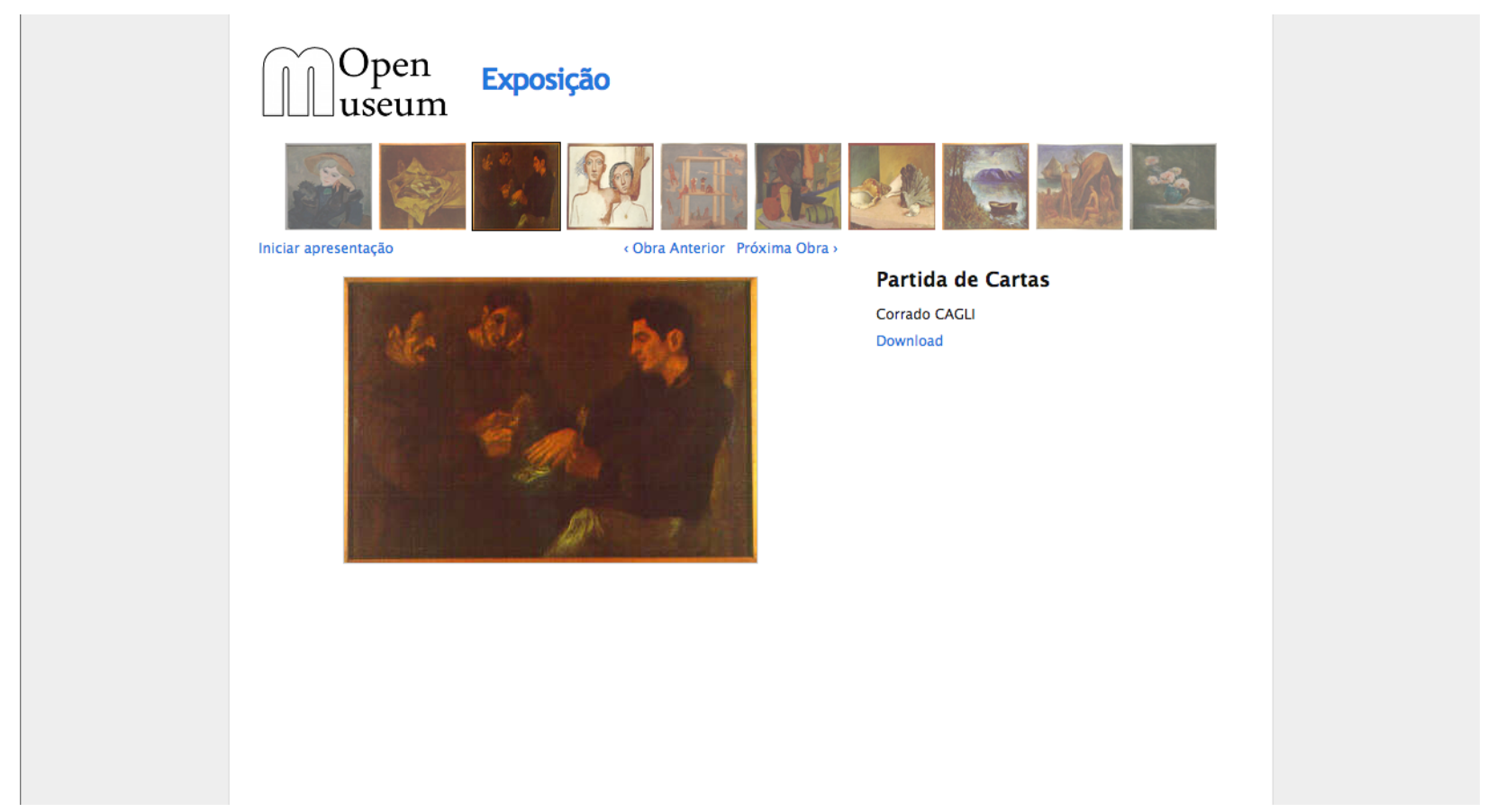

Figura 6.15: OpenMuseum - Exibição da exposição 


\section{Interface 3D}

Ainda no contexto do sistema OpenMuseum, são desejáveis diferentes tipos de interfaces com o usuário. Com esse objetivo, também foram realizados experimentos utilizando uma interface 3D. Este ambiente está ilustrado na Figura 6.16.

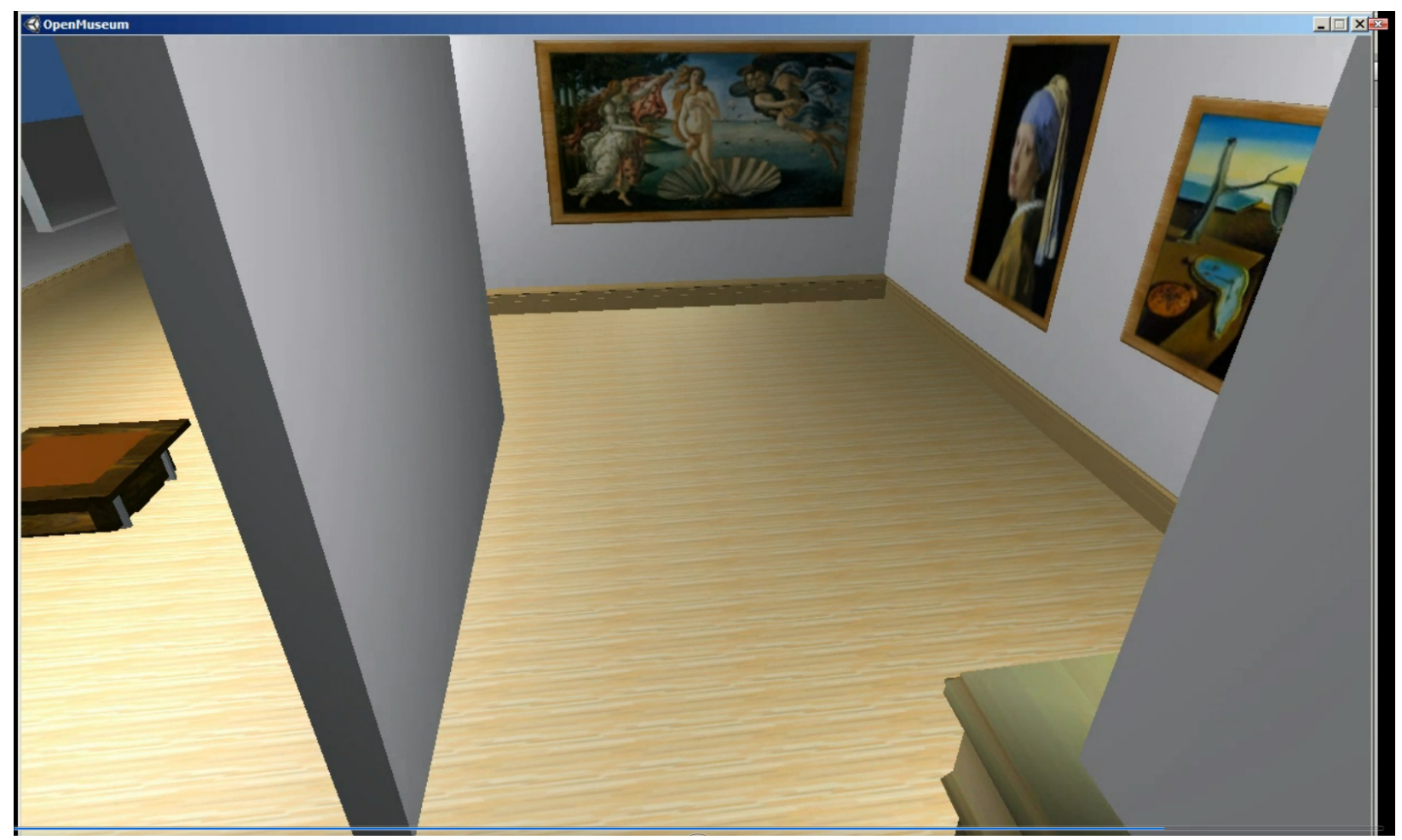

Figura 6.16: OpenMuseum - Interface $3 D$

\subsubsection{Tecnologia utilizada}

Abaixo estão as principais tecnologias utilizadas no desenvolvimento:

- O site ilustrado na Figura 6.14 foi desenvolvido em ASP.NET MVC $3^{11}$ usando a linguagem C\# havendo um cliente do JamSession integrado ao site. Para criar as interações nas páginas, foi utilizada a biblioteca jQuery ${ }^{12}$.

- A interface gráfica 3D foi desenvolvida utilizando a ferramenta de desenvolvimento de jogos digitais Unity $3 D^{13}$.

- O servidor de base de dados relacional utilizado é o Microsoft SQL Server ${ }^{14}$.

\footnotetext{
${ }^{11}$ http://www.asp.net/mvc/mvc3

${ }^{12}$ http://jquery.com/

${ }^{13}$ http://unity3d.com/

${ }^{14}$ https://www.microsoft.com/sqlserver/
} 


\subsection{Conclusão do capítulo}

Neste capítulo foram apresentados estudos de caso desenvolvidos para validar empiricamente a plataforma JamSession. O experimento na área de ambientes virtuais demonstra o uso da plataforma como mecanismo para coordenar sistemas interativos. Descrevemos como JamSession pode ser usado num caso concreto de integração envolvendo workflows interorganizacionais. Também apresentamos o projeto OpenMuseum, que usa o JamSession como plataforma para coordenação dos serviços. 


\section{Capítulo 7}

\section{Conclusões}

O paradigma da computação orientada a serviços tem sido cada vez mais utilizado. Uma arquitetura orientada a serviços mais desenvolvida necessita de elementos que permitam a integração dos serviços, de forma que possam ser executados de forma coordenada. Neste trabalho de mestrado foi desenvolvida uma nova plataforma para coordenação de serviços em ambientes distribuídos com as seguintes características:

- Alto desempenho computacional

- Facilidade de uso

- Fundações formais e declarativas

- Integração desacoplada de recursos computacionais heterogêneos

Esta dissertação inicialmente apresentou uma revisão dos conceitos básicos de coordenação de serviços, apresentando os conceitos e tecnologias mais empregados. A seguir foram abordados alguns projetos relacionados à este trabalho que inspiraram a construção dessa nova plataforma. Foram apresentados aspectos teóricos e a implementação da plataforma JamSession. Finalmente, foram apresentados experimentos e aplicações desenvolvidos que demonstram o potencial desta nova abordagem de coordenação.

\subsection{Principais contribuições}

Dentre as principais contribuições deste trabalho, destacam-se:

- Implementação da plataforma chamada JamSession para orquestração de serviços, objetivo principal deste trabalho.

- Aperfeiçoamento da plataforma proposta inicialmente com introdução de novos elementos, como descrito no Capítulo 5.

- Desenvolvimento de experimentos e aplicações para validar empiricamente a plataforma desenvolvida.

- Publicação do artigo "Interaction protocols for cross-organisational workflows" [16], que aborda o uso da plataforma JamSession na integração de workflows interorganizacionais, tema que tratamos na Seção 6.1. 


\subsection{Trabalhos futuros}

A plataforma desenvolvida neste trabalho é plenamente funcional e implementa as funcionalidades que foram descritas ao longo do texto. No entanto, diversos aperfeiçoamentos e extensões podem ser feitos no sistema desenvolvido.

A seguir descrevemos algumas questões importantes a serem pesquisadas como continuação deste projeto de mestrado:

- Os experimentos feitos no trabalho foram feitos considerando um grupo limitado de aplicações. Sugerimos ter um maior conjunto de aplicações e experimentos mais extensivos.

- Realização de análises comparativas com trabalhos relacionados e simulações de teste de desempenho de plataformas para coordenação de serviços. 


\section{Referências Bibliográficas}

[1] Bonita rest api javadoc. http://www.bonitasoft.org/docs/javadoc/rest/5.3/API/. 58

[2] Highlights of openknowledge. http://groups.inf.ed.ac.uk/OK/. 21

[3] Openknowledge manual. http://groups.inf.ed.ac.uk/OK/download/manual.pdf.

[4] G. Alonso, F. Casati, H. Kuno, and V. Machiraju. Web Services: Concepts, Architectures and Applications. Springer, Berlin, 2004.

[5] G. Boella, L. van der Torre, and H. Verhagen. Introduction to the special issue on normative multiagent systems. Autonomous Agents and Multi-Agent Systems, 17(1):1-10, 2008. 19

[6] A. Bogdanovych, M. Esteva, S. Simoff, C. Sierra, and H. Berger. A methodology for 3d electronic institutions. In Proceedings of the 6th international joint conference on Autonomous agents and multiagent systems, AAMAS '07, pages 57:1-57:3, New York, NY, USA, 2007. ACM. 26

[7] A. Bucchiarone, H. Melgratti, and F. Severoni. Testing service composition. In Proceedings of the 8th Argentine Symposium on Software Engineering (ASSE?07), 2007.

[8] N. Carriero and D. Gelernter. Linda in context. Commun. ACM, 32:444-458, April 1989. 36

[9] D. Chappell. Introducing windows communication foundation in .net framework 4 . http: //msdn.microsoft.com/en-us/library/ee958158.aspx. 37

[10] M. Chen, A. N. K. Chen, and B. Shao. The implications and impacts of web services to electronic commerce research and practices. Journal of Electronic Commerce Research, 4(4):128-139, 2003. 6

[11] Xi Chen. IT Supported Business Process Negotiation, Reconciliation and Execution of Crossorganisational e-Business Collaboration. PhD thesis - Loughborough University, UK, 2008. 53

[12] World Wide Web Consortium et al. Extensible markup language (xml) 1.0. W3C XML, February, 1998.

[13] F. S. Correa da Silva. Knowledge-based interaction protocols for intelligent interactive environments. Knowledge and Information Systems, 2011. 1

[14] F. S. Correa da Silva and W. W. Vasconcelos. Rule schemata for game artificial intelligence. Advances in Artificial Intelligence-IBERAMIA-SBIA 2006, pages 451-461, 2006. 19

[15] F. S. Correa da Silva and W. W. Vasconcelos. Rule schemata for game artificial intelligence. In Jaime Simão Sichman, Helder Coelho, and Solange Oliveira Rezende, editors, Advances in Artificial Intelligence - IBERAMIA-SBIA 2006, 2nd International Joint Conference, 10th Ibero-American Conference on AI, 18th Brazilian AI Symposium, Ribeirão Preto, Brazil, October 23-27, 2006, Proceedings, volume 4140 of Lecture Notes in Computer Science, pages 451-461. Springer, 2006. 20 
[16] F. S. Corrêa da Silva, M. L. F. Venero, D. M. David, M. Saleem, and P. W. H. Chung. Interaction protocols for cross-organisational workflows. Knowledge-Based Systems, 37(0):121 $-136,2013.77$

[17] M. Doerr. The cidoc conceptual reference module: an ontological approach to semantic interoperability of metadata. AI magazine, 24(3):75, 2003. 66

[18] M. Endrei, J. Ang, A. Arsanjani, S. Chua, P. Comte, P. Krogdahl, M. Luo, and T. Newling. Patterns: service-oriented architecture and web services. IBM Corporation, International Technical Support Organization, 2004. 5

[19] T. Erl. Service-oriented architecture (soa): Concepts, technology, and design. 2005. 8

[20] M. Esteva, J.A. Rodriguez-Aguilar, C. Sierra J. L. Arcos, and P. Garcia. On the formal specification of electronic institutions. In Agent Mediated Electronic Commerce - The European AgentLink Perspective, UK, 2001. Springer LNCS. 19, 20

[21] R.T. Fielding. Architectural styles and the design of network-based software architectures. PhD thesis, University of California, 2000. 72

[22] W3C Working Group, W3C Working Group, et al. Web services architecture. W3C Note, 2004. 7

[23] H. Haas and A. Brown. Web Services Glossary. http://www.w3.org/TR/ws-gloss/, 2004. W3C Working Group Note 11 February 2004. 5

[24] R. Hamadi and B. Benatallah. A petri net-based model for web service composition. In Proceedings of the 14th Australasian database conference-Volume 17, pages 191-200. Australian Computer Society, Inc., 2003.

[25] D. Hollingsworth. Wfmc: Workflow reference model. Specification, Workflow Management Coalition, 1995. TC00-1003. 53

[26] G. J. Holzmann. The model checker spin. Software Engineering, IEEE Transactions on, 23(5):279-295, 1997. 34

[27] K. Jensen. Coloured Petri nets: basic concepts, analysis methods, and practical use. Number v. 1 in EATCS monographs on theoretical computer science. Springer-Verlag, 1992. 33

[28] D. Jordan, J. Evdemon, A. Alves, A. Arkin, S. Askary, C. Barreto, B. Bloch, F. Curbera, M. Ford, Y. Goland, et al. Web services business process execution language version 2.0. OASIS Standard, 11, 2007. 12

[29] M. B. Juric, B. Mathew, and P. Sarang. Business process execution language for web services. Pakt, 2004. 12, 16

[30] N. Kavantzas, D. Burdett, G. Ritzinger, T. Fletcher, Y. Lafon, and C. Barreto. Web services choreography description language version 1.0. World Wide Web Consortium, Candidate Recommendation CR-ws-cdl-10-20051109, November 2005. 16

[31] D. Krafzig, K. Banke, and D. Slama. Enterprise SOA: Service-Oriented Architecture Best Practices (The Coad Series). Prentice Hall PTR, Upper Saddle River, NJ, USA, 2004. 7

[32] F. Leymann et al. Web services flow language (wsfl 1.0), 2001. 12

[33] I. Lomazova and P. Schnoebelen. Some decidability results for nested petri nets. In Perspectives of System Informatics, pages 208-220. Springer, 2000. 33 
[34] I. A. Lomazova. Modeling dynamic objects in distributed systems with nested petri nets. Fundamenta Informaticae, 51(1-2):121-133, 2002. 33

[35] S. Dustdar M. P. Papazoglou, P. Traverso and F. Leymann. Service-oriented computing: State of the art and research challenges. Computer, 40:38-45, 2007. 5

[36] N. Milanovic and M. Malek. Current solutions for web service composition. Internet Computing, IEEE, 8(6):51-59, 2004. 10

[37] T. Murata. Petri nets: Properties, analysis and applications. Proceedings of the IEEE, $77(4): 541-580,1989.33$

[38] M. Nottingham and R. Sayre. The atom syndication format. 2005. 72

[39] Oasis. OASIS Reference Model for Service Oriented Architecture, 2006. 9

[40] M. P. Papazoglou. Service-oriented computing: Concepts, characteristics and directions. In Web Information Systems Engineering, 2003. WISE 2003. Proceedings of the Fourth International Conference on, pages 3-12. IEEE, 2003. 2, 5, 7

[41] M. P. Papazoglou. Web Services - Principles and Technology. Prentice Hall, 2008.

[42] C. Peltz. Web services orchestration: a review of emerging technologies, tools, and standards. Technical report, and standards. Technical report, HP, January 2003. Technical white paper, http://devresource. hp. com/drc/technical_white_papers/WSOrch/WSOrchestra\% tion. pdf, 2003.

[43] C. Peltz. Web services orchestration and choreography. Computer, 36:46-52, 2003. 10, 11

[44] R. Pickering. Beginning F\#. Apress, Berkeley, CA, USA, 2009. 35

[45] K. Pijanowski. Visibility and control in a service-oriented architecture. MSDN, May, 2007. 7

[46] O. Prisecaru and T. Jucan. Interorganizational workflow nets: A petri net based approach for modelling and analyzing interorganizational workflows. Proceedings of EOMAS, 8:65, 2008. 33

[47] D. Robertson. A lightweight coordination calculus for agent systems. In Proceedings of Declarative Agent Languages and Technologies, USA, 2004. Springer LNCS. 21

[48] C. Smith. Programming F\# - a comprehensive guide for writing simple code to solve complex problems. O'Reilly, 2009. 35

[49] M. ter Beek, A. Bucchiarone, and S. Gnesi. Web service composition approaches: From industrial standards to formal methods. In Internet and Web Applications and Services, $200 \%$. ICIW'0\%. Second International Conference on, pages 15-15. IEEE, 2007.

[50] S. Thatte. Xlang: Web services for business process design. Microsoft Corporation, page 13, 2001. 12

[51] W. M. P. van der Aalst. Interorganizational workflows: An approach based on message sequence charts and petri nets, 1999. 34

[52] W.W. Vasconcelos, M. J. Kollingbaum, and T. J. Norman. Normative conflict resolution in multi-agent systems. Autonomous Agents and Multi-Agent Systems, 19:124-152, 2009. 10.1007/s10458-008-9070-9. 20

[53] M. L. F. Venero and F. S. Correa da Silva. A formal semantics for the jamsession coordination platform. relatório técnico, university of são paulo, institute of mathematics and statistics, 05 2012. 33,34 
[54] M. L. F. Venero and F. S. Correa da Silva. Studying the behavior of jamsession interaction protocols using spin. relatório técnico, university of são paulo, institute of mathematics and statistics, 04 2012. 34

[55] G. Vizzari. Dynamic interaction spaces and situated multi-agent systems: from a multi-layered model to a distributed architecture. PhD thesis - University of Milano-Bicocca, Italy, 2004. 19, 25

[56] D. Xu and Y. Deng. Modeling mobile agent systems with high level petri nets. In Systems, Man, and Cybernetics, 2000 IEEE International Conference on, volume 5, pages 3177-3182. IEEE, 2000. 33 


\section{Índice Remissivo}

Análise formal, 33

Aplicações, 53

BPEL, 12

Coreografia, 15

Editor de protocolos, 41

Espaço de tuplas, 36

Implementação de predicados, 46

Implementação de protocolos, 41

Instituições Eletrônicas, 20

JamSession, 27

Agentes, 28

Clientes, 38

Comunicação, 37

Coodernador, 36

Grafo de localizações, 27

Operações, 38

Predicados, 29

Projeto JamSession, 1

Protocolos, 29

Representação gráfica, 31

KBIP, veja Protocolos

LCC, 22

MMASS, 25

OpenKnowledge, 21

OpenMuseum, 64

Orquestração, 11

Redes de Petri, 33

SOA, 7

Modelo de referência OASIS, 9

Unity 3D, 62

Variáveis, 44

Web services, 5

Workflows, 53

WS-CDL, 16 